\title{
Proteomic investigation of the molecular targets of mycophenolic acid in human cells
}

\author{
Dissertation \\ for the award of the degree \\ “Doctor of Philosophy (Ph.D.)" \\ Division of Mathematics and Natural Sciences \\ of the Georg-August University Goettingen
}

Submitted by

Muhammad Qasim

from Mardan, Pakistan

Goettingen, 2012 


\section{D7}

Reviewer 1: $\quad$ Prof. Dr. Uwe Groß

Director, Department of Medical Microbiology, University Medical Center, Georg-August University, Goettingen, Germany.

Reviewer 2: Prof. Dr. Stefanie Pöggeler

Director, Department of Genetics of Eukaryotic Microorganisms, Institute of Microbiology and Genetics, Georg-August University, Goettingen, Germany.

Date of oral examination: 20/01/2012 


\section{DECLARATION}

I hereby declare that the Ph.D. thesis entitled "Proteomic investigation of the molecular targets of mycophenolic acid in human cells" has been written independently, with no other sources than quoted, and no portion of the work referred to in the thesis has been submitted in support of an application for another degree.

Muhammad Qasim 


\section{Table of contents}

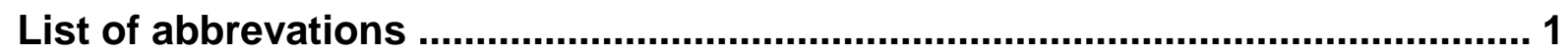

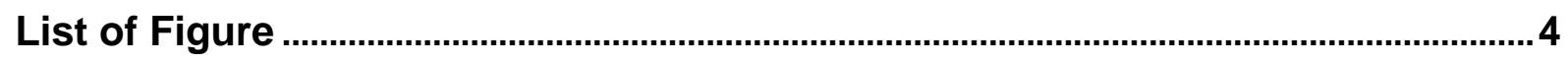

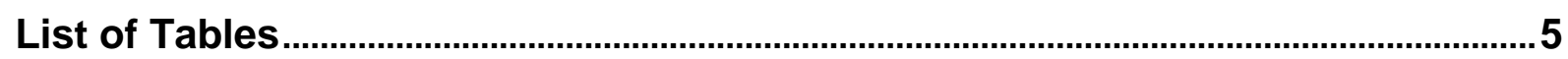

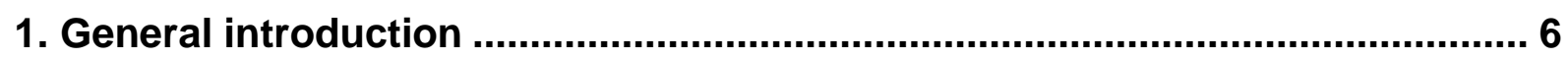

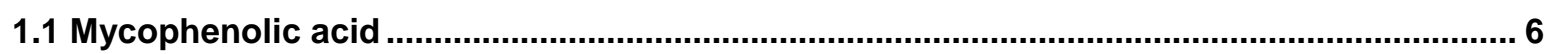

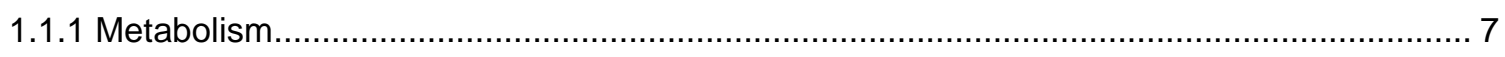

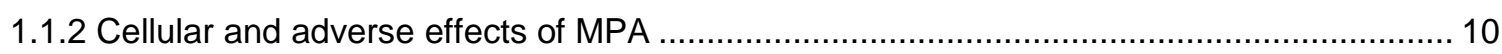

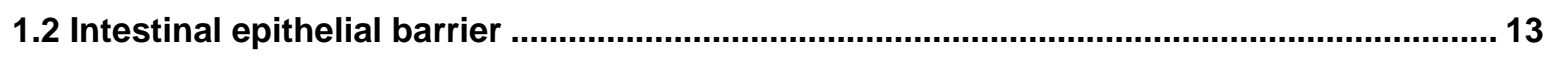

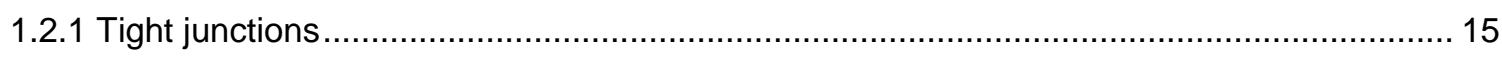

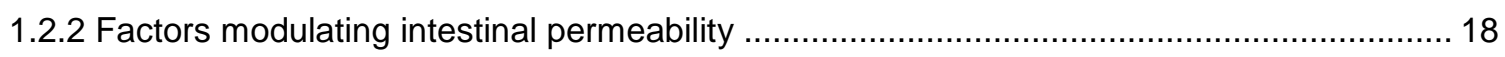

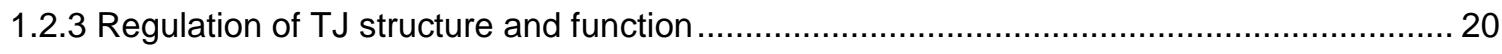

1.2.4 Caco-2 cells as an in vitro model for intestinal epithelial integrity ................................... 21

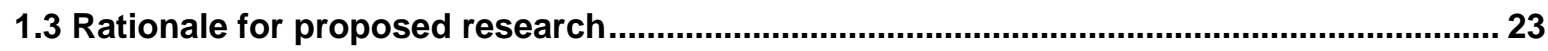

2. Differential proteome analysis of human embryonic kidney cell line (HEK-

293) following mycophenolic acid treatment .................................................... 24

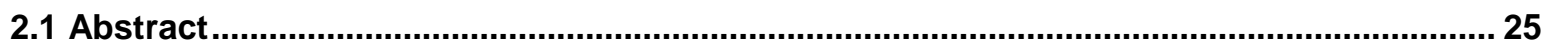

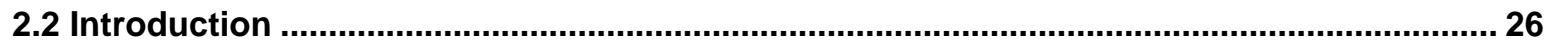

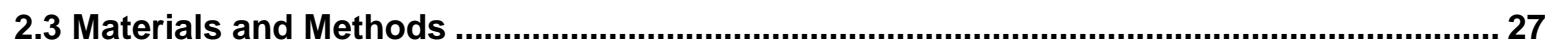

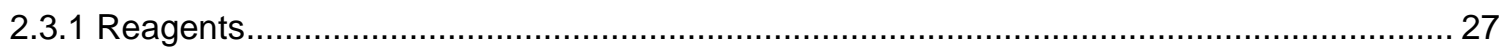

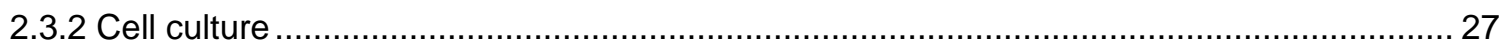

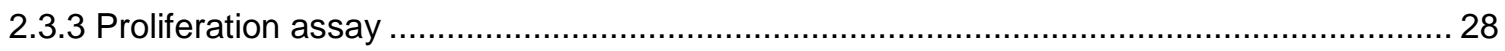

2.3.4 Sample preparation for proteome analysis ............................................................. 28

2.3.5 2-DE

2.3.6 Protein visualization, densitometric analysis and in-gel digestion ..................................... 29

2.3.7 Q-TOF LC-MS/MS analysis of protein identification ..................................................... 30

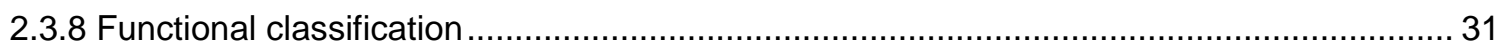

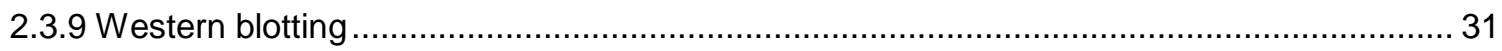

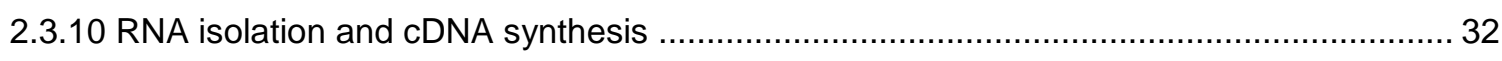




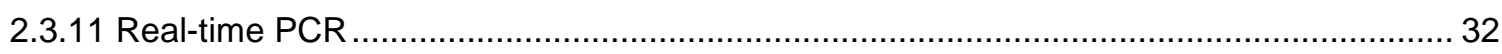

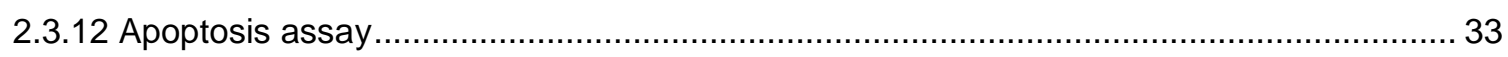

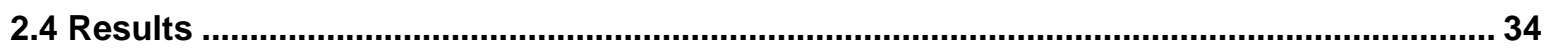

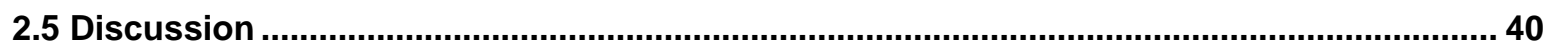

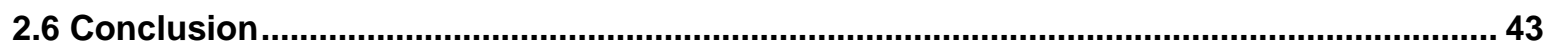

\section{Mycophenolic acid mediated disruption of the intestinal epithelial tight}

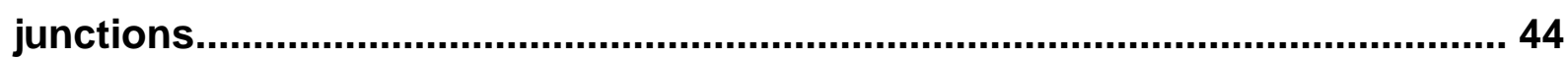

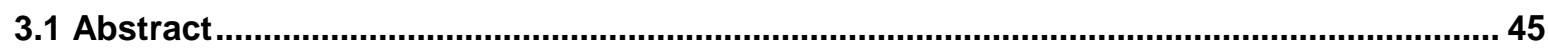

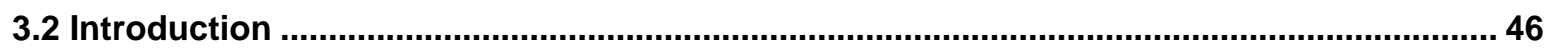

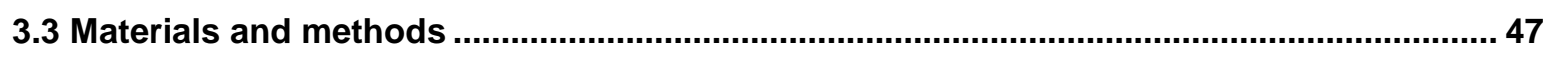

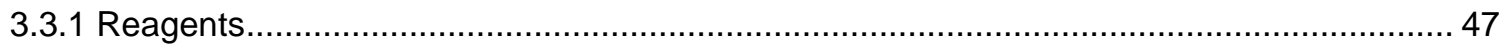

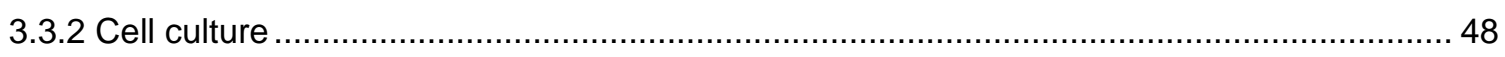

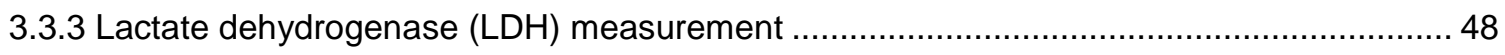

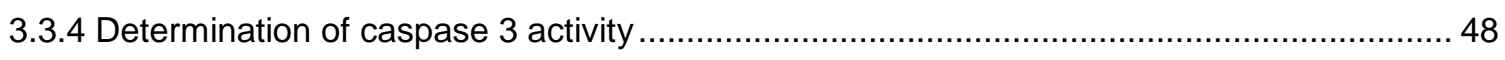

3.3.5 Determination of Trans-epithelial resistance (TER) ...................................................... 49

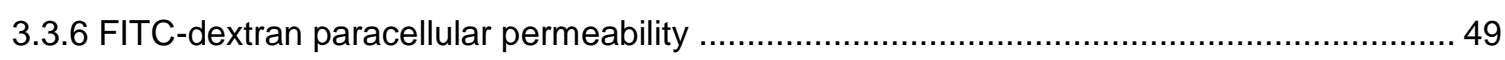

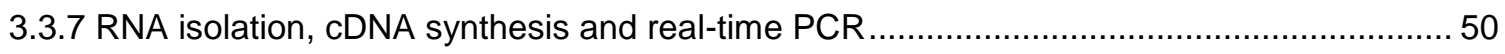

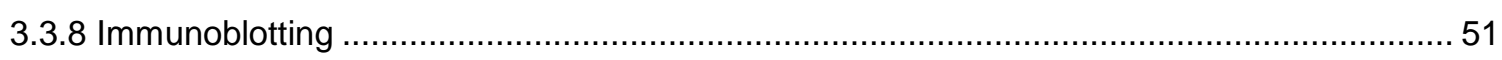

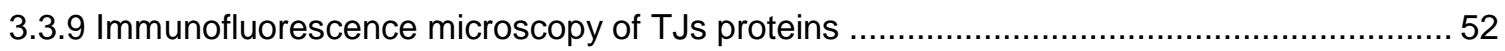

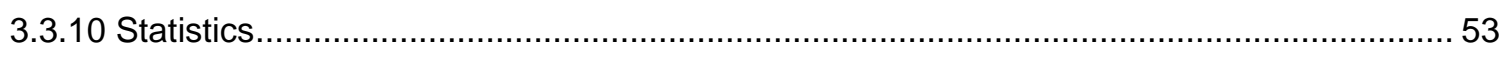

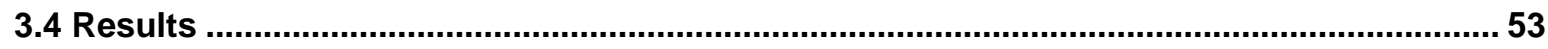

3.4.1 MPA altered TER and TJs permeability in a concentration and time dependant manner .. 53

3.4.2 AcMPAG modulation of TER and TJs permeability ...................................................... 54

3.4.3 MPA and AcMPAG mediated increase in permeability was not due to cell death/apoptosis

3.4.4 MPA and AcMPAG increased the expression of MLC2 and MLCK in Caco-2 cells ........... 56

3.4.5 MPA and AcMPAG increased MLC2 phosphorylation in Caco-2 cells............................... 58

3.4.6 MPA and AcMPAG altered TJ proteins expression and distribution ................................. 58

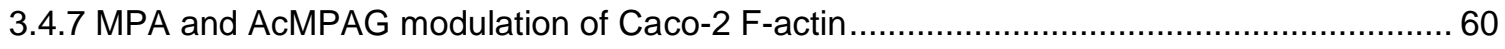

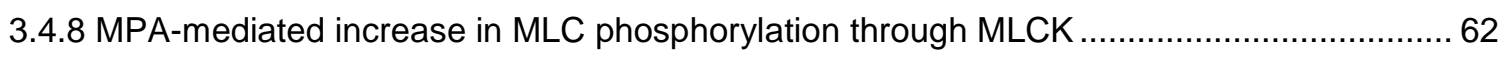

3.4.9 MLCK inhibition partially prevented MPA effects on TER and permeability ...................... 64 


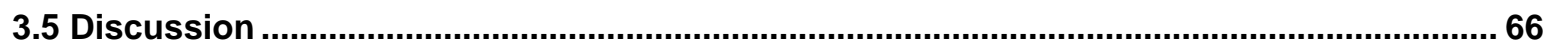

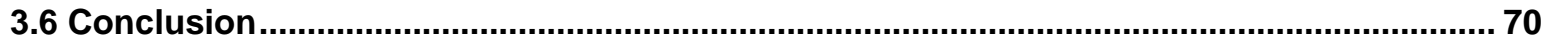

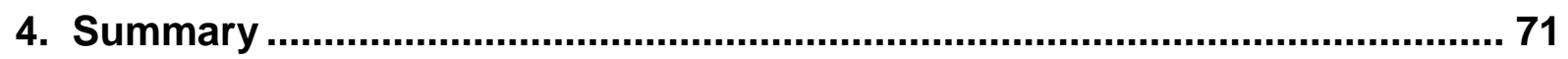

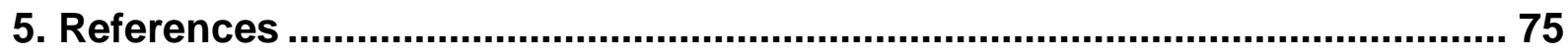

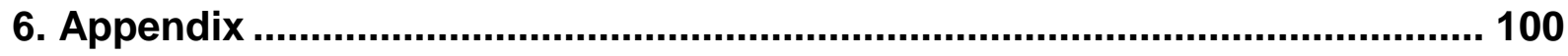

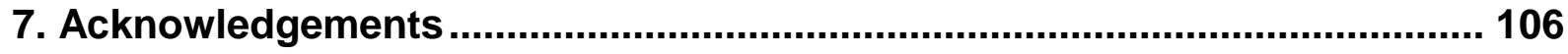

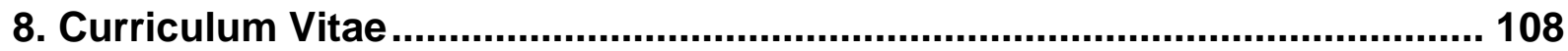




\section{List of abbrevations}

\begin{tabular}{|c|c|}
\hline AcMPAG & Acyl glucuronide of mycophenolic acid \\
\hline $\mathrm{ACN}$ & Acetonitrile \\
\hline BSA & Bovine serum albumin \\
\hline cAMP & 3',5'-cyclic monophosphate \\
\hline CD & Cytochalasin D \\
\hline $\operatorname{cdc} 42$ & Cell division control protein 42 homolog \\
\hline cDNA & Complementary DNA \\
\hline $\mathrm{C}_{\max }$ & Maximum plasma concentrations \\
\hline CRF & Corticotrophin-releasing factor \\
\hline $\mathrm{C}_{\mathrm{T}}$ & Threshold cycle \\
\hline CYP & Cytochrome P \\
\hline DEVD-pNA & Asp-Glu-Val-Asp p-nitroanilide \\
\hline DMEM & Dulbecco's modified Eagle's medium \\
\hline DMSO & Dimethyl sulfoxide \\
\hline DNA & Deoxyribonucleic acid \\
\hline dNTPs & Deoxyribonucleotides \\
\hline DSMZ & German collection of microorganisms and cell cultures \\
\hline DTT & Dithiothreitol \\
\hline $\mathrm{ECL}$ & Enhanced chemiluminescence \\
\hline EC-MPS & Enteric-coated mycophenolate sodium \\
\hline EF-2 & Elongation factor 2 \\
\hline ELISA & Enzyme linked immunosorbent essay \\
\hline EPEC & Enteropathogenic Escherichia coli \\
\hline ER & endoplasmic reticulum \\
\hline ERK & Extracellular signal regulated kinases \\
\hline ESI-QTOF-MS & Electro spray ionization time of flight mass spectrometry \\
\hline F-actin & Filamentous polymers actin \\
\hline FCS & Fetal calf serum \\
\hline FD 4 & Fluorescein isocyanate-dextran \\
\hline FDA & United States Food and Drug Administration \\
\hline FITC & Fluorescein isothiocyanate \\
\hline g & Gravitational (unit of centrifugation) \\
\hline
\end{tabular}




$\begin{array}{ll}\text { GI } & \text { Gastrointestinal } \\ \text { GMP } & \text { Guanosine monophosphate } \\ \text { GTP } & \text { Guanosine triphosphate } \\ \mathrm{H}_{2} \mathrm{O}_{2} & \text { Hydrogen peroxide } \\ \text { HDACs } & \text { histone deacetylases } \\ \text { HEK-293 } & \text { Human embryonic kidney-293 } \\ \text { hOAT } & \text { Human organic anion transporters } \\ \text { HRP } & \text { Horse radish peroxidase } \\ \text { IBD } & \text { Inflammatory bowel disease } \\ \text { IC } 50 & \text { Inhibitory concentration 50 } \\ \text { IEF } & \text { Iso-electric focusing } \\ \text { IgA } & \text { Immunoglobulin-A } \\ \text { IMP } & \text { Inosine monophosphate } \\ \text { IMPDH } & \text { Inosine monophosphate dehydrogenase } \\ \text { IPG } & \text { Immobilised pH gradient } \\ \text { JAMs } & \text { Junctional adhesion molecules } \\ \text { kDa } & \text { Kilo dalton } \\ \text { LC } & \text { Liquid chromatography } \\ \text { LDH } & \text { Lactate dehydrogenase } \\ \text { LPS } & \text { Lipopolysaccharide } \\ \text { MAGI } & \text { MAGUKS with inverted domain structure } \\ \text { MAGUK } & \text { Membrane-associated guanylate kinases } \\ \text { MAPK } & \text { Mitogen-activated protein kinase } \\ \text { Marvel } & \text { MAL-related proteins for vesicle trafficking and membrane link } \\ \text { MC } & \text { Mast cells } \\ \text { ML-7 } & \text { 1-5-lodonaphthalene-1-sulfonyl)-1H-hexahydro-1,4-diazepine } \\ \text { MLC } & \text { hydrochloride } \\ \text { MLCK } & \text { Myosin light chain } \\ \text { MLCP } & \text { Myosin light chain kinase } \\ \text { MMF } & \text { Myosin light chain phosphatase } \\ \text { MPA } & \text { Mycophenolate mofetil } \\ \text { MPAG } & \text { Mycophenolic acid } \\ \text { MRP } & \text { Mulidrug resistant protein } \\ & \end{array}$




$\begin{array}{ll}\text { MUPP } & \text { Multi-PDZ Domain Protein } \\ \text { NADH } & \text { Nicotinamide adenine dinucleotide } \\ \text { NO } & \text { Nitric oxide } \\ \text { NSAIDs } & \text { Nonsteroidal anti-inflammatory drugs } \\ \text { OD } & \text { Optical density } \\ \text { p } & \text { Probability } \\ \text { PAGE } & \text { Polyacrylamide gel electrophoresis } \\ \text { PAMR } & \text { Perijunctional actomyosin ring } \\ \text { Papp } & \text { Apparent permeability } \\ \text { PBS } & \text { Phosphate buffer saline } \\ \text { PEG } & \text { Polyethylene glycols } \\ \text { PKC } & \text { Protein kinase C } \\ \text { pkl } & \text { Peak list } \\ \text { PLC } & \text { Phospholipase C } \\ \text { PML } & \text { Multifocal leukoencephalopathy } \\ \text { PP2A } & \text { Protein phosphatase 2A } \\ \text { Prdx1 } & \text { Peroxiredoxin-1 } \\ \text { PVDF } & \text { Polyvinylidene fluoride } \\ \text { RNA } & \text { Ribonucleic acid } \\ \text { RNase } & \text { Ribonuclease } \\ \text { ROCKs } & \text { Rho-associated, coiled-coil containing protein kinase } \\ \text { ROS } & \text { Reactive oxygen } \\ \text { RT } & \text { Reverse transcriptase } \\ \text { SDS } & \text { Sodium dodecyl sulfate } \\ \text { SEM } & \text { Standard error of the mean } \\ \text { TBS-T } & \text { Tris boric acid-tween } \\ \text { TER } & \text { Transepithelial electrical resistance } \\ \text { TFA } & \text { Triflouroacetic acid } \\ \text { TJ } & \text { Tight junctions } \\ \text { TLR2 } & \text { Toll-like receptor 2 } \\ \text { UGT } & \text { Uridine diphosphate-glucuronosyltransferase } \\ \text { VEGF- } \alpha & \text { Vascular endothelial growth factor alpha } \\ \text { ZONAB } & \\ & \end{array}$




\section{List of Figure}

Figure 1.1 Chemical structure of MMF, EC-MPS, MPA, and their metabolites, AcMPAG, MPA 7-O-

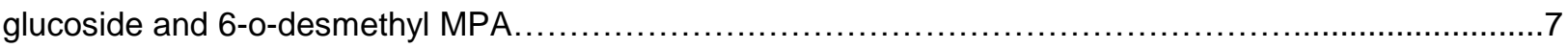

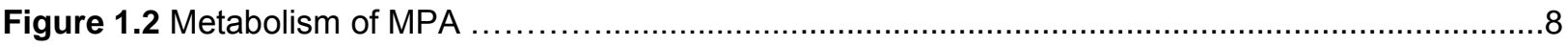

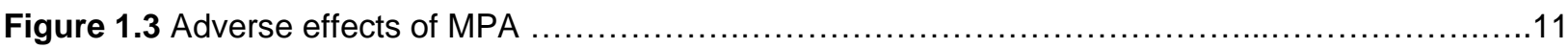

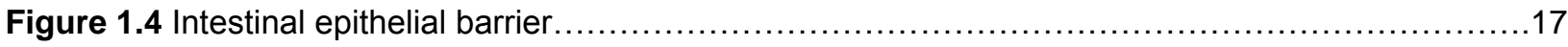

Figure 2.1 Inhibition of HEK-293 cells proliferation by MPA treatment.....................................36

Figure 2.2 Differential protein expression after incubation of HEK-293 cells with MPA.....................36

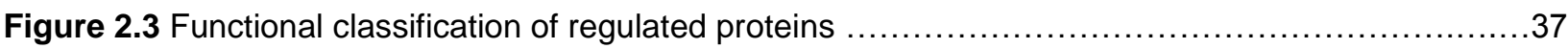

Figure 2.4 Differential expression of Prdx1 and MLC2 by MPA treatment...........................................38

Figure 2.5 Expression of MLC2 in MMF treated rat kidney lysate and HT-29 cells................................39

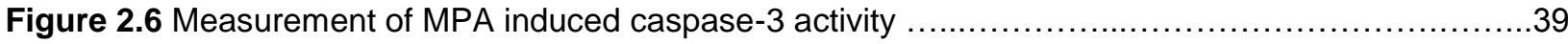

Figure 3.1 MPA treatment decreased TER and increased FD4 permeability of Caco-2 cell monolayers...54

Figure 3.2 AcMPAG treatment caused a time dependant decrease in TER and increase in FD4

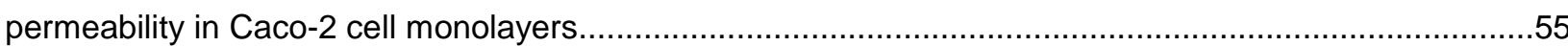

Figure 3.3 Effect of MPA and AcMPAG on cell viability and apoptosis in Caco-2 cells.................56

Figure 3.4 Effect of MPA and AcMPAG on MLC2, MLCK and ROCK expression in Caco-2 cells..........57

Figure 3.5 Effect of MPA and AcMPAG on the phosphorylation of MLC2 in Caco-2 cells................58

Figure 3.6 Effects of MPA and AcMPAG on ZO-1 and occludin distribution........................................59

Figure 3.7 Effect of MPA and AcMPAG on occludin protein expression in Caco-2 cells ..................60

Figure 3.8 MPA and AcMPAG-induced remodelling of the F-actin cytoskeleton....................................61

Figure 3.9 Effect of ML-7 on MPA-mediated increases in MLC2, MLCK and MLC phosphorylation........63

Figure 3.10 ML-7 co-treatment reversed the effect of MPA on TER and FD4 permeability .................64

Figure 3.11 ML-7 co-treatment reversed the effect of MPA on distribution of proteins .....................65

Figure 3.12 Effect of ML-7 co-treatment with MPA on occludin protein expression in Caco-2 cells.......... 66

Figure 4.1 A proteomic approach for identification of novel MPA molecular targets $\ldots \ldots \ldots \ldots \ldots \ldots \ldots \ldots \ldots . . .73$

Figure 4.2 Proposed model of MPA mediated TJ disruption ..................................................................

Figure 5.1 A graphical representation of relative abundance (\%volume) of all differentially regulated proteins 100 


\section{List of Tables}

Table 2.1 Differentially regulated proteins by MPA in HEK-293 cells identified by mass spectrometry .......35

Table 5.1 MS/MS analysis table of all differentially regulated proteins. 101 


\section{General introduction}

\subsection{Mycophenolic acid}

Mycophenolic acid (MPA) is an active fungal agent derived from Pencillium Brevicopactum and related fungi. MPA was discovered in 1893 by an Italian physician, Bartolomeo Gosio as an antibiotic against Bacillus anthracis (reviewed in [1]) and was named by Alsberg and Black in 1913 [2]. MPA selectively and competitively inhibits inosine monophphosphate dehydrogenase $(\mathrm{IMPDH})$, which is a key regulatory enzyme in the de novo pathway of purine biosynthesis. IMPDH converts inosine monophosphate (IMP) to guanosine monophosphate (GMP), an important intermediate in the synthesis of DNA, RNA, proteins, and glycoproteins. Inhibition of IMDPH leads to cell cycle arrest in synthesis (S) phase due to the blocking of de novo guanosine nucleotide synthesis. MPA exhibits cytotoxic effects on all cell types including its main target, lymphocytic cells [3][4,5]. Lymphocytes presumably utilize a de novo pathway for purine biosynthesis while non-lymphocytic cells depend only partially on this pathway, and can utilize a salvage pathway [4]. In the salvage pathway, guanine obtained from the breakdown of nucleic acids is directly converted to guanosine monophosphate and used for purine synthesis [6]. Additionally, MPA has five fold more potent inhibitory action on IMPDH II, an isoform mainly expressed in B \& T lymphocytes, than on IMPDH I, which is expressed in all body cells [4]. Consequently, the cytostatic effects of MPA on lymphocytes are greater than on other cell types, which contributes to the prevention of graft rejection, making MPA an especially useful immunosuppressant in transplantation medicine [3,4].

MPA is marketed in two forms: the ester pro-drug mycophenolate mofetil (MMF; CellCept, Roche, Grenzach-Wyhlen, Germany) and enteric-coated mycophenolate sodium (EC-MPS; myfortic $\circledast$; Novartis Pharma AG, Basel, Switzerland) [7]. MMF gained approval by the United States Food and Drug Administration (FDA) in 1995 for the prevention of renal, cardiac, and hepatic allograft rejection [8,9]. MPA is now the drug of choice in transplantation medicine for the prevention of acute rejection in patients undergoing allogenic renal, cardiac and liver transplantation $[4,10]$. Furthermore, MPA has proved to be effective in the treatment of autoimmune 
disorders of the eyes and skin as well as in Wegener's granulomatosis and lupus nephritis [11-14], hypertension [15,16] and neuromuscular autoimmune diseases [17,18]. MPA has also been reported to possess anti-viral [19], anti-fungal [20], antibacterial [1], anti-tumor [21], and anti-psoriasis [22,23] activities.

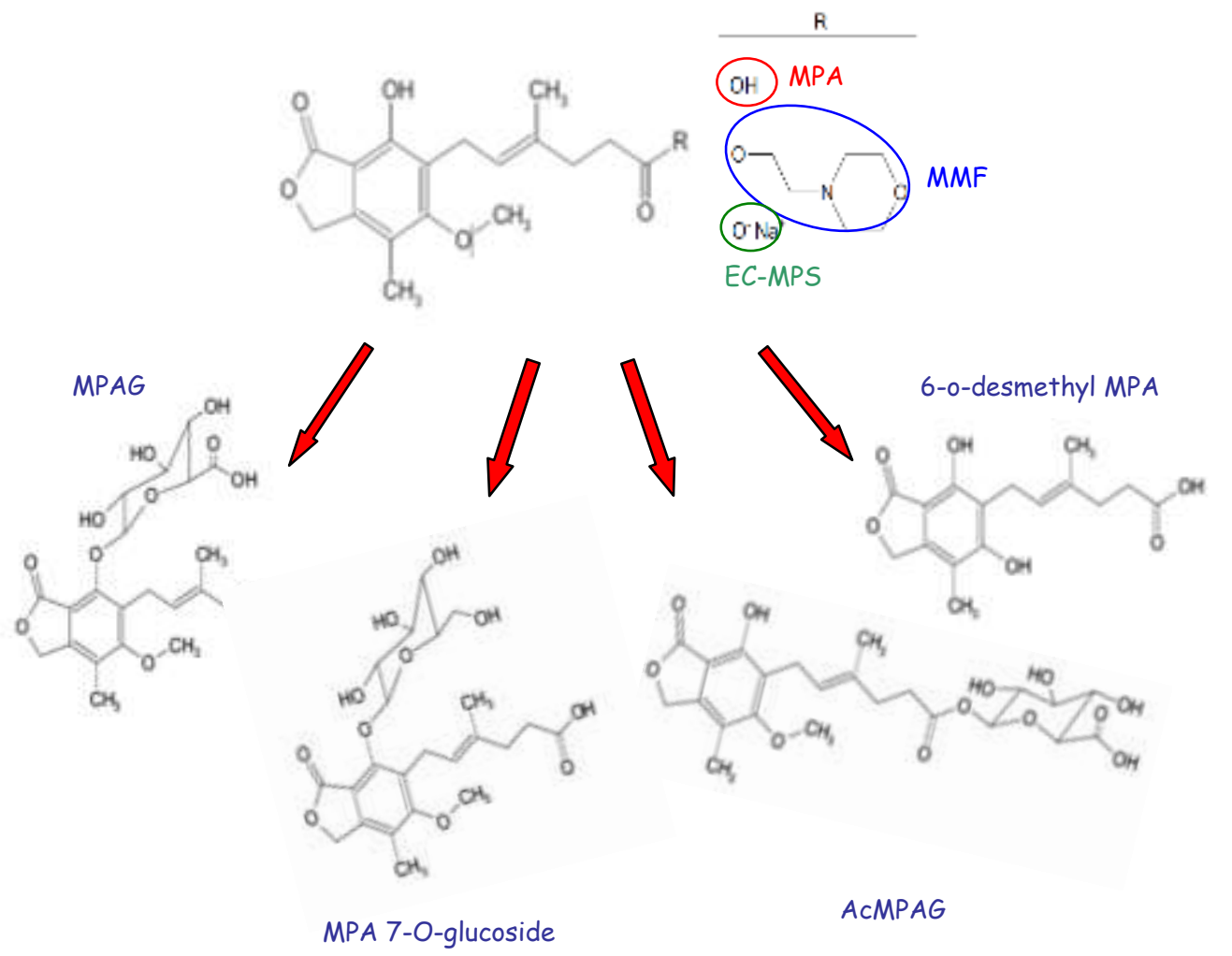

Figure 1.1: Chemical structure of MMF, EC-MPS, MPA, and their metabolites AcMPAG, MPA 7O-glucoside, and 6-0-desmethyl MPA.

\subsubsection{Metabolism}

MMF and EC-MPS is rapidly hydrolyzed by esterases in the gut, blood, liver, and kidney [24]. Maximal MPA plasma concentrations $\left(\mathrm{C}_{\max }\right)$ are generally reached within 1-1.5 hr and 1.5-2.5 hr after oral administration of MMF and EC-MPS respectively [7]. EC-MPS is insoluble in the acidic $\mathrm{pH}$ of the stomach but highly soluble in the neutral $\mathrm{pH}$ of the intestine. This effect is responsible for later peak concentrations seen after EC-MPS administration when compared to MMF $[7,25]$. Following intravenous administration, MMF is also rapidly hydrolyzed to MPA with $\mathrm{C}_{\max }$ achieved within approximately $1.58 \mathrm{hr}$ and with an absorption half life of only a 
few minutes [26]. The mean bioavailability of MPA is $81 \%-94 \%$ and $72 \%$ following administration of MMF and EC-MPS respectively [7,27], while the mean bioavailability of MPA after oral administration of MMF is estimated to be $94.1 \%$ relative to the intravenous route [28]. Trough plasma MPA concentrations are in the range of $0.3-3.4 \mathrm{mg} / \mathrm{L}$ [261]. MPA binds extensively (97-99\%) to plasma albumin producing free fractions of only $<3 \%$. The free fraction of MPA is mainly responsible for the pharmacological effects of MPA $[7,24,29,30]$.

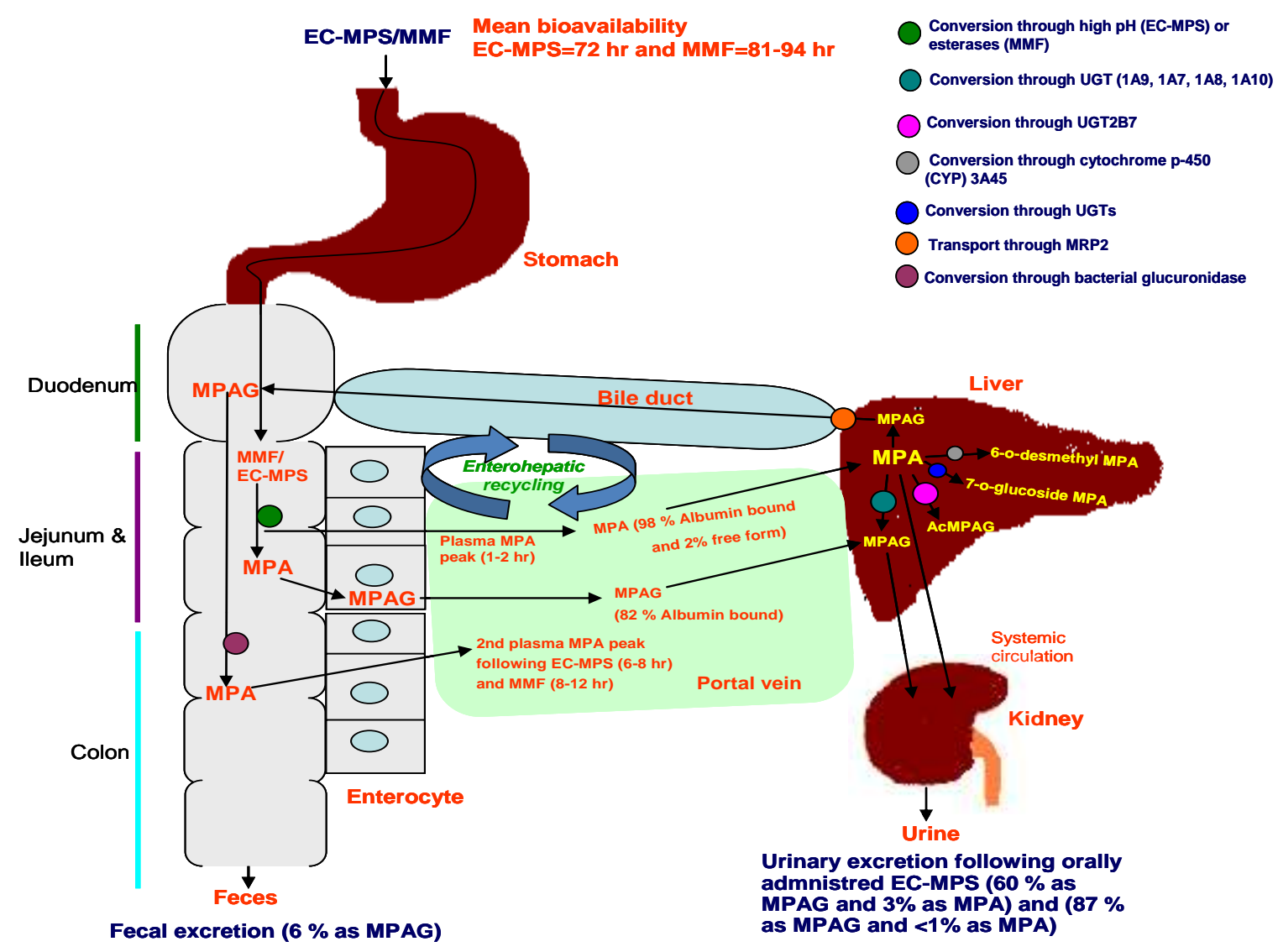

Figure 1.2: Metabolism of MPA.

MMF and EC-MPS are hydrolyzed to their active form MPA in the GI tract. MPA then absorbed and subsequently glucuronated by UGT to MPAG in the hepatocytes. In addition, other metabolites including AcMPAG, MPA 7-O-glucoside, and 6-o-desmethyl MPA are also formed. MPAG is largely excreted into urine by hOATs while some is secreted into bile by MRP, where it is then either excreted into feces or reconverted to MPA by glucuronidases present in gut bacteria and returned to the systemic circulation (enterohepatic recycling). 
Like many other xenobiotics, MPA undergoes glucuronidation, which is the major pathway for phase II metabolism for xenobiotics in humans [36]. MPA is conjugated by uridine diphosphate-glucuronosyltransferase (UGT) enzymes to form MPA glucuronide (MPAG) in hepatocytes, kidneys and intestinal mucosa [30,31]. UGT 1A9, UGT1A7, 1A8 and 1A10 are mainly responsible for MPAG formation [32]. Beside MPAG, other minor metabolites of MPA, such as 7-O-glucoside and the active acyl glucuronide of MPA (AcMPAG) are formed by UGT2B7 and miscellaneous UGTs respectively [32,33]. In addition, an oxidation product 6-Odesmethyl MPA is formed by cytochrome P-450 (CYP3A4/5) [34]. The chemical structures of MPA, its pro-drugs, and metabolites are given in Figure 1.1.

MPAG does not exhibit pharmacological activity but is present in 20 to 100 fold higher concentrations than MPA in the blood [24] and achieves its $C_{\max }$ in $1 \mathrm{hr}$ after the MPA $\mathrm{C}_{\max }$ [251]. MPAG has a protein binding of $82 \%$ and has the capacity to interfere with the MPA-albumin binding. MPAG at high concentrations is known to displace MPA from its albumin binding sites, thus modulating the free fraction of MPA, which is important for the pharmacological activity of MPA $[30,35]$.

AcMPAG, a pharmacologically active metabolite, is believed to be responsible for some of the adverse effects of MPA $[33,36,37]$. Acyl glucuronides are formed by esterfication of carboxylic acid with glucuronic acid [36]. Such acyl glucuronides have been observed for several clinically useful therapeutic drugs including non steroidal anti-inflammatory drugs (NSAIDs) [36]. AcMPAG plasma concentrations are 10-20\% of MPA concentrations [75,76]. Mean AcMPAG area under curve (AUC), over $12 \mathrm{hr}$ is generally $10.3 \%$ of simultaneous MPA-AUC [75] and AcMPAG reaches its $C_{\max }$ in 1-3 hr following the $C_{\max }$ of MPA \{Schutz, 2000680 /id\}.

MPA is eliminated from the body mainly through the kidneys. $93 \%$ of the orally administered dose of MMF is excreted in urine and $6 \%$ in the feces. MMF is predominantly $(87 \%)$ excreted as MPAG in the urine and a small amount $(<1 \%)$ as MPA. Like MMF, orally administered EC-MPS is also excreted maximally through urine, with $60 \%$ as MPAG and approximately $3 \%$ as MPA $1-7,4,8,9$. 
A proportion of MPAG is secreted into bile through multidrug resistant protein (MRP) transporters, specifically MRP2 [41]. MPAG then goes into the intestine where gut bacteria deglucuronidate MPAG to reform MPA, which is then reabsorbed back into systemic circulation [24,30]. This reabsorption is responsible for a second peak of MPA concentration detected in plasma 6 to $12 \mathrm{hr}$ and 6 to $8 \mathrm{hr}$ following oral administration of MMF and EC-MPS respectively [45]. This process is known as enterohepatic circulation and accounts for 10 to $60 \%$ of total MPA exposure $[24,30,31,42]$. The mean elimination half-life of MPA is 13 and $13-17 \mathrm{hr}$ following oral administration of MMF and EC-MPS respectively [7,24]. The simplified overview of distribution and metabolism of MPA is shown in Figure 1.2.

\subsubsection{Cellular and adverse effects of MPA}

MPA causes the depletion of guanosine triphosphate (GTP) pools, which is assumed to be responsible for MPA associated anti-proliferative effects in vitro and in vivo $[43,44]$. Nucleotide inhibition leads to $\mathrm{G} 1$ cell cycle arrest and thus inhibits cell growth of immune ( $T$ and $B$ lymphocytes) and non immune cells (smooth muscle cells, enthothelial cells, renal tubular and mesangial cells) in a dose-dependant manner [43,44,46-47]. MPA is also a potent anti-inflammatory agent which inhibits proliferation of immune cells, inhibits pro-inflammatory cytokines such as tumor necrosis factor alpha, interleukin 1 beta, interleukin-17, vascular endothelial growth factor alpha (VEGF- $\alpha$ ), and blocks the migration of leucocytes to inflammation sites $[48,49]$. MPA has promising effects in reducing myofibroblast infiltration, collagen III deposition and inhibition of the proliferation of both immune (lymphocytes) and non immune (fibroblasts, vascular smooth muscle and tubular) cells which are involved in the development of fibrosis [50-52]. MPA inhibits tumor growth and metastasis through G1-S cell cycle arrest, induction of differentiation in a variety of human tumor cell lines, induces apoptosis, as well as suppress the glycosylation and expression of several adhesion molecules (integrins, ICAM-1, VCAM-1, E-selectin and P-selectin) which promote tumor metastasis [21,53-56]. 


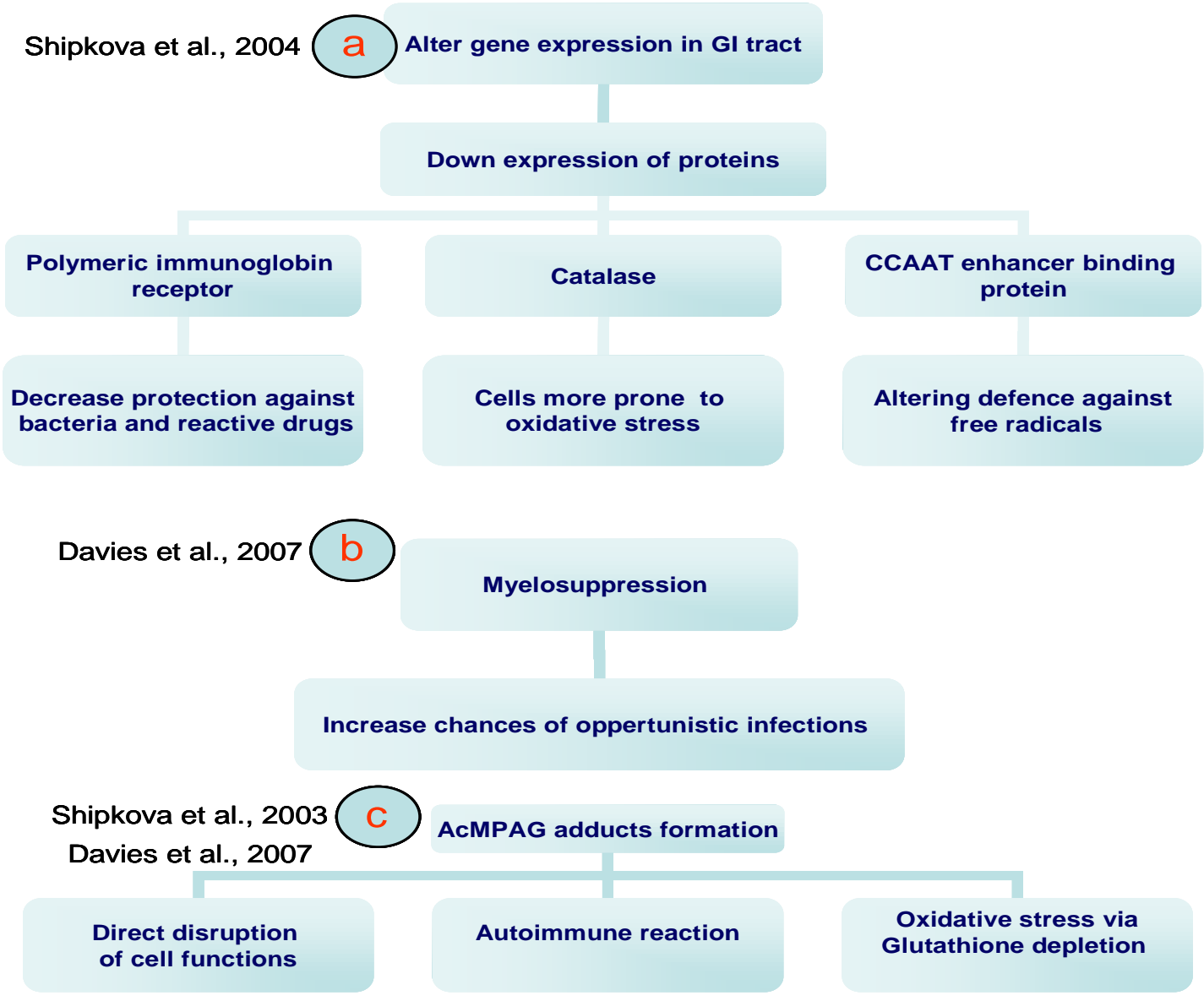

Figure 1.3: Adverse effects of MPA.

Various proposed mechanisms of MPA associated side effects are highlighted such as (a) alteration in gene expression making individuals more susceptible to stress [78], (b) immunosuppression leading to opportunistic infections [58], (c) AcMPAG adduct toxicity results in ultrastructural abnormalities, metabolic dysfunction, and oxidative damage [58][36].

MPA is generally a well tolerated immunosuppressive agent and produces less nephrotoxicity compared to other immunosuppressives drugs (reviewed in [57]). GI toxicity is the common adverse effect of MPA, occurs in $20 \%$ of renal patients on MMF therapy, and is dose dependant (reviewed in [57]). Symptoms of GI toxicity include diarrhea, abdominal pain, nausea, anorexia, vomiting, [58-60], gastritis, esophagitis, duodenal ulcers, colonic ulceration [60,61], and small intestinal villous atrophy [62,63]. MMF can cause enterocolitis and a Crohn's disease-like collitis syndrome $[37,64,65]$.

In addition to Gl tract symptoms MPA can cause genitourinary symptoms such as frequency, urgency, dysuria, sterile pyuria, and hematuria. These symptoms have 
reen reported to occur during the first year of MPA therapy (reviewed in [2,57]). In addition, MPA can also occasionally produce neurologic disturbances such as weakness, headache, tinnitus and insomnia (reviewed in [66]). Some cases of progressive multifocal leukoencephalopathy (PML) have been reported in patients on MMF therapy. These patients developed clinical features such as hemiparesis, apathy, confusion, cognitive deficiencies, and ataxia $[67,68,68]$. The occasional skin problems with MPA use include exanthematous eruptions, acne, pedal edema, urticaria, dishydrotic eczema, blistering hand dermatitis, and onycholysis (reviewed in $[57,66])$.

MPA can cause cardio-respiratory toxicity causing dyspnoea, cough, chest pain, palpitations, hypertension, acute respiratory failure, pulmonary edema, pulmonary fibrosis and pneumonitis [57,69]. Metabolic disturbances are also reported in MMF treated patients. Findings in these patients includes hypercholesterolemia, hypophosphatemia, hypokalemia, hyperkalemia, hyperglycemia (reviewed in $[57,66]$ ). There have been reports of mild, dose-related haematologic effects occurring in $5 \%$ of patients. Findings include anemia, leucopenia, and thrombocytopenia (reviewed in $[2,57])$. Pure red cell aplasia (PRCA) has been observed in some patients treated with MPA in combination with other immunosuppressive drugs [70]. An increased incidence of infectious complications occurs in $2 \%$ of renal and cardiac transplant patients and in 5\% of hepatic transplant patients treated with MPA (reviewed in [57]). Like other immunosuppressive therapies, opportunistic infections occur in up to $40 \%$ of transplant patients given MMF (reviewed in [66,71]). Several viral, bacterial and fungal complications have been observed, including infection with herpes simplex virus, herpes zoster virus, human herpes virus type 6, papillomavirus, aspergillosis, encephalitis, streptococcus $B$ septic shock, recurrent E.coli associated epididymitis, pediatric disseminated varicella, candidiasis, cryptococcosis, mucormycosis pneumocystis carinii pneumonia, and intestinal microsporidosis (Reviewed in $[3,56,74])$.

Diarrhoea is the most common Gl adverse effect caused by MPA but the exact mechanism responsible for this have not yet been clearly defined [72]. Several mechanisms have been suggested to be responsible for the adverse events associated with MPA therapy including direct cytotoxic effects on Gl cells, release of pro-inflammatory cytokines by AcMPAG [73,74], and formation of AcMPAG protein 
adducts [75]. Covalent AcMPAG-protein adducts are formed through two pathways; transacylation and glycation. Transacylation involves direct bounding of an aglycone moiety to the proteins while the glycation mechanism involves intramolecular rearrangement resulting in a open-chain conjugate with a free aldehyde group which binds with the amino group on various proteins $[36,77]$.

AcMPAG adducts may cause cellular toxicity through a number of proposed mechanisms. These adducts may modify protein structure and thus interfere with normal cell function, or they may activate the immune system resulting in hypersensitivity reactions or autoimmunity. Furthermore, AcMPAG adducts cause oxidative stress via glutathione depletion [58][36]. Previously, it was demonstrated that AcMPAG forms covalent protein adducts in the kidney, liver and intestine of rats treated with MMF [76,77]. The proteins involved are associated with diverse cellular functions. Another study revealed that MMF down-regulates mRNA expression of polymeric immunoglobulin receptor (resulting in decreased protection against invading pathogens and reactive drugs), catalase (cells were more prone to oxidative stress), and CCAAT/enhancer-binding proteins (interference with the defence system against free radicals) $[58,78]$. The adverse effects of MPA therapy are summarized in Figure 1.3.

\subsection{Intestinal epithelial barrier}

The mammalian intestine is lined with a single layer of specialized simple columnar epithelium that separates the intestinal lumen from the underlying lamina propria $[79,80]$. The intestinal lining consists of proliferative crypts, which contain intestinal stem cells, and villi, which contain differentiated specialized cell types such as the absorptive enterocytes, mucous-secreting goblet cells, and hormone-secreting enteroendocrine cells [81] (reviewed in [82]). In addition, there are Paneth cells which are differentiated cells at the bottom of crypts bottom that perform several functions including limiting gut microbial populations by secreting defensins, (antimicrobial peptides) and protecting the intestinal lining from bacterial toxins [80].

The intestinal epithelium represents the major contact between a person and their external environment and covers an extensive surface area of $>300 \mathrm{~m}^{2}$ [83]. 
Structural components of the intestinal barrier include the unstirred water layer, the hydrophobic mucosal surface, the surface mucous coat, epithelial factors (tight junctions), and endothelial factors [84]. The intestinal epithelium has two vital functions. It selectively filters, allowing the absorption of nutrients, electrolytes, and water from the intestinal lumen into the circulation while it serves as a barrier to prevent luminal pro-inflammatory factors, luminal pathogens and their antigens or toxins from invading the tissues [84-87]. In addition, the stirred water layer plays a role in transport of many nutrients and drugs, especially lipid-soluble compounds [84]. Mucus from goblet cells provides a protective layer against the physical friction, chemical digestion, and adhesion of bacteria. In addition, it also acts as a diffusion barrier $[84,88]$. The hydrophobicity of the mucosal surface acts as an important barrier to bacterial and other factors within the gut lumen. Many factors such as nonsteroidal anti-inflammatory drugs (NSAIDs), dextran sodium sulfate, trinitrobenzenesulfonic acid, lipopolysaccharide (LPS) and ammonium [89] can decrease this hydrophobicity.

The epithelial layer constitutes the key component of intestinal barrier. It acts as a selectively permeable filter allowing the transport of essential dietary nutrients, electrolytes, and water from the intestinal lumen into the circulation [84,90]. In addition, the intestinal epithelia controls chloride permeability which is responsible for secretion of protective fluids into the intestinal lumen which limits bacterial colonization and entry of toxins into the intestinal cells [91]. Another important function of the intestinal lining is its secretion of local immunoglobulins such as epithelial secretory immunoglobulin-A ( $\lg A)$ which targets antigens at the mucosal surface, and constitutes a humoral component of the mucosal immune system [9294].

Permeability of the intestinal epithelium is regulated via transepithelial/transcellular and paracellular pathways. Transcellular transport is an active process and involves transport of water, amino acids, electrolytes, short-chain fatty acids, and sugars across the plasma membrane by specific ion channels and transporters [15,16][95]. Paracellular transport is a passive process which involves the movement of solutes and water across the intercellular space and is regulated by intercellular complexes. Paracellular transport is determined by molecular size or the ionic charge or both and is mainly regulated by tight junctions (TJ) $[95,96]$. 


\subsubsection{Tight junctions}

Intestinal epithelial cells are connected to one another by adhesive junctional complexes which serve as a physiological and structural paracellular barrier. Components that constitute the multimolecular junctional complex include desmosomes, adherens junctions, and TJs $[97,98]$. TJ, the most apical component of the junctional complex are generally considered to be the major barrier to the passage of molecules between adjacent cells and through the intercellular space. The TJ barrier is not absolute but is selectively permeable and is able to discriminate between solutes on the basis of size and charge. TJ complex contains more than forty proteins, having various functions [99]. The structure of TJ was first described with the help of electron microscopy [100]. TJ consist of transmembrane proteins (JAMs, occludin and claudins), adaptors (ZO (type 1-3), MAGI (type 1-3), PAR 3/6, cingulin, PATJ and MUPP1), regulatory proteins (Rab 13, Rab 3b, G proteins, PKC, PP2A and PTEN), and both transcriptional and post-transcriptional regulators (symplekin, ZONAB, and huASH1). All these proteins interact with each other to form a complex protein network [101,102], responsible for TJ functions including their interaction with F-actin [103]. The basic architecture of $\mathrm{TJ}$ is shown in Figure 1.4. All of the TJ proteins listed above play an important role in the structure and function of TJ, but only a brief description of the function of some TJ proteins ( ZO-1, occludin, and claudin), which have been extensively studied in the context of TJ disruption [104] are described below.

ZO, the first TJ-associated protein to be identified [105], belongs to the membrane associated guanylate kinase family (MAGUK) and contains three $\mathrm{N}$ terminal PDZ repeats, an SH3 domain, and a C-terminal region homologous to guanylate kinases [106]. There are different isotypes of ZO including ZO-1, ZO-2 and ZO-3 with a variety of cellular functions. ZO-1 is a $210-225 \mathrm{KDa}$ peripheral membrane protein and is a major constituent of the cytoplasmic domain of TJ. The Cterminal domain of ZO-1 interacts with other TJ proteins including claudins [107]. ZO1 is also in close association with actin cytoskeleton responsible for linking transmembrane proteins of the $\mathrm{TJ}$ to the actin cytoskeleton that plays a regulatory role in TJ actions. The C-terminal portion of occludin, claudin, ZO-2, and ZO-3 interact closely with the $\mathrm{N}$-terminus of ZO-1. Additionally, the C-terminal half of ZO-1 
interacts with F-actin regulating cytoskeleton [107,108]. The expression and distribution of ZO proteins are regulated by myosin light chain kinase (MLCK) and their alteration can lead to defective function of epithelial barriers [109]. The downregulation and redistribution of ZO-1 has been observed in TJ disruption conditions, such as those involving cytokines [110,111], ethanol [112] and oxidants [113].

Occludin is a $60 \mathrm{KDa}$ protein and was identified as the first among transmembrane TJ proteins in 1993 [114,115]. Occludin is a member of the Marvel (MAL-related proteins for vesicle trafficking and membrane link) domain containing protein family [116]. Occludin has a tetraspan structure that constitutes its extracellular strand within TJ and amino- and carboxy-terminal chains projecting into the cytoplasm [117]. The interactions of occludin with various intracellular TJ proteins, including ZO-1, ZO-2, and ZO-3 have been well documented [118]. Occludin plays an important role in regulating $\mathrm{TJ}$ dynamics as demonstrated by the fact that its depletion leads to increases in the permeability of larger-sized molecules shown in both in vitro and in vivo intestinal models [119]. The down-regulation of occludin proteins, associated with increased permeability has been observed in several inflammatory bowel diseases such as Crohn's disease, ulcerative colitis, and celiac disease [120-122], as well as in animal models of inflammatory bowel disease $[123,124]$. It has been proposed that a decrease in intestinal occludin expression may be an important mechanism responsible for increased intestinal epithelial TJ permeability. Occludin in epithelial cells is highly phosphorylated on serine and threonine residues and its phosphorylation plays a critical role in the regulation of $\mathrm{TJ}$ integrity. Occludin phosphorylation is regulated by the balance between protein kinases (eg. C-Src, PKC $\zeta$, and PKCN/I, and protein phosphatases (eg. PP2A, PP1, and PTP1B) [125-127]. Occludin has also been reported to be phosphorylated at tyrosine which has been proposed to be implicated in disruption of TJs by various toxins such as hydrogen peroxide and acetyladehyde [128,129].

Claudins are $20-27 \mathrm{KDa}$ integral membrane $\mathrm{TJ}$ proteins that contains four hydrophobic transmembrane domains which have a cytoplasmic $\mathrm{N}$ terminus, two extracellular loops, and a C-terminal cytoplasmic domain. The claudin family is a multigene family comprised of at least 24 members [130]. On the basis of their role in controlling permeability, claudins has been divided into two sub-categories, 
paracellular barrier forming claudins and paracellular, ion permeability forming claudins. Both are vital for proper and tissue-specific functioning of the TJs; making claudins a critical player in regulation of paracellular function [131,132]. The carboxy terminus of claudins binds to PDZ domains of proteins including those of the ZO proteins [107]. In addition, interaction of claudin-1 with ZO-1 is critical for ZO-1 integration into epithelial TJs [133]. Claudin isotypes 1 to 5 are present in the intestinal cells in various intestinal regions [134,135]. Down-regulation of claudin 1 is believed to be linked to the TJ disruption in inflammatory mucosa by Crohn's diseaseand ulcerative colitis and is believed to be associated with enhanced paracellular permeability [136]. Claudin 4 down-regulation has also been observed in collagenous colitis, characterized by barrier defects and associated with reduced net $\mathrm{Na}^{+}$and $\mathrm{Cl}^{-}$absorption [137].

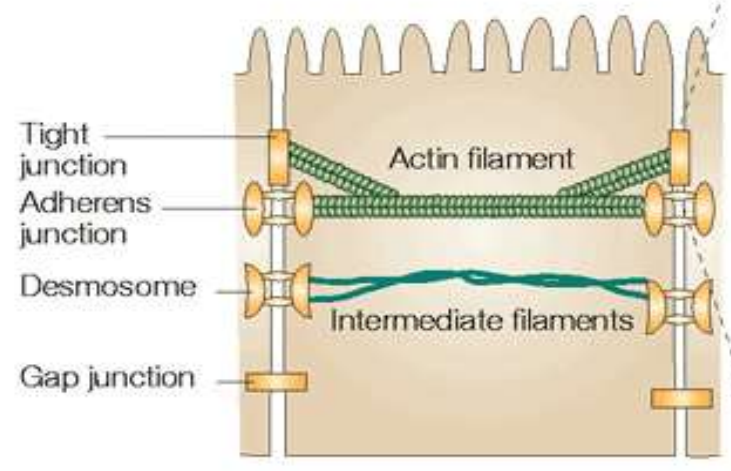

Figure 1.4: Intestinal epithelial barrier.

Schematic diagram of intestinal epithelial cells showing tight junctions (TJ), adherens junctions (AJs), desmosomes and gap junctions. The TJs are positioned at the most apical parts of the plasma membranes of entrocytes, whereas AJs and desmosomes are present mainly at the basal parts of the lateral membranes. TJ and AJ are linked to actin and play an important role in regulation of intestinal permeability (Left panel). The molecular components of epithelial tight junctions (TJs) are outlined (right panel), and consist of transmembrane proteins (occludin, claudins and JAMs), adaptors (ZO (13), PAR 6, and PATJ), regulatory proteins (Rac, cdc42, RhoA, and PKC), and other associated proteins. Occludin, claudins and JAMs are linked to the zona occludens, and they are connected to actin forming the main TJ assembly. Adopted from (Aktories $\mathrm{K}$ and Barbieri JT 2005, Nat Rev Microbiol) [138]. 
TJ defects have been described in several patho-physiological conditions such as brain diseases [139,140], pulmonary inflammation, allergic rhinitis [141], obstructive jaundice [142], kidney diseases [143,144], diabetic retinopathy [145], cancers [146], blood-borne metastases [140,147] and bowel diseases [148-150]. Intestinal epithelial barrier dysfunction is a major factor contributing to the predisposition to inflammatory diseases, including food allergy, IBD, and celiac disease. The presence of environmental factors in the intestinal lumen and inappropriate host immune responses are key determinants of the development of IBD [87,148]. In IBD, epithelial barrier function is impaired leading to either diarrhoea because of a leaky flux mechanism or translocation of toxins and macromolecules into intestinal cells causing associated dysfunction [151].

\subsubsection{Factors modulating intestinal permeability}

Several endogenous molecules such as glucose [153], hormones [154], nucleotides [155], and growth factors [156-158] provide physiological modulation of TJ permeability. In addition, a growing list of pathological agents has been suggested as etiologic factors in several diseases as a result of causing increased mucosal permeability [159]. Dietary components are crucial in the regulation of barrier integrity (reviewed in [160]). Gliadin, a glycoprotein present in wheat, is the key factor in the pathogenesis of celiac disease and is responsible for TJ disruption leading to increased permeability [161]. Several dietary components have been found to increase TJ permeability including: cayenne pepper (Capsicum frutescens), paprika (Capsicum anuum), galangal (Alpinia officinarum), marigold (Tagetes erecta), Acer nikoense, and hops (Humulus lupulus) (reviewed in [160]). In contrast, black pepper (Piper nigrum), green pepper, nutmeg, bay leaf extracts, linden (Tilia vulgaris), star anise (Illicium anisatum), Arenga engleri, and black tea (Camellia sinensis) have been found to decrease paracellular flux and increase transepithelial resistance (TER) (reviewed in [160]).

Pro-inflammatory cytokines have also been proposed as pathophysiological stimuli which trigger several cellular pathways leading to pathological conditions including bowel diseases [110,111,162-166]. For example, TNFa modulates epithelial barrier properties and has a critical role in IBDs [167] and graft-versus-host disease [152]. TNFa up-regulates MLCK which acts as the central player in TNFa induced 
barrier loss, both in vitro [168] and in vivo [150,169]. Additionally, TNFa has also been shown to be involved in the down regulation of apical $\mathrm{Na}^{+}-\mathrm{H}^{+}$exchange, which then is linked to the development of diarrhoea [169,170]. Mast cells (MC) have been reported to regulate intestinal permeability, as suggested by the fact that their degranulation results in blood flow modulation, as well as increased epithelial and endothelial permeability, mucosal secretion, gastrointestinal tract motility, immunologic reactions, and angiogenesis (reviewed in [84] ). Several physiological and pathological conditions have been reported to be associated with MC mediated intestinal permeability including food allergy, irritable bowel syndrome, and after stressful conditions [171,172]. Intracellular mediators including nitric oxide (NO) regulate barrier properties by altering the function of epithelial cells and the GI microcirculation [173]. The activity and synthesis of $\mathrm{NO}$ is increased by endotoxin (LPS), cytokines, and ethanol (EtOH), which results in barrier dysfunction via protein oxidation, nitration, S-nitrosylation, cGMP activation, and cellular energy depletion (reviewed in [84]).

Epithelial-microbe interactions are responsible for alterations in the structure and function of the epithelial barrier, regulation of fluid and electrolyte secretion, and modulation of inflammatory signalling (reviewed in [174]). More than 400 microbial species that have a profound impact on gut physiology reside in the gastrointestinal lumen [80]. Pathogenic bacteria, such as Escherichia coli, Klebsiella pneumoniae, Streptococcus viridans, Clostridium difficile, Bacteroides fragilis, Vibrio cholerae, and Helicobacter pylori, as well as viruses and parasites (giardia) can disrupt the intestinal barrier (reviewed in [84]). Beneficial bacteria:however, such as Lactobacillus brevis maintain TJ and reduce intestinal permeability [175]. Psychological stress is another factor responsible for alterations in epithelial barrier physiology (reviewed in [84]). Various parts of brain, brain stem, various CNS afferents, and the neuro-endocrinal system are proposed to be involved in the stress response. During psychological stress corticotrophin-releasing factor (CRF) is released, which triggers the enteric nervous system that causes alterations in gut motility, exocrine and endocrine functions, and the microcirculation (reviewed in [176]). Oxidative stress is caused largely by reactive oxygen (ROS) species such as hydrogen peroxide $\left(\mathrm{H}_{2} \mathrm{O}_{2}\right)$, nitric oxide, peroxynitrite and hypochlorous acid which disrupt the epithelial and endothelial barrier function by destabilizing TJs [177]. 


\subsubsection{Regulation of $\mathrm{TJ}$ structure and function}

Regulation of the assembly, disassembly, and maintenance of $\mathrm{TJ}$ structure is highly dynamic and is influenced by diverse protein-protein interactions that respond to both extra-cellular and intra-cellular physiological, pharmacological, and pathophysiological stimuli. TJ regulation is controlled by several signalling proteins, including tyrosine kinase, $\mathrm{Ca}^{+2}$, phospholipase $\mathrm{C}(\mathrm{PLC})$, protein kinase $\mathrm{C}(\mathrm{PKC})$, calmodulin, mitogen-activated protein kinase (MAPK), MLCK, the Rho family of small GTPases, adenosine, 3',5'-cyclic monophosphate (cAMP), and heterotrimeric G proteins [178-182]. Actin has a vital role in the structure and function of TJ. Multiple TJ components interact with the actin cytoskeleton and regulate the permeability of TJs [183,184]. Reorganization of the actin cytoskeleton as a result of interactions between transmembrane proteins and the actomyosin ring $[178,183,185,186]$ and as well as the phosphorylation state of TJ proteins are both critically involved in alterations in TJ physiology [187,188]. Members of the Rho family GTPase (Rac, Rho, and Cdc42) have also been shown to be able to reorganize the actin cytoskeleton and modulate TJ physiology [179,189-191]. Changes in the phosphorylation status of $\mathrm{TJ}$ proteins such as ZO, occludin, E-cadherin, $\beta$-catenin, and claudins act as a molecular switch that regulates $T J$ structure and function $[125,187,188,192,193]$.

MLC phosphorylation is an important regulator of barrier function in health and disease [194]. Increased MLC phosphorylation leads to the rearrangement of TJ proteins (ZO-1, occludin, claudin-1 and claudin-4), disruption of perijunctional F-actin, and increases TJ permeability $[103,184]$. The main pathways associated with MLC phosphorylation are controlled either directly by MLCK activity or indirectly by Rho kinase mediated inhibition of phosphatase [182]. MLCK mediated MLC phosphorylation is sufficient to trigger downstream events necessary for barrier regulation and has a central role in many diseases that are characterized by intestinal barrier dysfunction (reviewed in [170]). Increased MLCK expression or activity has been observed in GI pathology following TNF $\alpha$ [169], interleukin $1 \beta$ [195,196], lipopolysaccharide [197], and ethanol [112,198] exposure. Similar increased MLCK activity is observed after exposure to virulence factors associated with GI infections with Enteropathogenic Escherichia coli (EPEC) $[199,200]$ and 
Helicobacter pylori [201,202], as well as parasitic diseases like giardiasis [203]. The role of Rho family of small GTPases has been described in the regulation of TJ structure and function including the perijunctional actomyosin ring [194,204]. ROCKs regulate the phosphorylation of MLC by inactivating MLCP (myosin light chain phosphatase), which is involved in decreasing MLC phosphorylation [191]. ROCK inhibition causes the redistribution of F-actin structures and modulates TJ permeability. In addition, ROCK co-localizes with the ZO-1 and its inhibition prevents proper localization of TJ proteins during TJ assembly [204].

PKC is an important member of the serine-threonine kinases family which regulate epithelial barrier structure and function. PKC modulates the expression of subcellular localization and phosphorylation states of TJ proteins which alters barrier dynamics [206]. PKC proteins are also involved in various signal transduction pathways such as the Toll-like receptor 2 (TLR2) pathway. Activation by PKC isoforms results in increases in TER and redistribution of ZO-1 (reviewed in [160]). PKC also interacts with MLCK. PKC phosphorylates MLCK which leads to decreases in MLC phosphorylation, reduces tension on the perijunctional actomyosin ring (PAMR), and increases permeability [207]. The MAPK pathway is a major intracellular signalling pathway involved in cell growth, differentiation, and TJ regulation [208]. Several growth factors, cytokines, and oxidative stresses are involved in the stimulation of the MAPK pathway (reviewed in $[160,209])$. Members of MAPK have been implicated in modulation of TJ structure and function since extracellular signal regulated kinases (ERK) interact directly with the C-terminal region of occludin to prevent $\mathrm{H}_{2} \mathrm{O}_{2}$-induced disruption of TJ [208].

\subsubsection{Caco-2 cells as an in vitro model for intestinal epithelial integrity}

A number of both in vitro and in vivo experimental models are being used to study the integrity of TJs [210-213][214,215]. Caco-2 is one of the most widely used intestine cell models for in vitro studies of intestinal barrier functions [211,216,217], intestinal absorption, and toxicity of xenobiotics [216-218]. Caco-2 cells were first generated from the differentiated colon adenocarcinoma of a 72 -year old patient 
[219]. Caco-2 cells grown in culture usually reach confluency within 3-6 days, a stationary growth phase after 10 days [220], and complete their differentiation within 20 days [221]. Once differentiated these cells exhibit properties similar to enterocytes both structurally, bio-chemically, and functionally including having microvilli, intercellular junctions, nutrient transporters, efflux transporters, and enzymes (alkaline phosphatase, sucrase isomaltase and aminopeptidase) [222,223]. Caco-2 cells also express various transport and metabolizing enzymes such as cytochrome P450 isoforms and UDP-glucuronosyltransferases, sulfotransferases and glutathione-S-transferases $[224,225]$. Although, most Caco-2 properties resemble those of enterocytes, some differ. Caco-2 cells lack the crypt-villus axis (which is important for in vivo transport) and mucus producing goblet cells (leading to a lack of prominent mucus layers [226-228]).

Transepithelial electrical resistance (TER) and paracellular permeability to tracers molecules are two parameters that are commonly used to investigate the integrity and function of the $\mathrm{TJ}$ in in vitro models such as Caco-2 monolayers [213,229-232]. Usually, TJ barriers limit the ionic diffusion through cell monolayers, which creates a potential difference that is measured as transpithelial resistance (TER). TER has a direct relationship with TJ integrity. The greater the TER, the more intact the TJ $[223,233,234]$. Paracellular permeability of tracers in cell layers is measured by the diffusion rate of such tracers from apical to basal or vice versa. Paracellular flux is inversely related to $\mathrm{TJ}$ integrity (ie. increased paracellular flux suggests TJ disruption [213,233]). A variety of paracellular flux markers are used to investigate the effects of physiological and pathological agents on TJ integrity. The most frequently used paracellular markers include polyethylene glycols (PEG), fuorescein-5 and -6 sulfonic acid [235], inulin [119,236,237], fluorescein isothiocyanate dextrans (FITC-dextran), urea, mannitol, L-glucose [119,237], raffinose [238], atenolol [239] and lucifer yellow [240]. Size, shape, and charge of the solutes used control the permeability properties of any particular paracellular marker [233,241]. 


\subsection{Rationale for the proposed research}

Mycophenolic acid is a frequently used immunosuppressive agent and has a wide range of pharmacological actions. The present study was undertaken to identify novel molecular targets of MPA using a comprehensive 2-DE based expression proteomics approach. Whole cell lysates from HEK-293 cells which had been exposed to MPA were resolved by 2-DE, and differentially expressed proteins were identified by QTOF MS/MS analysis. In an attempt to examine effects with possible clinical relevance on a regulated protein, myosin light chain 2 (MLC2), we investigated the effects of MPA on TJ integrity using Caco-2 monolayers as a colonic cell culture model. After employing various physiological assays as well as immunoblotting and immunoflourescence analyses, we found that exposure to therapeutic concentrations of MPA modulated tight junction physiology via MLC2 phsophorylation. The current study may help to understand the etiology of MPA associated adverse intestinal effects. 


\section{Differential proteome analysis of human embryonic kidney cell line (HEK-293) following mycophenolic acid treatment}

Muhammad Qasim ${ }^{1,2}$, Hazir Rahman ${ }^{1,2}$, Michael Oellerich ${ }^{1}$, Abdul R. Asif ${ }^{1}$

1. Department of Clinical Chemistry, University Medical Centre Goettingen, 37075, Goettingen, Germany.

2. Department of Microbiology, Kohat University of Science and Technology, 26000, Kohat, Pakistan.

Published in "Proteome Science 2011, 9:57 


\subsection{Abstract}

Mycophenolic acid (MPA) is widely used as a post transplantation medicine to prevent acute organ rejection. In the present study we used proteomics approach to identify proteome alterations in human embryonic kidney cells (HEK-293) after treatment with therapeutic dose of MPA. Following 72 hours MPA treatment, total protein lysates were prepared, resolved by two dimensional gel electrophoresis and differentially expressed proteins were identified by QTOF-MS/MS analysis. Expressional regulations of selected proteins were further validated by real time PCR and Western blotting. The proliferation assay demonstrated that therapeutic MPA concentration causes a dose dependent inhibition of HEK-293 cell proliferation. A significant apoptosis was observed after MPA treatment, as revealed by caspase 3 activity. Proteome analysis showed a total of 12 protein spots exhibiting differential expression after incubation with MPA, of which 7 proteins (complement component 1 $Q$ subcomponent-binding protein, electron transfer flavoprotein subunit beta, cytochrome b-c1 complex subunit, peroxiredoxin 1, thioredoxin domain-containing protein 12 , myosin regulatory light chain 2 , and profilin 1) showed significant increase in their expression. The expression of 5 proteins (protein SET, stathmin, $40 S$ ribosomal protein $\mathrm{S} 12$, histone $\mathrm{H} 2 \mathrm{~B}$ type $1 \mathrm{~A}$, and histone $\mathrm{H} 2 \mathrm{~B}$ type $1-\mathrm{C} / \mathrm{E} / \mathrm{F} / \mathrm{G} / \mathrm{I}$ ) were down-regulated. MPA mainly altered the proteins associated with the cytoskeleton (26\%), chromatin structure/dynamics (17\%) and energy production/conversion (17\%). Both real time PCR and Western blotting confirmed the regulation of myosin regulatory light chain 2 and peroxiredoxin 1 by MPA treatment. Furthermore, HT-29 cells treated with MPA and total kidney cell lysate from MMF treated rats showed similar increased expression of myosin regulatory light chain 2. The emerging use of MPA in diverse pathophysiological conditions demands in-depth studies to understand molecular basis of its therapeutic response. The present study identifies the myosin regulatory light chain 2 and peroxiredoxin 1 along with 10 other proteins showing significant regulation by MPA. Further characterization of these proteins may help to understand the diverse cellular effects of MPA in addition to its immunosuppressive activity. 


\subsection{Introduction}

Mycophenolic acid (MPA) is a frequently used immunosuppressant for the prevention of acute rejection in patients undergoing allogenic renal, cardiac, lung, and liver transplantations [4,10]. MPA is a selective, reversible and uncompetitive inhibitor of inosine monophosphate dehydrogenase (IMPDH), a key regulatory enzyme in the de novo pathway of purine synthesis. It exhibits cytotoxic effects on most of the cell types, but exerts greater effects on $T$ and $B$ lymphocytes, thus preventing solid organ rejection [4]. IMPDH inhibition by clinically relevant concentration of MPA results in guanine nucleotide depletion which is associated with $\mathrm{G} 1$ cell cycle arrest. MPA also triggers apoptosis by up-regulating pro-apoptotic proteins (p53, p21 and bax) and down-regulating proteins that are important for cell cycle progression, such as bcl-2, survivin p27 and c-myc [242]. IMPDH type II is significantly over-expressed in several tumor cells, for this reason IMPDH could be considered as a potent target for anti-cancer therapy, as well as immunosuppressive chemotherapy [243].

MPA and its metabolites effect most of the cellular functions by influencing biological pathways, like apoptosis [244], immune associated signaling [245] and general cell signaling pathways involving mitogen-activated protein kinases, extracellular-signal regulated kinases, c-Jun N-terminal kinases, p53 and Rhoassociated protein kinase [244,246,247]. Collectively, MPA possesses anti-microbial, anti-inflammatory, anti-fibrotic, pro-apoptotic [4], anti-angiogenic, anti-cancerous [248] and anti-oxidant activities [249]. Due to MPA diverse therapeutic activities in the cell, it is also used for the treatment of dermatological diseases, neuromuscular diseases and autoimmune disorders such as lupus [248,250]. Gastrointestinal tract (GIT) complications i.e., diarrhoea, nausea, abdominal pain, vomiting, anorexia, gastritis, intestinal ulceration and small intestinal villous atrophy are common complication for some transplant patients on MPA therapy. Other MPA associated adverse effects are anemia, myelosuppression and risk of opportunistic infections [251]. The exact molecular mechanism of MPA organ toxicity is unknown, but possible mechanisms include direct toxicity by its anti-proliferative effect, opportunistic infections due to myelosuppression and toxicity, and acyl MPA glucuronide (AcMPAG) proteins adduct formation [36,251]. 
Here we use HEK-293 cell line to uncover cellular protein response to the exposure of clinical dose of MPA. In the present study we used a proteomics based approach to resolve proteins of total cell lysates on two dimensional electrophoresis (2-DE) gels following treatment with DMSO and MPA. The differentially expressed proteins were in-gel tryptic digested and identified by QTOF-MS/MS analysis. Several proteins were identified with modified expression in response to MPA treatment which might be helpful to broaden our understanding regarding the cellular effects of MPA.

\subsection{Materials and methods}

\subsubsection{Reagents}

Cell culture media (DMEM and MacCoy's), fetal calf serum (FCS), phosphate buffer saline (PBS), penicillin and streptomycin were purchased from PAA Laboratories, Colbe, Germany. Urea, thiourea, dithiothreitol (DTT), trypsin, triflouroacetic acid (TFA), sodium carbonate, ammonium bicarbonate, MPA and DMSO were purchased from Sigma-Aldrich, Steiheim, Germany. Acetonitril (ACN) was obtained from Promochem, Wasel, Germany. CHAPS was obtained from AppliChem, Darmstadt, Germany. Ampholytes, protein assay kit and immobilised pH gradient strips (IPG strips) were procured from Bio-Rad, Munich, Germany, while protease and phosphatase inhibitor cocktails were purchased from Roche, Mannheim, Germany. Bromophenol blue and trizma base were obtained from Carl Roth, Karlsruhe, Germany. Sodium dodecyl sulfate (SDS) was obtained from Serva, Heidelberg, Germany. Glycerin, potassium ferricynaide and sodium thiosulfate were purchased from Merck, Darmstadt, Germany and formic acid from BASF, Ludwigshafen, Germany.

\subsubsection{Cell culture}

HEK-293 and HT-29 cell lines were purchased from German collection of microorganisms and cell cultures (DSMZ), Braunschweig, Germany. The cells were 
grown in $75 \mathrm{~cm}^{2}$ culture flasks (Sarstedt, Nuemberecht, Germany) and maintained in culture at $37^{\circ} \mathrm{C}$ in $95 \%$ humidity, $20 \% \mathrm{O}_{2}$ and $5 \% \mathrm{CO}_{2}$. DMEM and MacCoy's media supplemented with L-glutamine, $10 \%$ fetal calf serum, $100 \mathrm{U} / \mathrm{mL}$ penicillin, and 0.1 $\mathrm{mg} / \mathrm{mL}$ streptomycin was used to grow HEK-293 and HT-29 cells respectively.

\subsubsection{Proliferation assay}

Briefly, cells were grown in 96 well plates at a density of $3.5 \times 10^{4}$ cells/well at least $24 \mathrm{~h}$ prior to the start of the experiment. The cells were then incubated with DMSO (control) or 0 to $100 \mu \mathrm{mol} / \mathrm{L}$ MPA for a period of $72 \mathrm{hr}$. After completion of incubation, proliferation was determined using ELISA based BrdU cell assay (Roche Diagnostics) according to manufacturer's recommendations. Four independent experiments were performed. $\mathrm{IC}_{50}$ values were calculated by a Grafit software package, version 5 (Erithacus Software, London, UK).

\subsubsection{Sample preparation for proteome analysis}

The HEK-293 and HT-29 cells were grown for $24 \mathrm{hr}$ followed by treatment with DMSO or MPA $(7.5 \mu \mathrm{mol} / \mathrm{L}$ and $10 \mu \mathrm{mol} / \mathrm{L}$ for HEK-293 and HT-29 respectively) for $72 \mathrm{~h}$. Cells were harvested by scraping and were washed three times with ice cold PBS. After washing, cells were pelleted down at $250 \times \mathrm{g}$ for $10 \mathrm{~min}$ and lysed in a buffer containing $7 \mathrm{~mol} / \mathrm{L}$ urea, $2 \mathrm{~mol} / \mathrm{L}$ thiourea, $4 \% \mathrm{w} / \mathrm{v}$ CHAPS, $2 \%$ ampholyte $\mathrm{pH}$ 3-10 and 1\% DTT. The lysates were centrifuged and protein content was measured by Bradford assay [252] using Bio-Rad protein reagent (Bio-Rad, Munich, Germany) according to manufacturer's instructions. Sample aliquots were kept at $-80^{\circ} \mathrm{C}$ until further use. Protein lysate was prepared from 21 days MMF treated adult female Wistar rat's kidney according to the previously reported protocol [253] and were used for Westernblotting. 


\subsubsection{2-DE}

The 2-DE was performed as described by Gorg et al 2000 [254] with some minor modifications. Protein samples of HEK-293 cell $(110 \mu \mathrm{g})$ were mixed with rehydration buffer $(7 \mathrm{~mol} / \mathrm{L}$ urea, $2 \mathrm{~mol} / \mathrm{L}$ thiourea, $4 \%$ CHAPS, $0.2 \%$ ampholyte $[\mathrm{pH}$ 3-10], and $0.2 \%$ DTT) containing trace amount of bromophenol blue to a total volume of $350 \mu \mathrm{L}$. Samples were applied to linear IPG strips [pH 3-10], Bio- Rad) for $1 \mathrm{hr}$ and then covered with mineral oil for passive rehydration overnight at room temperature. Iso-electric focusing (IEF) was performed in Protean IEF cell (Bio-Rad) with a program of $1 \mathrm{~h}$ at 100 volts, $1 \mathrm{~h}$ at 500 volts, $2 \mathrm{hr}$ at 1000 volts and 8000 volts with a total of 32000 volts-hr. For the second dimension electrophoretic separation, focused strips were equilibrated for $30 \mathrm{~min}$ at room temperature in a buffer containing 50 $\mathrm{mmol} / \mathrm{L}$ Tris-HCL [pH 8.8], $6 \mathrm{~mol} / \mathrm{L}$ urea, 30\% v/v glycerol, $2 \%$ SDS and $10 \mathrm{~g} / \mathrm{L}$ DTT followed by an identical incubation but replacing DTT with $40 \mathrm{~g} / \mathrm{L}$ iodoacetamide. The proteins in the equilibrated strips were then resolved on the 12.5\% SDS-PAGE in a Protean II chamber (Bio-Rad) at $100 \mathrm{~V} / 4^{\circ} \mathrm{C}$.

\subsubsection{Protein visualization, densitometric analysis and in-gel digestion}

Gels were silver stained as described by Blum et al 1987 [255]. After fixation, gels were washed and sensitized. The gels were then incubated in freshly prepared silver nitrate solution $(0.2 \%$ silver nitrate and $0.026 \%$ formaldehyde) for $20 \mathrm{~min}$ at room temperature followed by 3 times washes of $20 \mathrm{sec}$ each in distilled water. Gels were placed in developing solution ( $6 \%$ sodium carbonate, $0.018526 \%$ formaldehyde and $6 \%$ sodium thiosulfate) until standard marker stained completely and adequate spots were visualized. Gels were scanned with a gel Cano scan 8400 (Canon, Tokyo, Japan). Densitrometric analysis was done by using Delta 2D software version 3.6 (Decodon GmbH, Gerifswald, Germany) [256]. Spot intensities were first normalized and the relative intensity of each spot was calculated by dividing the intensity of each spot by the sum of all spots intensities on the corresponding gel. Fold change, SD and Student's t test probability were calculated using Microsoft excel software. Spots having at least 1.5 fold expressional changes $(p<0.05)$ were 
considered statistically significant. Four independent 2-DE experiments were performed.

Differentially regulated protein spots were excised from the silver stained gel with a clean scalpel blade followed by in-gel digestion according to the method adopted and modified from Shevchenko et al [257]. Briefly, the gel pieces were washed twice in $100 \mathrm{mmol} / \mathrm{L}$ ammonium bicarbonate/acetonitrile $(1: 1, \mathrm{v} / \mathrm{v})$ initially for 10 min and then until all visible dye was removed. The gel pieces were dried using vacuum centrifuge (UNIVAPO $150 \mathrm{H}$; uniEquip, Matinsried, Germany) followed by reconstitution in the trypsin digestion solution $(10 \mathrm{ng} / \mu \mathrm{L}$ in $100 \mathrm{mmol} / \mathrm{L}$ ammonium bicarbonate) overnight at $37^{\circ} \mathrm{C}$. After incubation the supernatant containing digested peptides was transferred to a tube and $50 \mu \mathrm{L}$ of $0.1 \%$ TFA was added followed by sonication for $30 \mathrm{~min}$. After sonication, the supernatant was pooled with the previous one. Two further extractions were collected in the same way using $0.1 \%$ TFA in $30 \%$ and then $60 \% \mathrm{ACN}$. The pooled extracts of peptides were dried in vacuum centrifuge and reconstituted in $0.1 \%$ formic acid.

\subsubsection{Q-TOF LC-MS/MS analysis of protein identification}

The reconstituted peptide samples $(1 \mu \mathrm{L})$ were introduced onto $\mu$-precolumn ${ }^{\mathrm{TM}}$ cartridge (C18 pepMap; $300 \mu \mathrm{m} \times 5 \mathrm{~mm}$; $5 \mu \mathrm{m}$ particle size) and further separated

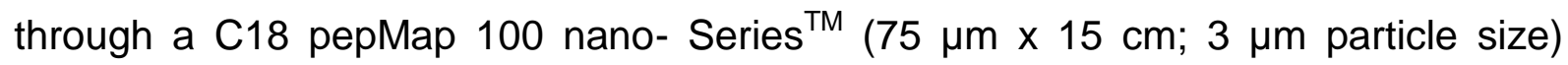
analytical column (LC Packings, Germering, Germany) using an CapLC autosampler (Waters, Eschborn, Germany). The mobile phase consisted of solution A $(0.1 \%$ formic acid prepared in $5 \% A C N)$ and solution $B(0.1 \%$ formic acid prepared in $95 \%$ ACN). The sample run time was set to $60 \mathrm{~min}$ and the flow rate of the pump to 5 $\mu \mathrm{L} / \mathrm{min}$. The exponential gradient was initiated at $5 \mathrm{~min}$ after loading from $10 \%$ to $95 \%$ for the period of $50 \mathrm{~min}$. Tip flow rate of $250 \mathrm{~nL} / \mathrm{min}$ was achieved through a flow splitter. The eluted peptides were injected into a Q-TOF Ultima Global (Micromass, Manchester, UK) mass spectrometer equipped with a nanoflow ESI Zspray source in positive ion mode. Data was acquired by MassLynx (v 4.0) software and peak list (pkl file) was generated from acquired MS/MS raw data using ProteinLynx Global Server bioinformatics tool (PLGS; v 2.2; Waters, Manchester, 
U.K.) under the following settings; Electrospray, centroid $80 \%$ with minimum peak width 4 channel, noise reduction 10\%, Savitzky-Golay, MSMS, medium deisotoping with $3 \%$ threshold, no noise reduction and no smoothing.

The generated pkl files were searched using the online MASCOT (http://www.matrixscience.com) algorithm against the SwissProt data base release 15.5 (515203 sequence entries, 181334896 elements). The search criteria was set as follows: enzyme, trypsin; allowance of up to one missed cleavage peptide; mass tolerance $\pm 0.5 \mathrm{Da}$ and $\mathrm{MS} / \mathrm{MS}$ tolerance $\pm 0.5 \mathrm{Da}$; modifications of cysteine carboamidomethylation and methionine oxidation. Proteins were finally identified on the basis of two or more peptides, whose ion scores exceeded the threshold, $P<$ 0.05 , which indicated the $95 \%$ confidence level for these matched peptides. To ensure accurate identification, protein spots were digested from more than two gels and analyzed with MS. Proteins were considered as identified if the threshold was exceeded and the protein spot possessed the correct molecular weight and pl value of the corresponding spot on 2-DE.

\subsubsection{Functional classification}

Biological function annotations for all of the identified proteins were done by KOGnitor (http://www.ncbi.nlm.nih.gov/COG/grace/kognitor.html) [258].

\subsubsection{Western blotting}

Proteins were separated on $12.5 \%$ SDS-PAGE and blotted onto PVDF membrane (ImmobilonP, Millipore) using semidry Trans-Blot ${ }^{\circledR}$ SD cell system (BioRad, Munich, Germany) for $30 \mathrm{~min}$ at $15 \mathrm{~V}$ in a blotting buffer (192 mmol/L glycine, $20 \%$ methanol, $25 \mathrm{mmol} / \mathrm{L}$ Tris $[\mathrm{pH} 8.3]$ ). The membranes were blocked with $5 \%$ (w/v) skimmed milk repared in TBS-T buffer $(50 \mathrm{mmol} / \mathrm{L}$ Tris-HCl $[\mathrm{pH} 7.5], 200$ $\mathrm{mmol} / \mathrm{L} \mathrm{NaCl}, 0.05 \%$ Tween 20 ) for $1 \mathrm{hr}$ at room temperature and washed twice with TBS-T buffer. The membranes were incubated with 1:1000 mouse anti Prdx1 antibody (Abcam, Cambridge, MA), 1:1000 rabbit anti MLC2 (Cell Signaling Technology, Inc., Danvers, MA) and 1:1000 mouse anti beta tubulin (Biovender, 
Czech Republic) overnight at $4^{\circ} \mathrm{C}$, followed by washes with TBS-T buffer. Membranes were further incubated with appropriate HRP-conjugated secondary antibodies for $1 \mathrm{hr}$ at room temperature. The signals on the blots were detected by using ECL system (GE Healthcare) according to manufacturer's instructions. Signal intensities from each Western blot were quantified by using Lab Image software, version 2.71 (Leipzig, Germany). $\beta$ tubulin was used as a loading control and at least four independent experiments were performed.

\subsubsection{RNA isolation and cDNA synthesis}

RNA was extracted using Trizol reagent (Invitrogen, Carlsbad, CA) according to manufacturer's recommendations. Briefly, cells were scraped, washed and then homogenized in Trizol reagent. RNA was separated by chloroform/isopropanol precipitation method. The concentration of RNA was determined by the GeneQuant II RNA/DNA calculator (Pharmacia Biotech, Freiburg, Germany). The RNA quality was verified at $\mathrm{OD}_{260} / \mathrm{OD}_{280} \mathrm{~nm}$ ratios and subsequent electrophoretically on $1 \%$ agarose gels using ethidium bromide staining. The cDNAs were synthesized from $2 \mu \mathrm{g}$ total RNA in a $30 \mu \mathrm{L}$ reaction mix containing $1 \mathrm{X}$ reverse transcriptase (RT) PCR buffer (10 mmol/L Tris-HCL [pH 8.3], $15 \mathrm{mmol} / \mathrm{L} \mathrm{KCl,} 0.6$ $\mathrm{mmol} / \mathrm{L} \mathrm{MgCl}_{2}$ ), $0.5 \mathrm{mmol} / \mathrm{L}$ of dNTPs mix, $1 \mathrm{U} / \mu \mathrm{L}$ RNase inhibitor and $13.3 \mathrm{U} / \mu \mathrm{L} \mathrm{M}$ MLV RT enzyme. The RT reaction was performed in a thermocycler (Biometra, Goettingen, Germany) at $42^{\circ} \mathrm{C}$ for $1 \mathrm{hr}$. cDNA was stored at $-70^{\circ} \mathrm{C}$ until use.

\subsubsection{Real-time PCR}

Relative quantitative PCR were carried out using the LightCycler instrument (Roche Diagnostic Systems, NJ, USA). The primers for the human Prdx1 (forward 5'TGGGGTCTTAAAGGCTGATG-3' and reverse 5'-TCCCCATGTTTGTCAGTGAA -3'), human MLC2 (forward 5'- CAGGAGTTCAAAGAGGCCTTCAAC -3 ' and reverse 5'CTGTACAGCTCATCCACTTCCTCA -3') and elongation factor 2 (forward 5'GACATCACCAAGGGTGTGCAG-3' and reverse 5'-GCGGTCAGCACACTGGCATA3) were designed by the Primer3 software (http://frodo.wi.mit.edu) [259]. The total volume of $20 \mu \mathrm{L}$ PCR contained $1 \mu \mathrm{L}$ of cDNA solution, $2 \mu \mathrm{L}$ of $10 \mathrm{X}$ PCR buffer 
(Invitrogen), $2 \mu \mathrm{L}$ Syber green, $1 \mu \mathrm{L}$ BSA, $1 \mu \mathrm{L}$ DMSO, $0.25 \mu \mathrm{L}$ of each primer (Eurofins MWG-Biotech, Ebersberg, Germany), $2.0 \mathrm{mmol} / \mathrm{L} \mathrm{MgCl}_{2}, 0.2 \mathrm{mmol} / \mathrm{L}$ dNTPs mix and $0.15 \mathrm{U} / \mu \mathrm{L}$ PAN Script DNA polymerase (PAN Biotech, Aidenbach, Germany). The amplification conditions for Prdx1 and MLC2 were: initial denaturation $30 \mathrm{sec}$ at $95^{\circ} \mathrm{C}$ and repeated cycles of denaturation $\left(95^{\circ} \mathrm{C}\right.$ for $\left.1 \mathrm{sec}\right)$, primer annealing $\left(55^{\circ} \mathrm{C}\right.$ for $\left.5 \mathrm{sec}\right)$, elongation $\left(72^{\circ} \mathrm{C}\right.$ for $\left.10 \mathrm{sec}\right)$, and fluorescence reading at $82^{\circ} \mathrm{C}$. For elongation factor 2 (EF-2) PCR conditions were similar to Prdx 1 except for primer fluorescence reading which was measured at $88^{\circ} \mathrm{C}$.

The relative expression of Prdx1 and MLC2 mRNA in the treated samples was determined as a fold increase compared with control samples using the

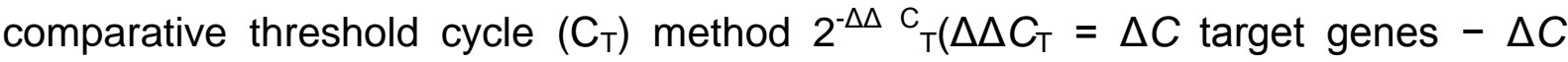
reference gene) [260]. EF-2 was used as the internal control gene. Experiments were performed four times. Statistical difference ( $p$ value) in mRNA expression level between MPA and DMSO samples were calculated using the Mann-Whitney $U$ test. The PCR product was run on a $1 \%$ ethidium bromide-agarose gel to confirm the presence of desired specific amplified product.

\subsubsection{Apoptosis assay}

The caspase 3 activity was measured using CaspACE ${ }^{\text {TM }}$ Assay kit (Promega Corporation, WI, USA) according to the manufacturer's protocol. Cells were treated with DMSO and MPA for $72 \mathrm{hr}$, harvested and briefly suspended in lysis buffer. Proteins were extracted and quantified by Bradford method [252]. Briefly, $70 \mu \mathrm{g}$ of protein lysate were mixed with reaction mixtures containing colorimetric substrate peptides specific for caspase 3 (DEVD-pNA) and then incubated at room temperature for overnight. The absorbance of the cleaved $p$-nitroanilide from the substrate DEVD-pNA was measured at $405 \mathrm{~nm}$ using EL808 microplate reader (BioTek instruments, VT, USA). Five independent experiments were performed. 


\subsection{Results}

In the present study the alteration in the cellular proteome by the MPA treatment was investigated using HEK-293 as cell culture model. Incubation of HEK-293 cells with MPA followed a dose dependent inhibition of cell proliferation (Figure 2.1). The $\mathrm{IC}_{50}$ concentration $(7.5 \mu \mathrm{mol} / \mathrm{L}$ or $2.4 \mathrm{mg} / \mathrm{L})$ of MPA was selected as standard dose for further analysis, which is within the therapeutic range (0.3 to $3.4 \mathrm{mg} / \mathrm{L})$ [261]. Cells were treated with MPA and DMSO (as vehicle) for 3 days, and total cell lysates were prepared. Total protein extracts of MPA and DMSO treated cells were separated by 2-DE using pH 3-10 linear IPG strips and visualized by silver stain. The protein spots which showed $\geq \pm 1.5$ fold change ( $p<0.05$ using Student's $t$ test) as compared to DMSO treated controls were considered as differentially expressed proteins. Statistical analysis showed that a total of 12 proteins exhibited significantly altered expression due to MPA treatment (Table 2.1). The altered expression pattern of the HEK-293 proteins by MPA is shown in Figure 2.2.

Among 12 regulated proteins spot under MPA treatment, 7 proteins were significantly up-regulated and 5 proteins showed down-regulated expression. The upregulated spots under MPA treatment were identified as complement component $1 \mathrm{Q}$ subcomponent binding protein (C1q), electron transfer flavoprotein subunit beta, cytochrome b-c1 complex subunit, thioredoxin domain-containing protein 12, myosin regulatory light chain 2 (MLC2), peroxiredoxin1 (Prdx1) and profilin 1. Five proteins, which showed down-regulated expression, were identified as protein SET, stathmin, 40 S ribosomal protein S12, histone H2B type 1-A, and histone H2B type 1-C/E/F/G/I. A bar diagram, showing relative abundance (\% Vol), SD and statistical significance of all the significantly regulated protein is provided as figure 5.1 . Figure 2.2 shows an exemplary gel of DMSO (vehicle) and MPA with marked regulated proteins. The extent of regulation in protein expression with predicted and actual pl, as well as molecular masses with their SwissProt accession numbers are provided in Table 2.1 and $\mathrm{MS} / \mathrm{MS}$ spectral information is provided in the figure 5.2. 
Table 2.1. Differentially regulated proteins by MPA in HEK-293 cells identified by mass spectrometry

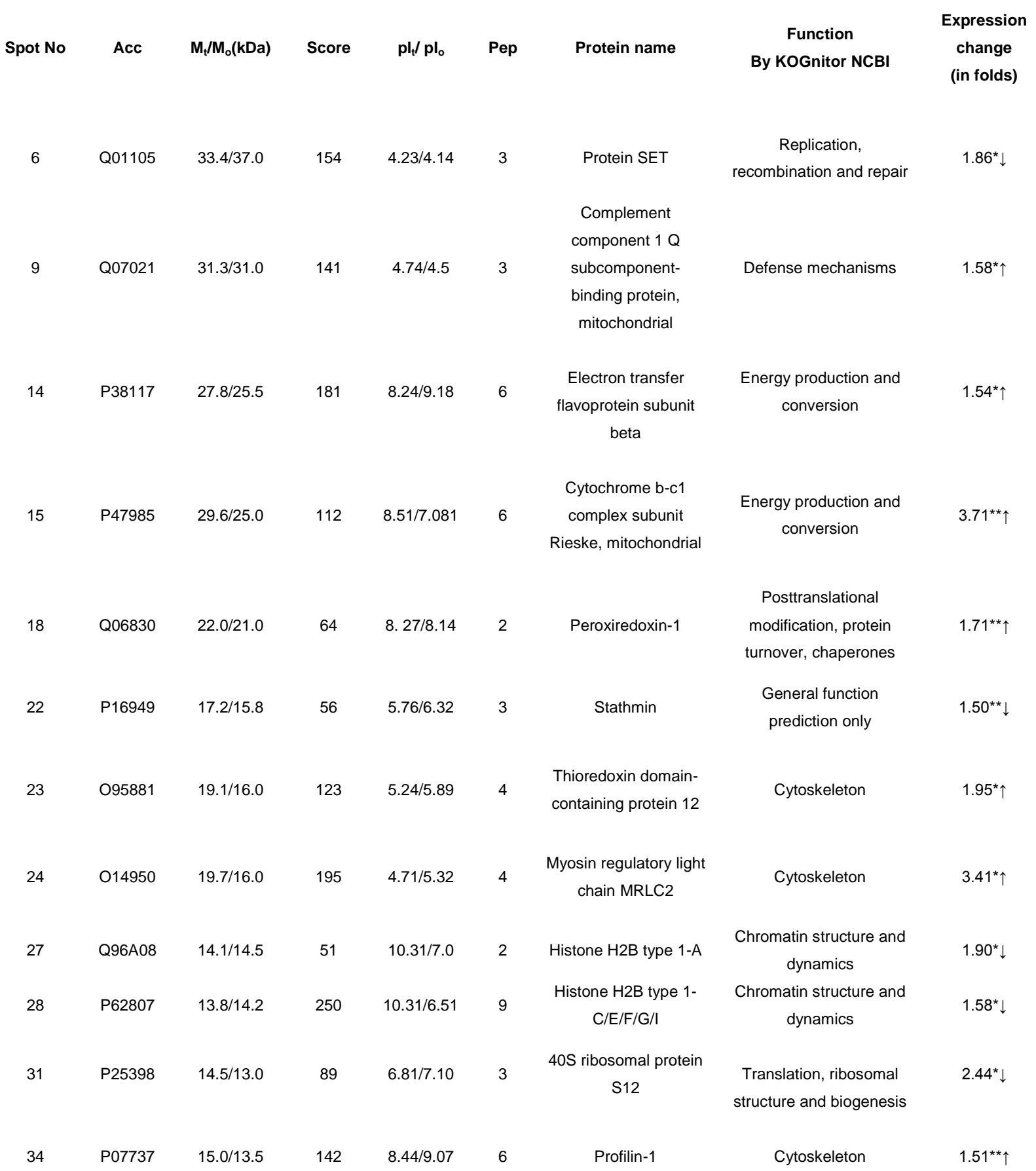

Acc: Accession number; Mt: theoretical molecular mass; Mo: observed molecular mass; plt: theoretical isoelectric point; plo: observed isoelectric point; pep: number of peptides sequenced for identification; Score: Peptide mass fingerprint probability score as defined by Mascot (www.matrixscience.com). Individual ions score $>42$ indicate identity or extensive homology $(p<0.05)$; $\downarrow$ : down-regulated; $\uparrow$ upregulated; ${ }^{*} p<0.05,{ }^{* *} p<0.005$. Molecular function determined from the online protein reference database KOGnitor NCBI. (http://www.ncbi.nlm.nih.gov/COG/grace/kognitor.html). 


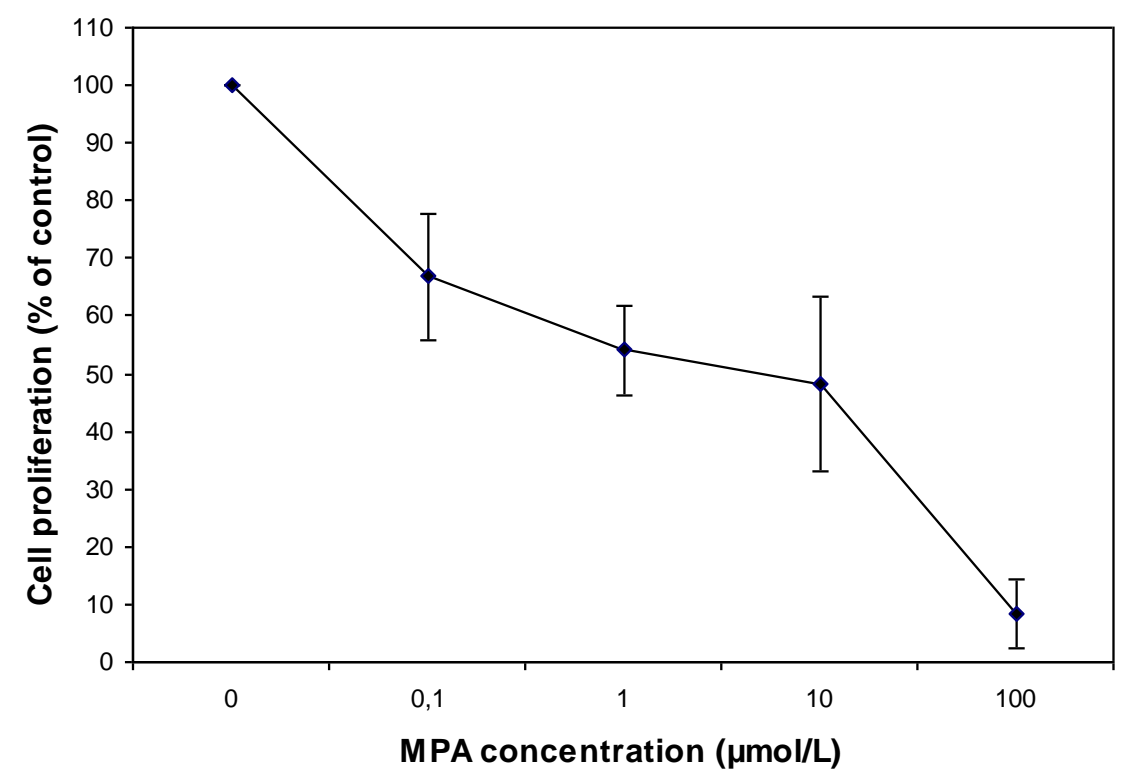

Figure 2.1: Inhibition of HEK-293 cells proliferation by MPA treatment.

The cell proliferation was determined after $72 \mathrm{hr}$ of treatment with different doses of MPA $(0-100$ $\mu \mathrm{mol} / \mathrm{L}$ ) using BrdU colorimetric based method. Results are shown as percentage of control (DMSO treated) and represent four independent experiments.
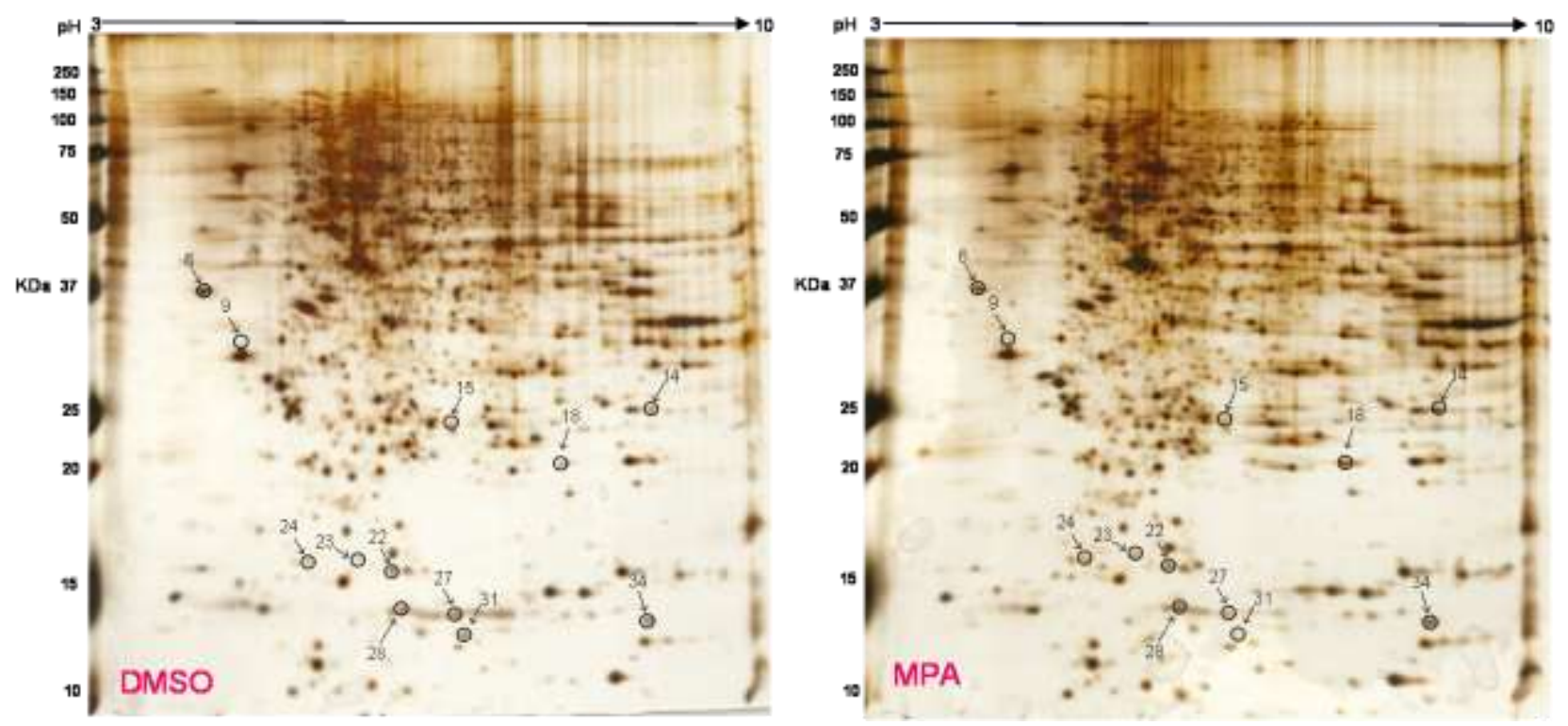

Figure 2.2: Differential protein expression after incubation of HEK-293 cells with MPA.

Total protein lysate from DMSO and MPA treated cells was separated by 2-D gel electrophoresis and silver stained. Encircled differentially regulated proteins spots were identified using Q-TOF MS/MS analysis. The figure shows exemplary 2-DE gels of DMSO and MPA treated HEK-293 cells. 


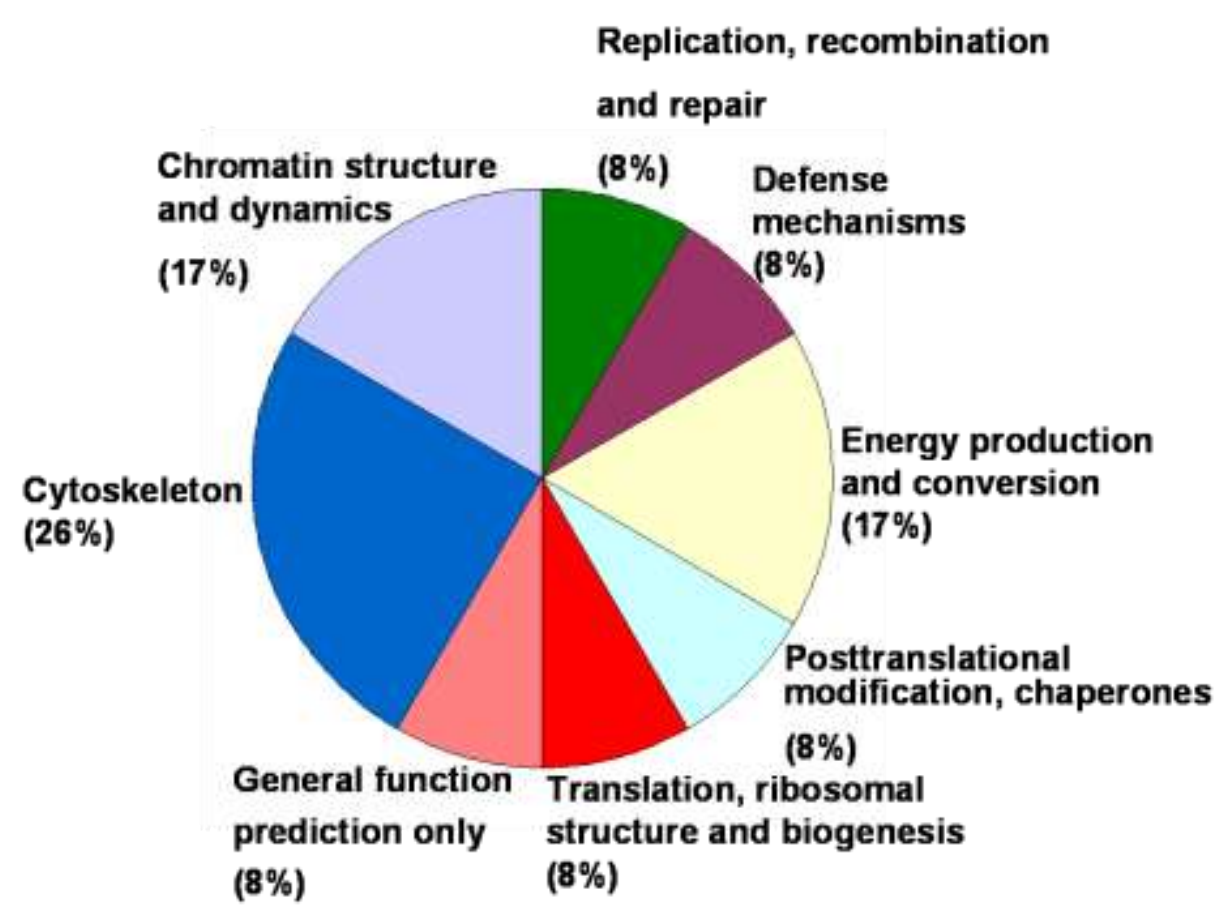

Figure 2.3: Functional classification of regulated proteins.

Biological functions were assigned using online KOGnitor NCBI. (http://www.ncbi.nlm.nih.gov/COG/grace/kognitor.html) software.

Functional classification of differentially regulated proteins was done using KOGnitor, an online biological function annotation tool [258]. The proteins altered by MPA treatment belong to various categories i.e., cytoskeleton (26\%), chromatin structure/dynamics and energy production/conversion (17\% each) (Figure 2.3). Gels spot diagram of two selected protein spots (MLC2 and Prdx1) in 4 biological replicates are shown in Figure 2.4a

To validate the 2-DE results, the expression of MLC2 and Prdx1 were confirmed by Western blotting and real time PCR analysis. Expression of Prdx1 and MLC2 were up-regulated at both transcriptional (Figure 2.4b) and protein level (Figure 2.4c). Specifically, MPA increased MLC2 protein (Mean fold: $+1.78, p<0.005, n=4$, Western blotting) and mRNA expression (Mean fold: $+2.25, p<0.05, n=4$, real time PCR). Prdx1 expression was also up-regulated, both at protein level (Mean fold: +2.73, $\mathrm{p}<0.005, \mathrm{n}=4$ ) and mRNA level (Mean fold: +1.93, $\mathrm{p}<0.05, \mathrm{n}=4$ ). To check whether over-expression of MLC2 following MPA treatment is only HEK-293 cells specific, we determined MLC2 expression in total protein lysate prepared from kidney of MMF (pro-drug of MPA) treated rats (Figure 2.5a) and MPA treated HT-29 
cells (Figure 2.5b). MLC2 expression was increased both in kidney total protein lysate and HT-29 cells by (Mean fold: $+2.57, \mathrm{p}<0.005, \mathrm{n}=4$ ) and (Mean fold: +1.95 , $\mathrm{p}<0.005, \mathrm{n}=4$ ) respectively.

a

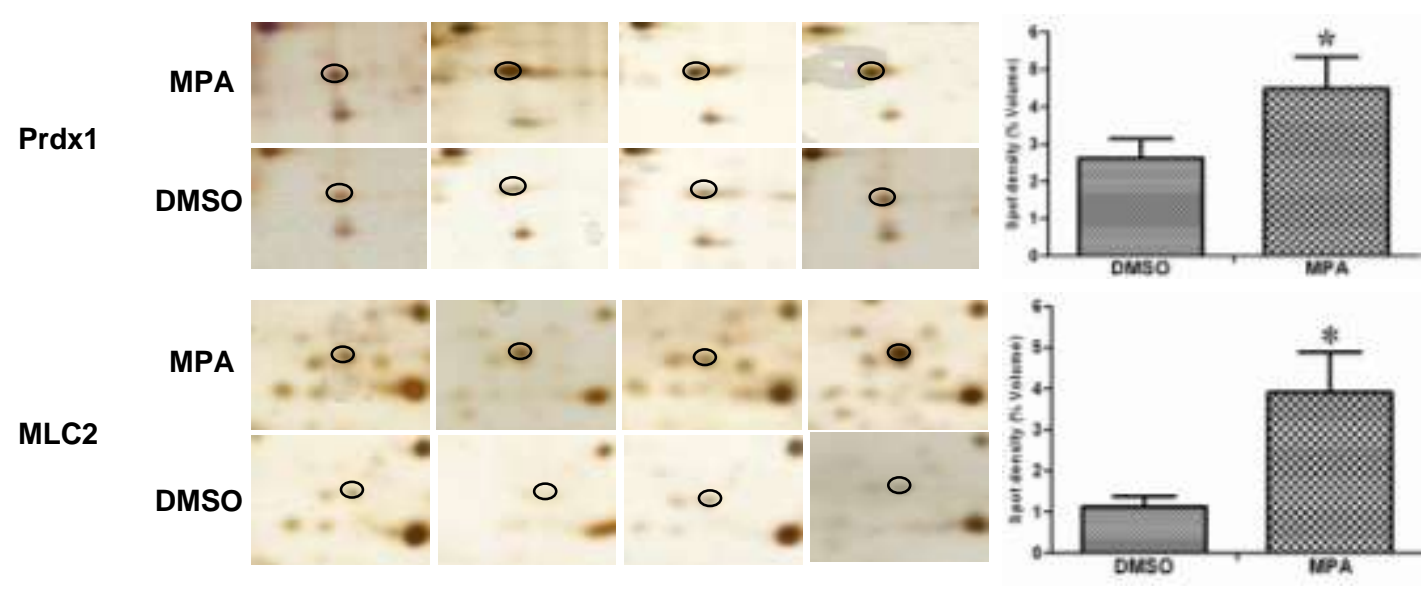

b

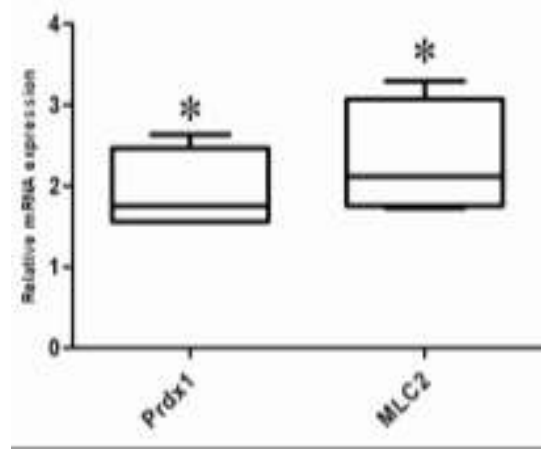

C

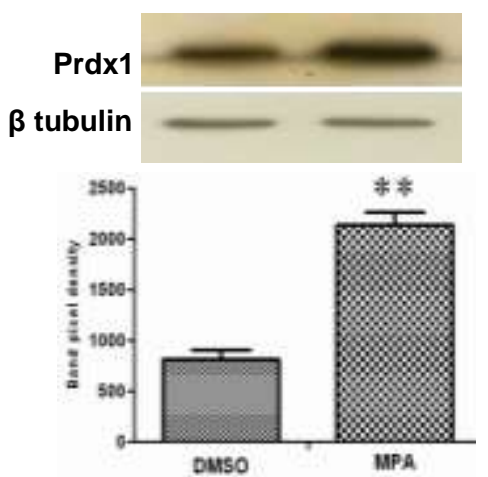

Figure 2.4: Differential expression of Prdx1 and MLC2 by MPA treatment.

(a) Selected areas in the silver stained gels showing differential expression of Prdx1 and MLC2. Delta 2D software was used for densitrometric analysis. The quantification of the level of expression (\% volume) in MPA treated cells and control cells (DMSO) is illustrated as a bar chart with the mean and $S D$ of four separate experiments $\left({ }^{*} p<0.05\right)$. (b) Expression patterns of Prdx1 and MLC2 genes determined by real-time PCR. The relative expression of Prdx1 and MLC2 mRNA in the treated samples was determined as a fold change compared with control samples using the comparative threshold cycle $\left(C_{T}\right)$ method $\left(2^{-\Delta \Delta C}\right)$ as described in materials and methods part. Results shown are representative of four independent experiments. EF-2 was used to normalize the values. The boxes represent range in variation statistics and the lines across the boxes represent the medians and the whiskers extend to the highest and lowest values. Significance was calculated using the MannWhitney-U test ( ${ }^{*} \mathrm{p}<0.05$ ) (c) Effect of MPA treatment on Prdx1 and MLC2 protein expression. Protein extracts from MPA and DMSO treated cells were Western blotted using specific antibodies against $\operatorname{Prdx} 1$ and MLC2. Densitometric analysis was done using Lab image version 2.71 software. $\beta$ tubulin signal was used to control the equal protein load. The experiments were repeated four times and error bars represent $\pm \mathrm{SD}\left({ }^{* *} \mathrm{p}<0.005\right)$. 
a

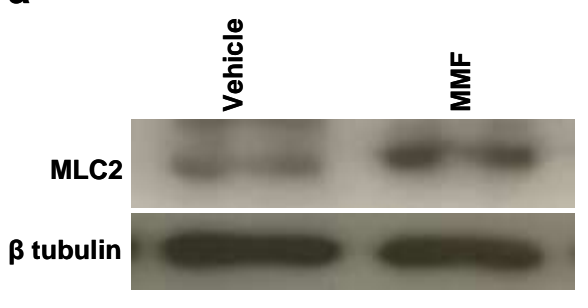

b

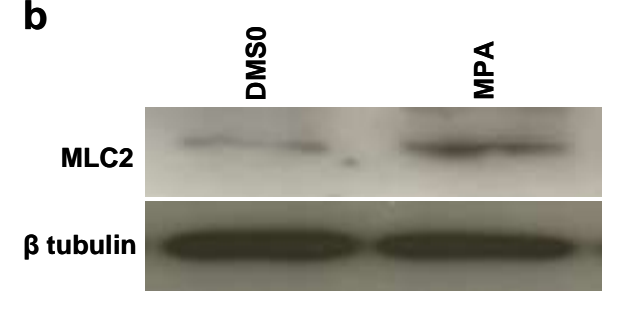

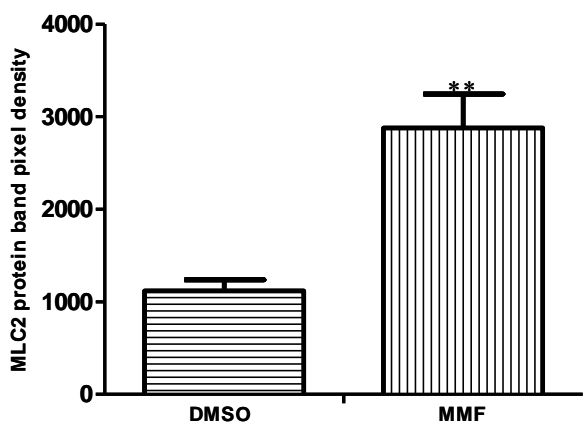

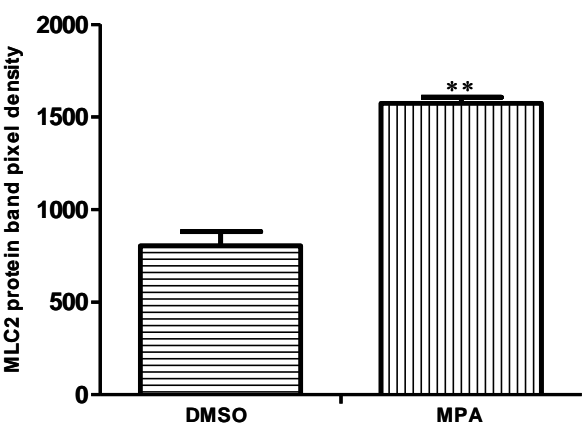

Figure 2.5: Expression of MLC2 in MMF treated rat kidney lysate and HT-29 cells.

Protein lysate was prepared and immunoblotted for MLC2 as described in method section. $\beta$ tubulin was used to show equal protein load. Lab image software was used for quantification of protein bands. Four independent experiments were performed and results presented as mean $\pm S D\left({ }^{* *} p<0.005\right)$.

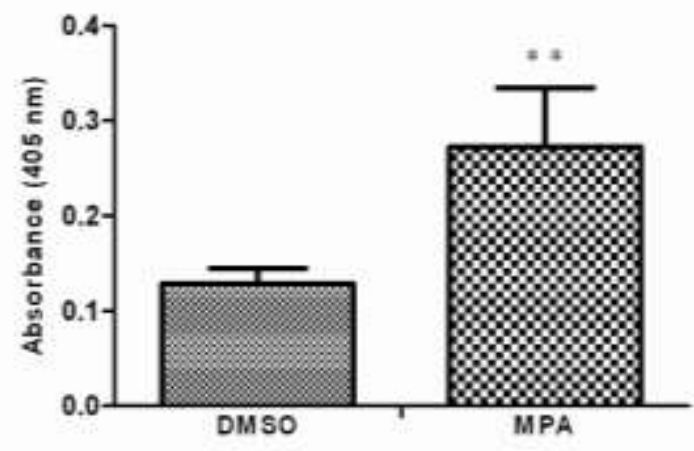

Figure 2.6: Measurement of MPA induced caspase-3 activity.

Cells were treated with MPA and DMSO for $72 \mathrm{hr}$. Protein extracts from each was measured for caspase-3 activity. Five independent experiments were performed and results presented as mean absorbance \pm SD $\left({ }^{* *} p<0.005\right)$. 
To demonstrate the effect of MPA on cell apoptosis, caspase-3 activity (apoptosis marker) was determined using a commercially available colorimetric assay. There was a significant difference in caspase-3 activity between MPA and DMSO treatment groups. MPA increased mean absorbance by 2 fold $(p<0.005$, $n=5$ ) as compared to DMSO treated cells. The results from caspase- 3 assay revealed that MPA treated cells exhibit more apoptosis than cells treated with DMSO alone (Figure 2.6).

\subsection{Discussion}

We have used a 2-DE and mass spectrometric based proteomics approach to develop a better understanding of the influence of MPA therapeutic dose on the proteome in HEK-293 cells. HEK-293 cells are widely used cell culture model to study the mechanisms of drug action, investigating drug targets and molecular aspects of xenobiotic toxicity [262-264]. The regulated proteins are found to be involved in diverse functions including apoptosis and cell signaling mechanism. Apoptosis assay showed that MPA has a pro-apoptotic role in HEK-293 cell line, a property which makes it a drug with potential anti-tumor activities. MLC2 is an important myosin regulatory subunit, which regulates smooth muscle and nonmuscle cells contractile activity [265]. MLC2 displayed an increased expression by MPA treatment. It is already reported that MPA influences the cellular cytoskeletal architecture via modulating mesangial actin reorganization by activating actin polymerization and inhibiting actin-depolymerization [266,267]. Phosphorylation of MLC2 causes significant changes in the physiological dynamics of actin cytoskeleton, leading to barrier defects in intestine [184], heart [268] and lungs [269]. However, it remains unclear if such cytoskeleton reorganization in different organs may lead to a completely different outcome, for example in intestine, diarrhoea is associated with MPA therapy in some patients [251]. In the present study, we observed that MLC2 over-expression is not limited to a specific cell type (i.e. HEK-293) but was reproducible in MMF treated rat kidney and in MPA treated HT-29 cells protein lysates. 
We observed an increase Prdx1 expression by MPA treatment, both at gene and protein level. Prdx1 is a cytoplasmic stress-inducible anti-oxidant enzyme and a major member of peroxiredoxin family [270]. Cells deficient in $\operatorname{Prdx} 1$ have increased sensitivity to oxidative DNA damage [271]. Prdx1 along with its anti-oxidant activity also possesses anti-inflammatory and anti-atherogenic effects [272]. Oxidative stress contributes to the pathophysiology of diverse clinical conditions, including ischemiareperfusion mediated post transplantation graft injuries [273]. Prdx1 expression was also reported to be up-regulated in human gingival fibroblasts by cyclosporine $A$ (another commonly used immunosuppressive drug) treatment [274]. MPA has previously been reported to diminish oxidative injuries and induce anti-oxidant effects by preventing the production of reactive oxygen species [249]. Furthermore, MPA exerts lesser oxidative stress in renal transplant patients, as compared to everolimus, cyclosporine and other calcineurin inhibitors $[275,276]$.

Prdx1 contribute to the inhibition of tumorigenesis through PTEN/Akt pathway [277] and its lower expression in the tumor indicated high tumor proliferation, increased metastasis and could be used as cancer biomarker [278]. Prdx1 is also involved in ageing process as Prdx1-deficient mice have a shortened lifespan and other malignancies [271]. Anti-tumor drugs like histone deacetylase inhibitors (HDACls) activate Prdx1, a tumor suppressor, which leads to apoptosis [279]. Previously it was observed that MPA also inhibit histone deacetylases (HDACs) [21]. A further investigation is needed to gain a deeper insight into the $\operatorname{Prd} 11$ regulation by MPA through HDACs inhibition interaction with Prdx1 and its role in anti-tumor activities.

Profilin 1, another cytoskeletal protein was up-regulated by MPA treatment. Profilins are widely distributed actin binding proteins [280], involved in actin filament dynamics and several signaling pathways [281]. Profilin 1 over-expression has been reported to cause cell proliferation inhibition, apoptosis induction and tumor suppression [282]. Whether MPA via profilin over-expression exerts extended antiproliferative or anti-tumor activities requires further investigation. Stathmin was down regulated by MPA. Stathmin is a $19 \mathrm{kDa}$ cytoplasmic protein, which plays an important role in the regulation of the microtubule cytoskeleton. Stathmin regulates microtubule turnover by promoting microtubules depolymerization and hydrolyze 
guanosine triphosphate (GTP) from terminal tubulin, preventing polymerization of tubulin heterodimers [283]. Previously, our group demonstrated that AcMPAG alters tubulin polymerization in a concentration-dependent manner [284]. Furthermore, stathmin repression stabilizes microtubules, inhibits angiogenesis [285] and suppress tumors [286].

Thioredoxin domain-containing protein 12, also known as endoplasmic reticulum resident protein 18 (ERp18) is ubiquitous in mammalian cells and acts as a disulfide isomerase in the endoplasmic reticulum (ER). It provides defense against oxidative stress, refolds disulfide-containing proteins, and regulates transcription factors [287]. ERp18 expressional up-regulation might cause cell adoptivity in response to MPA induced ER stress. SET protein was down-expressed by MPA. SET, a major cellular serine threonine phosphatase is a potent inhibitor of protein phosphatase 2A (PP2A) activity [288] and a negative regulator of histone acetylation [289], thus involved in cell growth and signaling cascades [290]. PP2A expression induced by downregulation of SET leads to the apoptosis and growth suppression [291],

MPA triggers nuclear stress and causes disruption of the nucleus, leading to the activation of p53, which may initiate cell cycle arrest and apoptosis [292]. In the present study histone H2B was down-regulated by MPA treatment, which is a major component of eukaryotic nucleosome core. Post translational modification such as methylation, acetylation, phosphorylation and ubiquitination of histone proteins alter transcription, DNA replication, and DNA repair [293,294]. Previous data showed that MPA mediated down-regulation of HDAC2 which might relate with potential epigenetic regulations [21]. The microrarray analysis of mononuclear cells treated with AcMPAG (a metabolite of MPA) showed down-regulation of histones in a previous study by our group [295].

MPA affects ribosomal machinery by decreasing intracellular guanine nucleotide level, depending on dosage and cell type, resulting in global reduction of RNA synthesis [292]. Other studies suggested that guanine nucleotide depletion by IMPDH leads to a decrease in pre-ribosomal RNA synthesis, nuclear disruption, and p53 activation [296]. Disorganization of nuclear and ribosomal biogenesis is suggested to be an effective therapeutic target in cancers [297]. We observed a 
down-regulation of $40 \mathrm{~S}$ ribosomal protein $\mathrm{S} 12$ by MPA, which might be due to the altered ribosome biogenesis. The proapoptotic stimuli including chemotherapeutic agents induced a dose-dependent increase in the expression of the cytochrome $\mathrm{c}$ proteins [298].

In the present study we also observed up-regulation of cytochrome b-c I complex by MPA which suggests a possible role of MPA in the regulation of energy metabolism. Complement component $1 \mathrm{Q}$ subcomponent-binding protein (C1q), a component of complement system involved in the clearance of apoptotic cells was up-regulated by MPA. C1q binds to surface blebs of apoptotic cells, which follows subsequent phagocytosis [299]. C1q deficiency leads to a significant decline in the clearance of apoptotic cells in both $\mathrm{C} 1 \mathrm{q}$ - and C4-deficient mice, causing glomerulonephritis [300]. MPA causes cellular apoptosis and cells might utilize C1q over-expression to clear the apoptotic cells.

\subsection{Conclusion}

This investigation identifies proteins related to diverse cellular functions which altered their expression by MPA treatment; many of which are reported for the first time in this context. The expression of Prdx1 (involved in apoptosis) and MLC2 (protein important for epithelial barrier integrity) were observed to be regulated at RNA and protein level. Further investigations of the regulated proteins will provide new insights into the cellular pathways influenced by MPA therapy and could help in more rational use of MPA in transplantation medicine. 


\section{Mycophenolic acid mediated disruption of the intestinal epithelial tight junctions}

Muhammad Qasim ${ }^{1,2}$, Hazir Rahman ${ }^{1,2}$, Raees Ahmed ${ }^{3}$, Michael Oellerich $^{1}$, Abdul R. Asif $^{1}$

1. Department of Clinical Chemistry, University Medical Centre Goettingen, 37075, Goettingen, Germany.

2. Department of Microbiology, Kohat University of Science and Technology, 26000, Kohat, Pakistan.

3. Institute for Applied Science and Clinical Trials GmbH - IFS, Georg-August University Goettingen, 37075, Goettingen, Germany.

Submitted 


\subsection{Abstract}

Gastrointestinal toxicity is a common adverse effect of mycophenolic acid (MPA) treatment in solid organ transplantation patients, through poorly understood mechanisms. Phosphorylation of myosin light chain 2 (MLC2) is associated with epithelial tight junction modulation which leads to defective epithelial barrier function, and has been implicated in gastrointestinal diseases. The aim of this study was to investigate whether MPA could induce epithelial barrier permeability via MLC2 regulation. Human colonic cells (Caco-2) monolayers were exposed to therapeutic concentrations of MPA, and MLC2 and myosin light chain kinase (MLCK) expression were analysed using PCR and immunoblotting. Permeability was assessed by measuring transepithelial resistance (TER) and the flux of paracellular permeability marker FITC-dextran across the epithelial monolayers. MPA increased the expression of both MLC2 and MLCK at both the transcriptional and translational levels. In addition, the amount of phosphorylated MLC2 was increased after MPA treatment. Confocal immunofluorescence analysis showed disrupted distribution of tight junction proteins (ZO-1 and occludin) after MPA treatment. This MPA mediated tight junction disruption was not due to apoptosis or cell death. AcMPAG, a reactive metabolite of MPA, also showed similar effects on TER and TJ proteins expression and distribution. Additionally ML-7, a specific inhibitor of MLCK was able to reverse both the MPA mediated decrease in TER and the increase in FITC-dextran influx, suggesting a modulating role of MPA on intestinal epithelial barrier permeability via MLCK activity. These results suggest that MPA induced alterations in MLC phosphorylation may have a role in the patho-physiology of intestinal epithelial barrier disruption and may be responsible for the adverse effects of MPA on the intestine. 


\subsection{Introduction}

The tight junctions (TJs) are intercellular, multifunctional complexes present in the epithelial and endothelial cells which form the paracellular diffusion barrier $[97,100]$. This barrier contributes to the regulation of epithelial permeability and intramembrane diffusion of ions and solutes through the paracellular space [301303]. TJs are comprised of transmembrane (occludin, claudins and junctional adhesion molecules) and peripheral membrane proteins (zonula occludins [ZO-1], membrane-associated guanylate kinase, and the Ras-related protein Rab13). These proteins interact with each other to form a complex protein network [304]. Various intestinal and non-intestinal disorders including inflammatory bowel disease, celiac disease, and diarrhoeal infections are characterized by barrier dysfunction which is thought to play a crucial role in their pathogenesis [303].

Mycophenolic acid (MPA) is the active agent in the two currently commercially available formulations: the MPA ester mycophenolate mofetil (MMF) and the entericcoated salt mycophenolate sodium (EC-MS) [7]. After oral ingestion, MPA is liberated in the gastrointestinal tract, absorbed and metabolized in the liver to form MPA glucuronide (MPAG) and two other metabolites, 7-O-glucoside and acyl glucuronide (AcMPAG). AcMPAG is pharmacologically active and believed to be responsible for some MPA associated Gl tract adverse effects [30]. MPA is an immunosuppressant which is frequently used for the prevention of acute transplant rejection. MPA is also used for the treatment of non-transplant, autoimmune, renal, rheumatological, gastrointestinal, ophthalmological, dermatological and neurological diseases [250].

Several immunosuppressive drugs including MPA used in solid organ transplantation lead to diarrhoea [305]. Various possible aetiologies of this diarrhoea have been described including infectious agents, drug reactions, metabolic alterations, and surgical complications. MPA has been claimed to account for $50 \%$ of all drug induced post-transplantation diarrhoea [306], while $20 \%$ of total MPA complications involve the GI tract $[307,308]$. GI symptoms similar to those seen with Crohn's disease and enterocolitis are also observed in patients receiving MPA therapy [65,309-312]. The underlying mechanisms of MPA induced Gl toxicity remain unclear; however, several hypotheses exist including direct toxicity as a 
result of its anti-proliferative effects, myelosuppression induced opportunistic infections, variations in local immune response, and AcMPAG adduct toxicity $[36,251,305]$.

Several Gl associated abnormalities, including inflammatory bowel disease (Crohn's disease and ulcerative colitis), and Graft verses host disease are characterized by epithelial barrier defects which contribute to increased intestinal permeability [313]. The effects of MPA or its metabolites on cell junction biophysical properties including paracellular permeability, and the regulation of $\mathrm{TJ}$ proteins, especially in relation to intestinal barrier defects, have not been well studied. Studies were conducted to explore the molecular effects of MPA and its active AcMPAG metabolite on gut integrity via possible effects on TJs. We used Caco-2 cell monolayers as in vitro model of intestinal epithelia [314] and incubated them with therapeutic concentrations $(3.1 \mathrm{mg} / \mathrm{L}$, or $10 \mu \mathrm{mol} / \mathrm{L})$ of MPA and $(10 \mu \mathrm{mol} / \mathrm{L})$ AcMPAG. Trans-epithelial resistance (TER) measurements, paracellular influx assays, immunoblotting and immunofluorescence analyses were then conducted to evaluate integrity of the TJs complex. We hypothesized that MPA may modulate the TJs by altering expression and distribution of crucial TJs proteins.

\subsection{Materials and methods}

\subsubsection{Reagents}

Reagents (and their sources) included: agarose (Gibco BRL, Paisley, UK), Magnesium chloride $\left(\mathrm{MgCl}_{2}\right)$, M-MLV RT enzyme and $5 \mathrm{X}$ buffer (Invitrogen, Karlsruhe, Germany), deoxynucleotide triphosphate (dNTP) (Roche, Mannheim, Germany), Ribonuclease (RNAase) inhibitor (Promega, Mannheim, Germany), MPA, fluorescein isocynate-dextran $4 \mathrm{KDa}$ (FD4), 1-5-lodonaphthalene-1-sulfonyl)-1Hhexahydro-1,4-diazepine hydrochloride (ML-7) and cytochalasin (CD) (Sigma-Aldrich, Mannheim, Germany) and PCR primers (Eurofins, Ebersberg, Germany). AcMPAG was a kind gift from Roche (Roche, Mannheim, Germany). 


\subsubsection{Cell culture}

The human colon adenocarcinoma cell line (Caco-2) was purchased from DSMZ (German collection of microorganisms and cell cultures, Braunschweig, Germany). Tissue culture media ingredients were obtained from PAA Laboratories (Pasching, Austria). Cells were grown in Dulbecco's modified Eagle's medium (DMEM) (4.5 g/L glucose) supplemented with $10 \%$ heat-inactivated fetal calf serum, $2 \mathrm{mmol} / \mathrm{L}$ glutamine, $50 \mathrm{IU} / \mathrm{mL}$ penicillin, $50 \mathrm{mg} / \mathrm{mL}$ streptomycin and non-essential amino acid supplement ( $1 \% \mathrm{v} / \mathrm{v})$ under conditions of $37^{\circ} \mathrm{C}, 5 \% \mathrm{CO}_{2}$ and $90 \%$ relative humidity. The Caco-2 cells were allowed to grow for 21 days of post-confluence to form differentiated and polarised monolayer growth [315]. The culture medium was changed every second day.

\subsubsection{Lactate dehydrogenase (LDH) measurement}

LDH measurements were performed using a commercially available LDH measurement kit (Roche, Mannheim, Germany) according to the manufacturer's instructions. This assay is based on the principle that LDH catalyzes the conversion of NADH (substrate) to NAD and the rate of this conversion is directly proportional to LDH activity. Briefly, cells were incubated in DMSO, $10 \mu \mathrm{mol} / \mathrm{L} \mathrm{MPA}$ or $10 \mu \mathrm{mol} / \mathrm{L}$ AcMPAG for $72 \mathrm{hr}$. Following incubation, supernatant medium was collected, centrifuged for $5 \mathrm{~min}$ at $15,700 \times \mathrm{g}$ at $4^{\circ} \mathrm{C}$ and LDH was measured photometrically using a Hitachi analyzer (Roche, Mannheim, Germany). The experiments were repeated at least four times and values were represented as mean IU/L $\pm S E M$.

\subsubsection{Determination of caspase 3 activity}

Cell were treated with DMSO, $10 \mu \mathrm{mol} / \mathrm{L}$ MPA or $10 \mu \mathrm{mol} / \mathrm{L}$ AcMPAG for $72 \mathrm{hr}$ and the caspase specific activity was measured using CaspACE ${ }^{\mathrm{TM}}$ Assay kits (Promega, WI, USA) as previously described [316]. Briefly, cell proteins $(70 \mu \mathrm{g})$ were mixed with reaction mixtures containing the colorimetric substrate Ac-DEVD-pnitroanaline (Ac-DEVD-pNA). The pNA released from Ac-DEVD-pNA due to caspase 
activity was measured at a wavelength of $405 \mathrm{~nm}$ using a EL808 microplate reader (Bio-Tek instruments, VT, USA). Caspase 3 specific activity (CSA) in the cell extract was measured using the standard formula (CSA = pmol pNA liberated per hour/ $\mu \mathrm{g}$ protein). Five independent experiments were performed and results were expressed as mean pmol pNA liberated per hour/ $\mu \mathrm{g}$ protein.

\subsubsection{Determination of trans-epithelial resistance (TER)}

TER was measured as previously described [317]. Briefly, cells were seeded on polyester transwell inserts $\left(6.5 \mathrm{~mm}\right.$ diameter, $0.4 \mu \mathrm{m}$ pore size, $0.33 \mathrm{~cm}^{2}$ growth area, Corning Costar Corporation, NY, USA) at $2.0 \times 105$ cells/well and grown for 21 days post-confluence. Cells were treated with DMSO, $10 \mu \mathrm{mol} / \mathrm{L}$ MPA, $10 \mu \mathrm{mol} / \mathrm{L}$ AcMPAG or CD $(10 \mu \mathrm{mol} / \mathrm{L})$ for $72 \mathrm{hr}$ or pre-treated with $\mathrm{ML}-7(10 \mu \mathrm{mol} / \mathrm{L})$ for $1 \mathrm{hr}$ followed by $72 \mathrm{hr}$ treatment of MPA (10 $\mu \mathrm{mol} / \mathrm{L})$ after cells developed into a differentiated and polarised monolayer. TER was measured using an EVOM voltohmmeter with a STX2 electrode (WPI, FL, USA). For epithelial resistance measurements, both the apical and basolateral sides of the epithelia were bathed in cell culture medium. Resistance $(T E R)=[R C-R E] \times A$; where $R C$ is resistance of the cells $(\Omega)$; RE is resistance of the blank $(\Omega)$; and A is surface area of the membrane insert $\left(\mathrm{cm}^{2}\right)$. TER was calculated as $\Omega . \mathrm{cm}^{2}$ for at least four consecutive measurements.

\subsubsection{FITC-dextran paracellular permeability}

Epithelial permeability was assessed using a previously reported method [318,319]. Briefly, Caco-2 cells were grown into monolayers and treated as described above. Following treatment, cells were rinsed with PBS and incubated in Hank's balanced salt solution containing 1mg/mL FITC-dextran 4 kD (FD4) solution for $2 \mathrm{hr}$. Permeability marker flux was assessed by taking $100 \mu \mathrm{L}$ from the basolateral chamber. Fluorescent signal was measured using a Lambda fluoro 320 fluorescence plate reader (MWG Biotech, Ebersberg, Germany) using $492 \mathrm{~nm}$ excitation and 520 $\mathrm{nm}$ emission filters. FD4 concentrations were determined using standard curves 
generated by serial dilution of FD4. Fluxes were calculated using the apparent permeability coefficient $\left(P_{\text {app }}\right)$ equation: $\left.\left.P_{\text {app }}=\Delta C_{A} / \Delta t\right)^{*} V_{A}\right] / A^{*} C_{L}$, where $P_{\text {app }}$ is the apparent permeability $(\mathrm{cm} / \mathrm{s}), \Delta \mathrm{C}_{\mathrm{A}}$ is the change of FD4 concentration, $\mathrm{A}$ is the surface area of the membrane $\left(\mathrm{cm}^{2}\right), \Delta t$ is the change of time, $V_{A}$ is the volume of the abluminal medium, and $C_{L}$ is the initial concentration in the luminal chamber.

\subsubsection{RNA isolation, cDNA synthesis and real-time PCR}

Total cellular RNA was extracted using the acid guanidinium-phenolchloroform method (Trizol reagent; Invitrogen, CA) according to manufacturer's recommendations. Briefly, Caco-2 monolayers were scraped into Trizol reagent, homogenized, and RNA was extracted using chloroform/isopropanol precipitation. The precipitated RNA was dissolved in sterile water and stored at $-80^{\circ} \mathrm{C}$ until analysis. RNA concentration was determined with the GeneQuant II RNA/DNA calculator (Pharmacia Biotech, Freiburg, Germany) and quality was verified by $\mathrm{OD}_{260} / \mathrm{OD}_{280} \mathrm{~nm}$ ratios and subsequent electrophoresis in $1.5 \%$ agarose gels using ethidium bromide staining. cDNA was synthesized from $2 \mu \mathrm{g}$ total RNA in a $30 \mu \mathrm{L}$ reaction mix containing 1x RT-PCR buffer (10 mmol/L Tris-HCL [pH 8.3], $15 \mathrm{mmol} / \mathrm{L}$ $\mathrm{KCl}, 0.6 \mathrm{mmol} / \mathrm{L} \mathrm{MgCl} 2), 0.5 \mu \mathrm{mol} / \mathrm{L}$ of each dNTP, $1 \mathrm{U} / \mu \mathrm{L}$ RNase inhibitor and 13.3 $\mathrm{U} / \mu \mathrm{L}$ M-MLV RT enzyme. The RT reactions were performed in a thermocycler (Biometra, Goettingen, Germany) at $75^{\circ} \mathrm{C}$ for $5 \mathrm{~min}$, and then $42^{\circ} \mathrm{C}$ for $1 \mathrm{hr}$. cDNA was stored at $-80^{\circ} \mathrm{C}$ until use.

Primers for real time PCR were selected using the online Primer 3 software [320]. The primers used in this study were as follows: MLC2 (forward 5'CAGGAGTTCAAAGAGGCCTTCAAC-3', reverse 5 'CTGTACAGCTCATCCACTTCCTCA-3'); MLCK (forward 5'CAACAGGGTCACCAACCAGC-3', reverse 5'-GCCTTGCAGGTGTACTTGGC-3'); ROCK (forward 5'-GTGAAGGTGATTGGTAGAGGTGC-3', reverse 5'CCACCAGGCATGTATTCCATCAC-3') and elongation factor 2 (forward 5'-

GACATCACCAAGGGTGTGCAG-3', reverse 5'-GCGGTCAGCACACTGGCATA-3). Relative quantitative PCR was carried out using the LightCycler instrument (Roche, Manheim, Germany). The total PCR volume of $20 \mu \mathrm{L}$ contained $1 \mu \mathrm{L}$ of cDNA solution, $2 \mu \mathrm{L}$ of 10X PCR buffer (Invitrogen, Darmstadt, Germany), $2 \mu \mathrm{L}$ syber 
green, $1 \mu \mathrm{L}$ BSA, $1 \mu \mathrm{L}$ DMSO, $0.25 \mu \mathrm{L}$ of each primer (Eurofins MWG-Biotech AG, Ebersberg, Germany), $2.0 \mathrm{mmol} / \mathrm{L} \mathrm{MgCl} 2,0.2 \mathrm{mmol} / \mathrm{L}$ of each $\mathrm{dNTP}$, and $0.15 \mathrm{U} / \mu \mathrm{L}$ PAN Script DNA polymerase (PAN Biotech, Aidenbach, Germany). Amplification conditions were set to: MLC2 (initial denaturation $30 \mathrm{sec}$ at $95^{\circ} \mathrm{C}$, repeated cycles of denaturation at $95^{\circ} \mathrm{C}$, for $1 \mathrm{sec}$, primer annealing at $55^{\circ} \mathrm{C}$ for $5 \mathrm{sec}$, elongation at $72^{\circ} \mathrm{C}$ for $10 \mathrm{sec}$, and fluorescence reading at $82^{\circ} \mathrm{C}$ ), MLCK (initial denaturation for 30 sec at $95^{\circ} \mathrm{C}$ and repeated cycles of denaturation at $95^{\circ} \mathrm{C}$ for $1 \mathrm{sec}$, primer annealing at $60^{\circ} \mathrm{C}$ for $5 \mathrm{sec}$, elongation at $72^{\circ} \mathrm{C}$ for $10 \mathrm{sec}$, and fluorescence reading at $82^{\circ} \mathrm{C}$ ). ROCK (initial denaturation for $30 \mathrm{sec}$ at $95^{\circ} \mathrm{C}$ and repeated cycles of denaturation at $95^{\circ} \mathrm{C}$ for $1 \mathrm{sec}$, primer annealing at $60^{\circ} \mathrm{C}$ for $5 \mathrm{sec}$, elongation at $72^{\circ} \mathrm{C}$ for $10 \mathrm{sec}$, and fluorescence reading at $80^{\circ} \mathrm{C}$ ), elongation factor 2 (EF-2) (initial denaturation for 30 sec at $95^{\circ} \mathrm{C}$, repeated cycles of denaturation at $95^{\circ} \mathrm{C}$, for $1 \mathrm{sec}$, primer annealing $\left(55^{\circ} \mathrm{C}, 5 \mathrm{sec}\right)$, elongation $\left(72^{\circ} \mathrm{C}, 10 \mathrm{sec}\right)$, and fluorescence reading at $\left.88^{\circ} \mathrm{C}\right)$. For each sample, real-time PCR reactions were performed in quadruplicate. RNA relative expression was calculated as fold change using the comparative threshold cycle $\left(\mathrm{C}_{T}\right)$ method $\left(2^{-\Delta \Delta} C_{T}\right)$ [260] with EF-2 used as the internal control gene. The relative expression of mRNA in the treated samples was determined as a fold increase compared with control samples. The PCR product was run on $1.5 \%$ agarose gel electrophoresis to confirm the specificity of the amplified product.

\subsubsection{Immunoblotting}

Protein lysates were separated by SDS-PAGE and blotted onto PVDF (Immobilon, Millipore, MA, USA) using the Trans-Blot SD cell system (Bio-rad, Munich, Germany) for $30 \mathrm{~min}$ at $15 \mathrm{~V}$ in a blotting buffer (192 mmol/L glycine, 20\% methanol, and $25 \mathrm{mmol} / \mathrm{L}$ tris [pH 8.3]). The membranes were blocked with $5 \%(\mathrm{w} / \mathrm{v})$ milk in TBS-T buffer $(50 \mathrm{mmol} / \mathrm{L}$ TrisHCl [pH 7.5], $200 \mathrm{mmol} / \mathrm{L} \mathrm{NaCl}, 0.05 \%$ Tween 20) for $1 \mathrm{hr}$ at room temperature followed by washing twice in TBS-T for $5 \mathrm{~min}$. The membranes were incubated with a 1: 500 dilution of a mouse monoclonal anti-MLC antibody (Sigma, Mannheim , Germany), 1: 10000 dilution of mouse monoclonal antiMLCK antibody (Sigma, Mannheim , Germany), 1: 1000 rabbit anti-phospho MLC antibody (Cell Signaling, Beverly, USA), $1 \mu \mathrm{g} / \mathrm{mL}$ rabbit anti-ZO-1, $0.5 \mu \mathrm{g} / \mathrm{mL}$ mouse anti-occludin (Zymed, CA, USA), or 1: 5000 anti- $\beta$ actin (Sigma, Mannheim, 
Germany) in 5\% BSA in TBS-T overnight at $4^{\circ} \mathrm{C}$. Following washing in TBS-T, membranes were then incubated with appropriate HRP-conjugated secondary antibodies (Bio-rad, Munich, Germany). The membranes were washed with PBS and prepared for enhanced chemiluminescence (GE, Buckinghamshire, UK) according to the manufacturer's instructions. Developed membranes were then exposed to hyperfilm-ECL (GE, Buckinghamshire, UK). The films were scanned and protein band densities were quantified with the Lab Image software, version 2.71 (Kapelan, Leipzig, Germany).

\subsubsection{Immunofluorescence microscopy of TJs proteins}

Cell monolayers were grown on Lab-Tek ${ }^{\mathrm{TM}}$ eight chamber slides (Nunc, Naperville, IL, USA) and treated as indicated above. Cells were immunolabelled as previously described [321] with some modifications. Briefly, cells were rinsed with PBS and fixed in $3.7 \%$ formaldehyde at room temperature for $20 \mathrm{~min}$. Cell monolayers were then rinsed in PBS and permeabilized in $0.2 \%$ Triton X-100 for 7 min at room temperature. Cells were rinsed in PBS followed by blocking with $1 \%$ bovine serum albumin (BSA) for $30 \mathrm{~min}$ at room temperature. Cells were incubated with $3 \mu \mathrm{g} / \mathrm{mL}$ anti-rabbit ZO-1 and $2 \mu \mathrm{g} / \mathrm{mL}$ anti-mouse occludin (Zymed, San Francisco, USA) overnight at $4^{\circ} \mathrm{C}$. After washing with PBS, cells were incubated with anti-rabbit IgG conjugated to Alexa 488 and anti-mouse IgG conjugated to cydye 3 (Molecular Probes, Eugene, OR, USA) in 1\% BSA for $1 \mathrm{hr}$ at room temperature. For $F$ actin localization cells were incubated in $0.33 \mu \mathrm{g} / \mathrm{mL}$ of FITC-conjugated phalloidin (Sigma-Aldrich, St. Louis, USA) in PBS for $30 \mathrm{~min}$ as described previously [322]. Cells were also incubated with Hoechst dye $(10 \mu \mathrm{g} / \mathrm{mL}$ in PBS) (Molecular Probes, Eugene, USA) for 10 minutes to stain nuclei. After washing with PBS, cells were mounted using the Dako fluorescence mounting medium (Dako, Carpintera, USA) and stored at $4^{\circ} \mathrm{C}$ in the dark until analyzed. The fluorescence was visualized using Axiovert 200M confocal microscope (Carl Zeiss, Jena, Germany). All of the fluorescent labelling experiments were repeated four times to ensure reproducibility. 


\subsubsection{Statistics}

The data are presented as sample means with error bars indicating the standard error of the mean. The $p$ value was calculated using a Student's $t$ test and a $p$ value $<0.05$ was considered statistically significant

\subsection{Results}

\subsubsection{MPA altered TER and TJs permeability in a concentration and time dependant manner}

In the present study, the effect of MPA on Caco-2 TJ integrity was determined by measuring TER and epithelial permeability to the paracellular marker FD4. To assess the influence of MPA treatment on TER, cells were incubated with different concentrations of MPA $(5-100 \mu \mathrm{mol} / \mathrm{L})$ for up to $72 \mathrm{hr}$. DMSO did not have any significant effect on TER of polarised Caco-2 cell monolayers. Increasing concentrations of MPA exhibited concentration- and time-dependant decreases in Caco-2 TER (Figure 3.1a). The mean cell monolayer TER decreased from 190.4 to 181.5, 190.8 to 147.5 and 193.1 to $120.4 \Omega . \mathrm{cm}^{2}$ after 5,10 and $50 \mu \mathrm{mol} / \mathrm{L}$ MPA treatment respectively. The maximal decrease in Caco-2 TER was observed at 100 $\mu \mathrm{mol} / \mathrm{L}$ MPA concentration $\left(86 \pm 0.7 \Omega . \mathrm{cm}^{2}\right)$. The decrease in Caco-2 TER increased with time between $12 \mathrm{hr}$ and $72 \mathrm{hr}$ (Figure 3.1a).

Similarly, MPA was associated with a concentration-dependent increase in Caco-2 paracellular permeability to FD4 (Figure 3.1b). FD4 permeability analysis following 72 hr MPA treatment showed a concentration-dependant increase in FD4 influx. The FD4 influx from the apical to the basolateral chamber was increased 1.5, 2.7, 4.6 and 7.9 fold after incubation with 5, 10, 50 and $100 \mu \mathrm{mol} / \mathrm{L}$ MPA concentrations respectively (Figure $3.1 \mathrm{~b}$ ). 
a

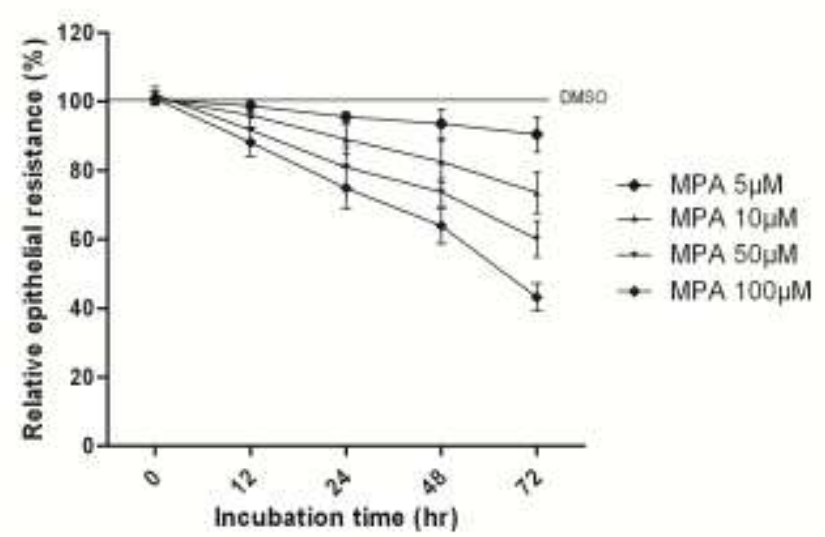

b

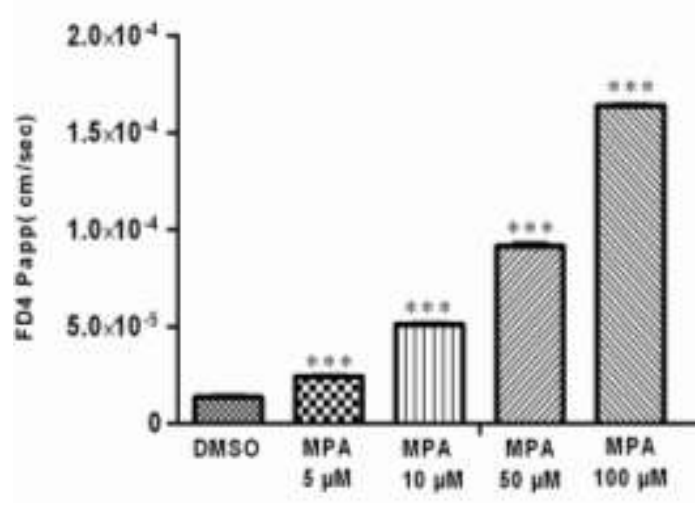

Figure 3.1: MPA treatment decreased TER and increased FD4 permeability of Caco-2 cell monolayers.

Caco-2 cells were cultured on filter inserts and grown for 21 days post-confluence to form differentiated monolayers. (a) Caco-2 cells were treated with MPA $(5-100 \mu \mathrm{M})$ for 0-72 hr. MPA concentration and time dependent decrease in TER were observed. Graph shows TER $\left(\Omega . \mathrm{cm}^{2}\right)$ vs. time (hr) with means \pm SEM from four independent experiments. (b) Paracellular flux of FD4. Values are means of apparent permeability for FD4 $(\mathrm{cm} / \mathrm{sec})$ which is the amount of apical FD4 crossing the insert membrane per $\mathrm{cm}^{2}$ per sec. Bars show SEM and ${ }^{* * *}=\mathrm{p}<0.0005$.

\subsubsection{AcMPAG modulation of TER and TJs permeability}

To determine whether AcMPAG, a reactive metabolite of MPA, influenced the TER and FD4 influx, we incubated Caco-2 cells with AcMPAG (10 $\mu \mathrm{mol} / \mathrm{L})$. A time dependant decrease in TER (0 hr: 101.1\%, 12 hr: 94.2\%, 24 hr: 86.5\%, 48 hr: 74.4\%, $72 \mathrm{hr}: 67.1 \%$ relative to the DMSO control) (Figure 3.2a) was observed after incubation with AcMPAG. FD4 influx analysis from apical to basal chamber showed that AcMPAG exhibited a mean 2.78 fold increase in FD4 permeability (Figure 3.2b). 
a

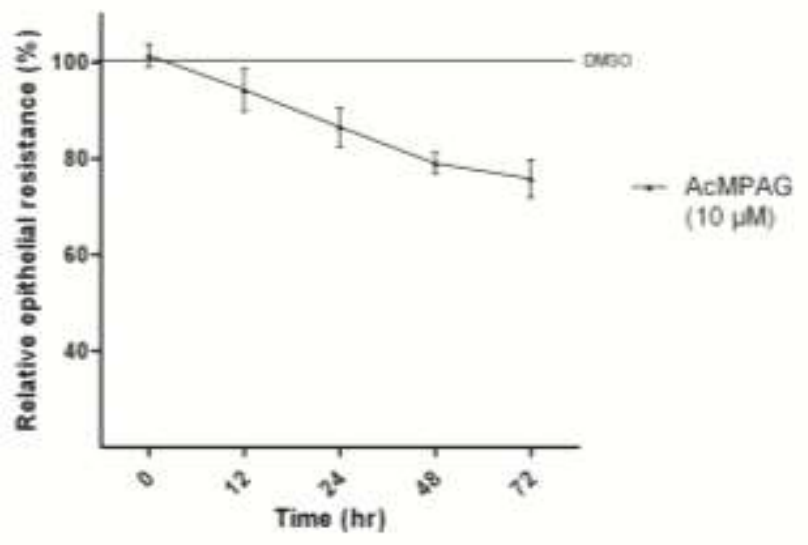

b

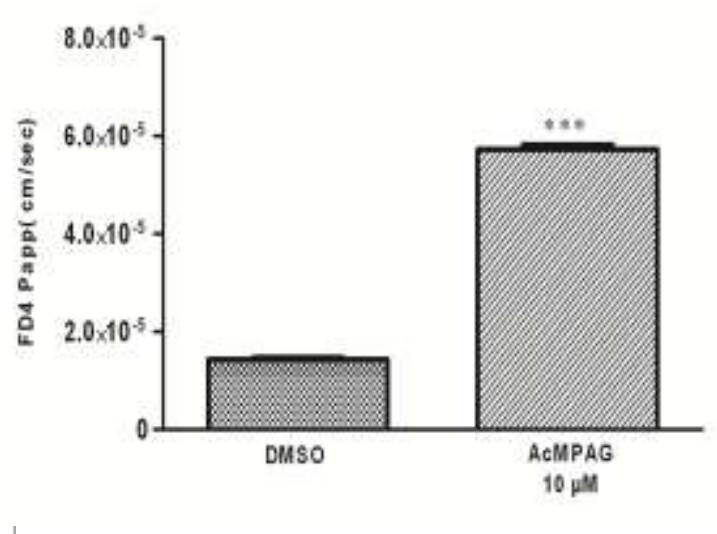

Figure 3.2: AcMPAG treatment caused a time dependant decrease in TER and increase in FD4 permeability in Caco-2 cell monolayers.

Caco-2 cells were grown for 21 days post-confluence and treated with AcMPAG (10 $\mu \mathrm{M})$ for $72 \mathrm{hr}$ following which TER (a) and FD4 influx (b) were determined. Values are means \pm SEM of four independent experiments. ${ }^{* * *}=p<0.0005$.

\subsubsection{MPA and AcMPAG mediated increase in permeability was not due to cell death/apoptosis}

To determine whether MPA or AcMPAG induced decreases in TER and increased FD4 permeability were due to TJs regulation and not due to the cell death, the $\mathrm{LDH}$ release from the treated cells was determined. LDH measurement has previously been used as an indicator of cell death [112]. Exposure to $10 \mu \mathrm{mol} / \mathrm{L}$ MPA and $10 \mu \mathrm{mol} / \mathrm{L}$ AcMPAG for up to $72 \mathrm{hr}$ did not result in any significant increase in LDH release from the Caco-2 cells (Figure 3.3a). Furthermore, caspase 3 activity was measured to check the effect of MPA or AcMPAG on cell apoptosis. Neither 10 $\mu \mathrm{mol} / \mathrm{L}$ MPA nor $10 \mu \mathrm{mol} / \mathrm{L}$ AcMPAG exposure for $72 \mathrm{hr}$ caused any significant apoptosis as compared to DMSO (vehicle) (Figure 3.3b). These findings suggest that the TJs disruption caused by MPA/AcMPAG was not associated with cell death or apoptosis. 
a

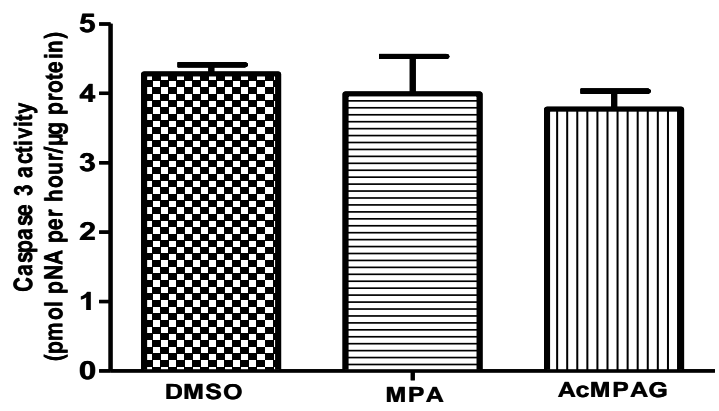

b

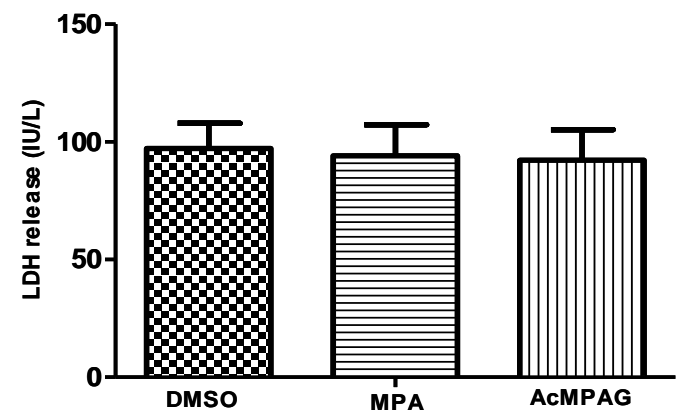

Figure 3.3: Effect of MPA and AcMPAG on apoptosis and cell viability in Caco-2 cells.

Caco-2 were grown for 21 days post-confluence and treated with MPA or AcMPAG for 72 hr. (a) Apoptosis was determined by measuring the caspase- 3 activity in cell lysates using CaspACE ${ }^{\mathrm{TM}}$ Assay

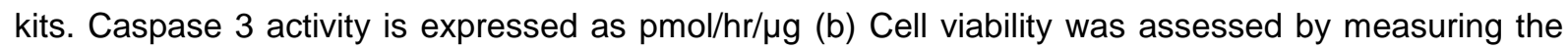
lactate dehydrogenase (LDH) release in the culture media. Data represent IU/L LDH released into the media. Values are presented as the mean \pm SEM; of four independent experiments and the significance was determined by Student's t-test.

\subsubsection{MPA and AcMPAG increased the expression of MLC2 and MLCK in Caco-2 cells}

In a previous study we reported that MPA increased the total MLC2 in HEK293 cells [323]. Additionally we observed up-regulation of MLCK and ROCK expression by MPA in HEK-293 and HT-29 cells (data not shown). In view of these findings, we investigated regulation of MLC2 expression and MLCK in Caco-2 cells. MLCK is involved in the regulation of barrier function through the phosphorylation of MLC2 in response to diverse stimuli $[153,324]$. In line with the previous findings [323], MPA treatment increased the expression of MLC2 at both the mRNA (1.5 fold increase) and protein level (1.47 fold increase) in Caco-2 cells (Figure 3.4a and Figure 3.4b). AcMPAG (10 $\mu \mathrm{mol} / \mathrm{L})$ exposure for $72 \mathrm{hr}$, however, increased MLC2 protein expression (1.68 fold increase) without any significant change in mRNA expression. MLCK expression was also up-regulated by MPA $(10 \mu \mathrm{mol} / \mathrm{L})$ at the mRNA (1.9 fold) and protein level ( 2.1 fold). AcMPAG also increased the expression of MLCK at the mRNA (1.3 fold increase) and protein (1.7 fold increase) level. ROCK expression was significantly regulated by MPA (1.53 fold increase) while AcMPAG had no significant effect (Figure $3.4 \mathrm{a}$ ). 

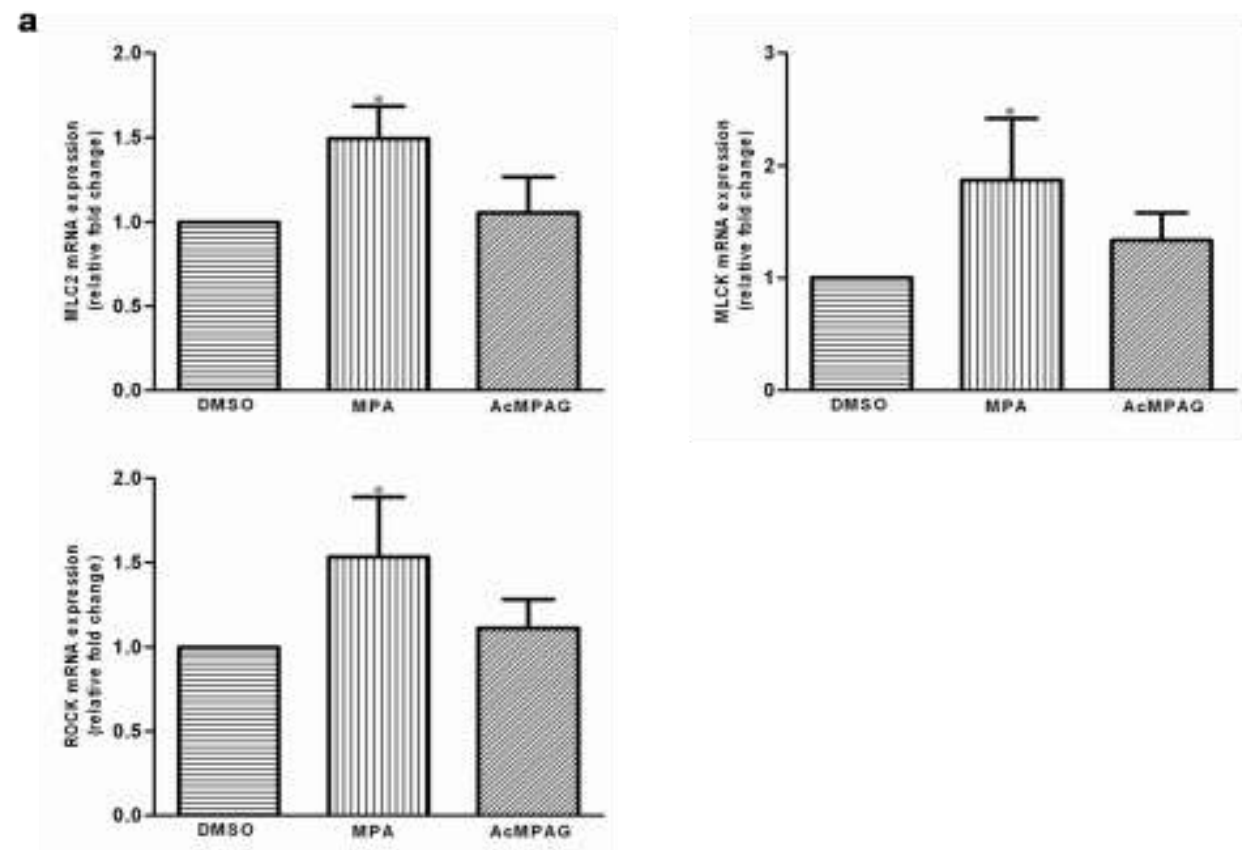

b
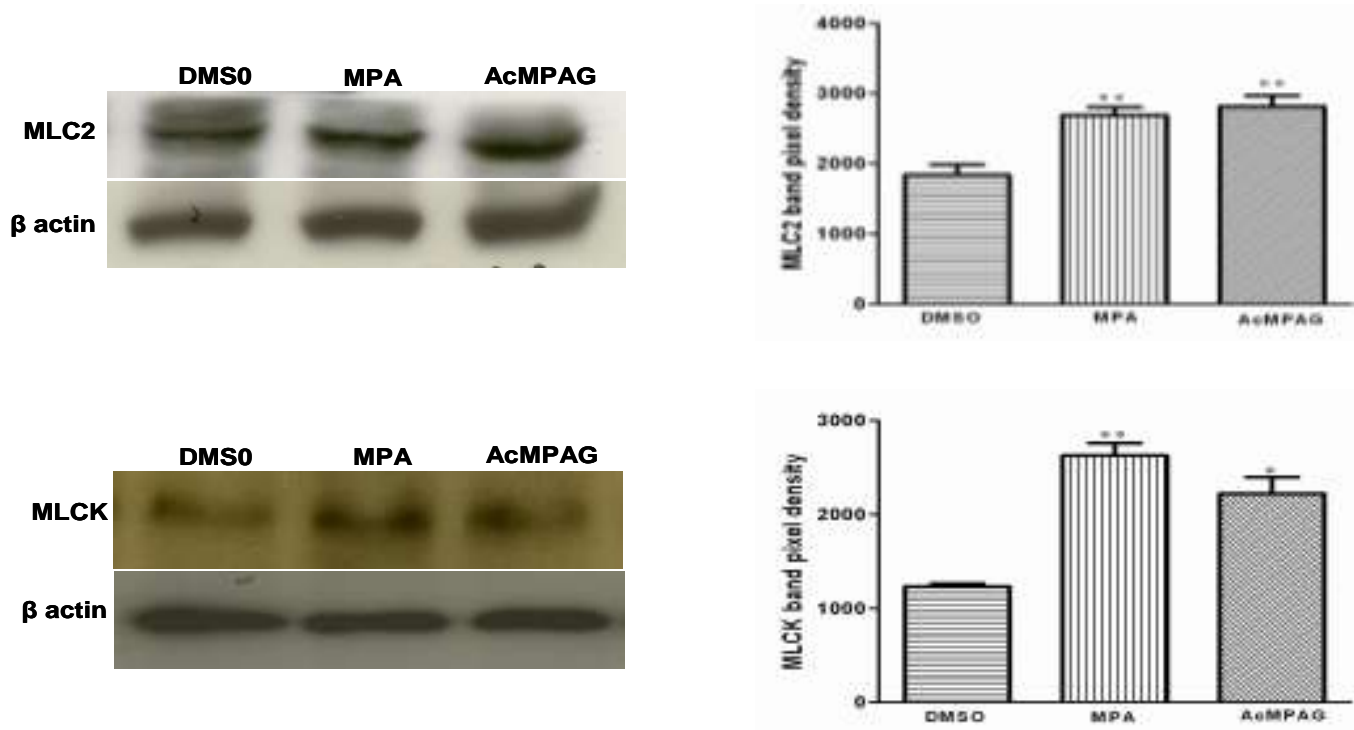

Figure 3.4: Effect of MPA and AcMPAG on MLC2, MLCK and ROCK expression in Caco-2 cells.

Caco-2 monolayers (21 days post-confluence) were incubated with DMSO (vehicle), MPA (10 $\mu \mathrm{mol} / \mathrm{L}$ ) or AcMPAG (10 $\mu \mathrm{mol} / \mathrm{L})$ for $72 \mathrm{hr}$. (a) mRNA expression analysis for MLC2, MLCK and ROCK. Total RNA was extracted, reverse transcribed and subjected to real time PCR analysis. EF-2 was used as a house keeping gene and the relative mRNA expression of MLC2, MLCK, and ROCK in the MPA, AcMPAG and DMSO (vehicle) treated samples was determined using the comparative threshold cycle $\left(\mathrm{C}_{\mathrm{T}}\right)$ method $\left(2^{-\Delta \Delta \mathrm{C}} \mathrm{T}\right)$ as described in material and methods. Data indicate the mean of four independent experiments \pm SEM. (b) Immunoblot analyses for MLC2 and MLCK. Whole cell lysates were resolved on $1 \mathrm{DE}$ and immunoblotted using MLC2 and MLCK specific antibodies. $\beta$ actin was used as a control for an equal amount of protein load. Densitrometric analysis was done using the Lab image software. The data represent mean relative intensities \pm SEM from four independent immunoblots. ${ }^{*} p<0.05$ and ${ }^{* *} p<0.005$ significance relative to DMSO. 


\subsubsection{MPA and AcMPAG increased MLC2 phosphorylation in Caco-2 cells}

MLC phosphorylation has been extensively studied with regard to tight junction regulation and has been reported to be required for increased paracellular permeability $[153,184]$. To determine whether MPA and AcMPAG caused any defect in the epithelial barrier through phosphorylation of MLC2, we checked the phosphorylaton of MLC2 using specific phospho-MLC2 antibody. MPA and AcMPAG treatment $(10 \mu \mathrm{mol} / \mathrm{L}$ each) for $72 \mathrm{hr}$ increased the expression of phospho-MLC2 by 2.8 and 2.3 fold respectively (Figure 3.5).
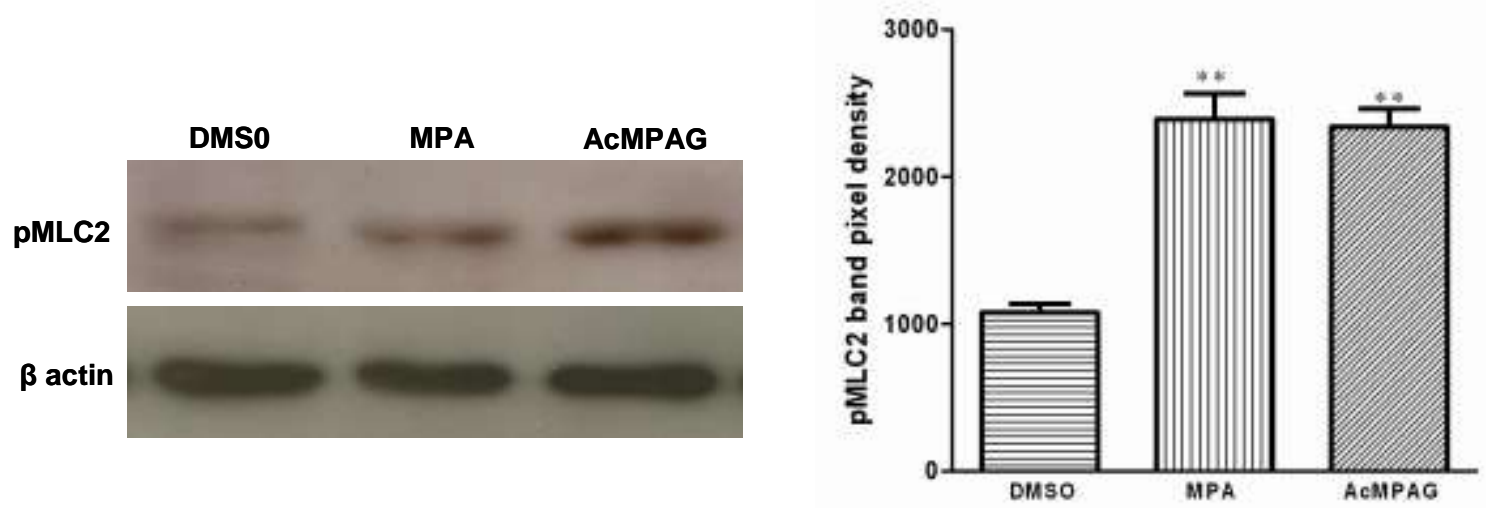

Figure 3.5: Effect of MPA and AcMPAG on the phosphorylation of MLC2 in Caco-2 cells.

Caco-2 monolayers (21 days post-confluent) were incubated with either vehicle (DMSO), MPA or AcMPAG (10 $\mu \mathrm{mol} / \mathrm{L}$ each) for $72 \mathrm{hr}$. Whole cell lysates were resolved on 1DE and immunoblotting was performed using a specific phospho-MLC2 antibody. $\beta$ actin was used as a loading control for equal amount of protein load. Densitrometric analyses were done using the Lab image software. The representative data are average of relative intensities \pm SEM from four independent immunoblot. ${ }^{* *}=p<0.005$.

\subsubsection{MPA and AcMPAG altered TJ proteins expression and distribution}

The modulatory effect of MPA on TJs proteins, ZO-1 and occludin was investigated by immunofluorescent labelling. Changes in the distribution and expression of occludin and ZO-1 can be used as the markers for determination of TJs disruption which has been implicated in several GI tract diseases [147,325]. 


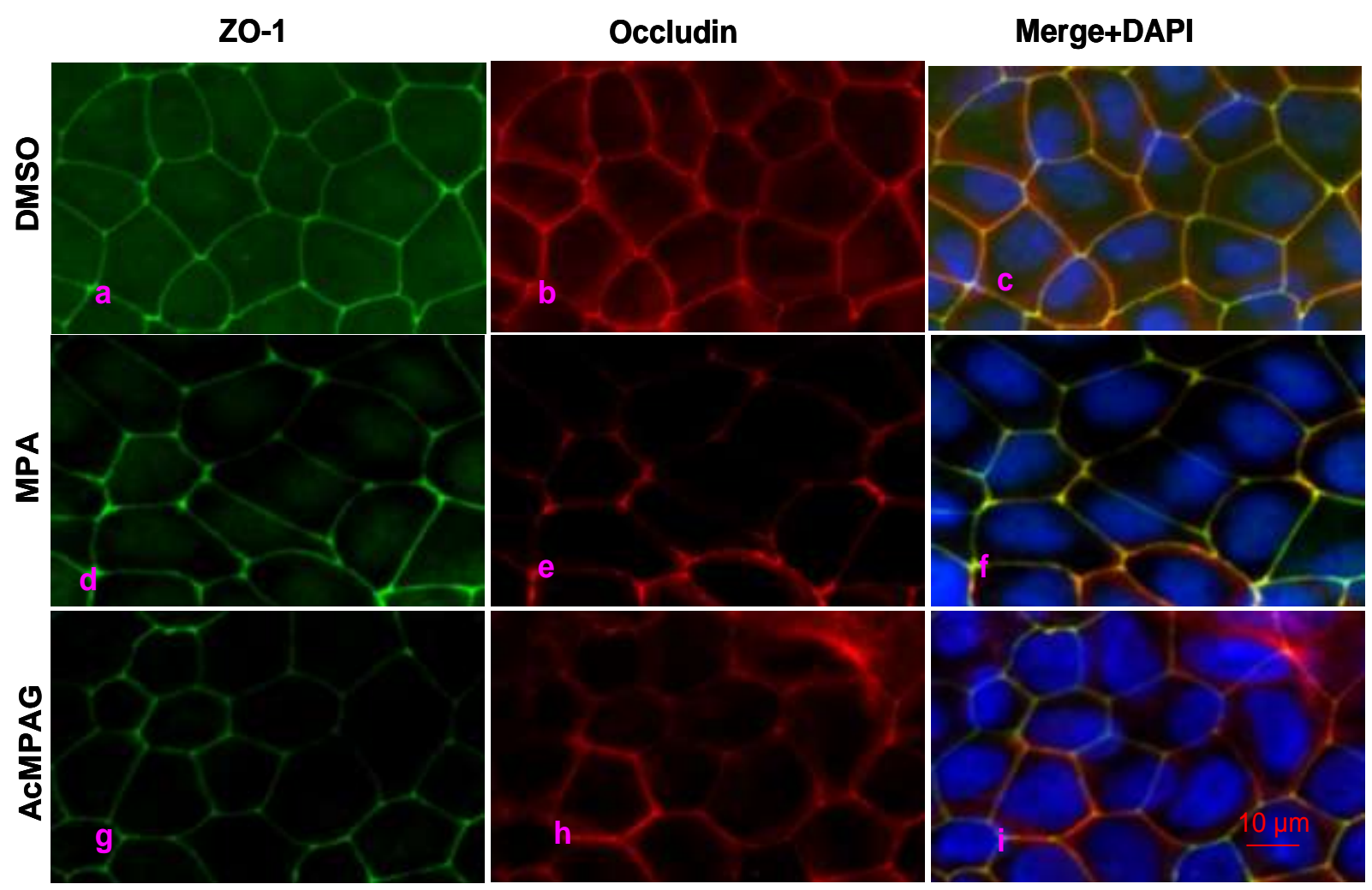

Figure 3.6: Effects of MPA and AcMPAG on ZO-1 and occludin distribution.

Caco-2 cells were grown for 21 days post-confluence and treated with DMSO (vehicle), MPA or AcMPAG for $72 \mathrm{hr}$. Cells were fixed, permeated, and stained for ZO-1 and occludin, as described in materials and methods section. Figure shows the distribution of ZO-1 and occludin in Caco-2 cells exposed to DMSO (vehicle) ( $a, b$, and $c$ ), $10 \mu \mathrm{mol} / \mathrm{L}$ MPA ( $d$, e, and $f$ ) alone, $10 \mu \mathrm{mol} / \mathrm{L} \mathrm{AcMPAG} \mathrm{(} g, h$, and $I)$. Cells were doubled stained for ZO-1 $(a, d, g)$ and occludin $(b, e, h)$. An overlay (ZO-1, occludin, DAPI) is shown in the right panel $(c, f, i)$. Corresponding proteins were detected with secondary antibodies conjugated with either FITC 488 (green; ZO-1) or cydye 3 (red; occludin). DAPI (blue; nuclei) was used to stain nuclei. Images were examined using confocal microscopy. Images presented are representative images of 5 independent experiments.

Confocal analyses of ZO-1 and occludin distribution showed uniform and continuous staining at the plasma membrane in control cells (DMSO) (Fig 3.6 (a-c)). MPA and AcMPAG treatment $(10 \mu \mathrm{mol} / \mathrm{L})$ for $72 \mathrm{hr}$ led to redistribution of ZO-1 and occludin proteins. The most prominent features were disappearance of staining at the cellular periphery, with aggregation and paracellular openings between the adjacent cells (MPA: Figure $3.6(\mathrm{~d}-\mathrm{f})$, AcMPAG: Figure $3.6(\mathrm{~g}-\mathrm{i}))$. These microscopic alterations at the apical cellular borders correlated with the amount of increased TJs permeability (Figure 3.1 and Figure 3.2) observed. 
We further investigated whether MPA or AcMPAG quantitatively altered the expression of TJs proteins in Caco-2 cells. Immunoblot analysis showed that 10 $\mu \mathrm{mol} / \mathrm{L}$ of both MPA and AcMPAG decreased the expression of occludin by 2.1 and 2.7 fold respectively (Figure 3.7). These expressional changes are consistent with the immunostaining of occludin protein which also revealed disappearance and redistribution of occludin protein from the membranes (Figure 3.6).
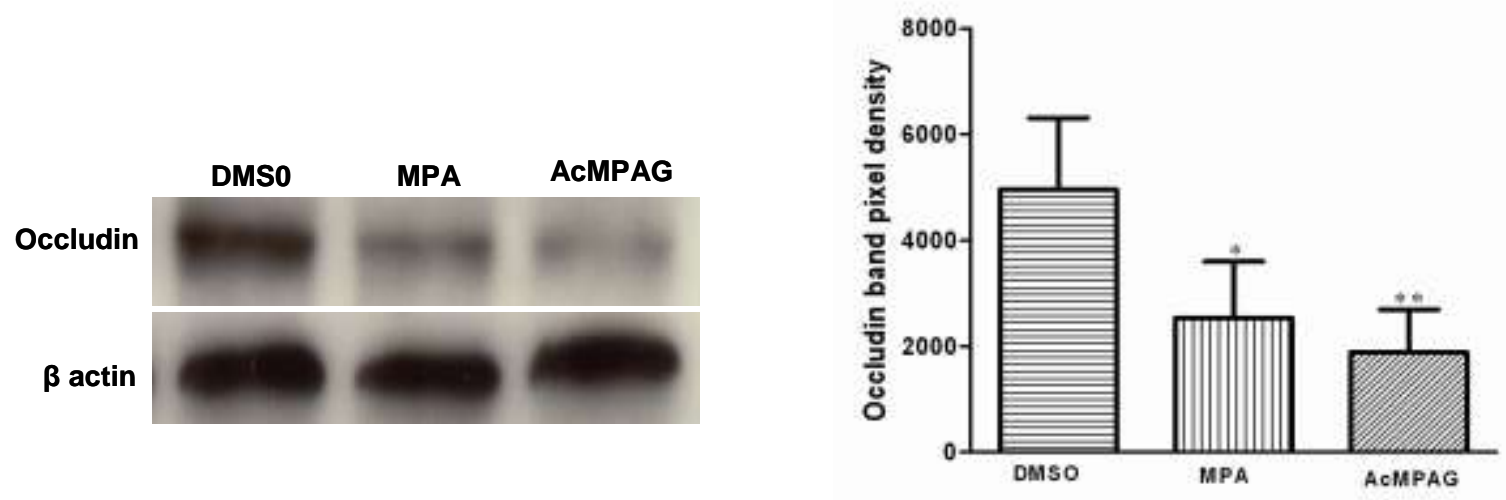

Figure 3.7: Effect of MPA and AcMPAG on occludin protein expression in Caco-2 cells.

Cell were grown to 21 days post-confluency and then treated for $72 \mathrm{hr}$ with DMSO (vehicle), MPA or AcMPAG (10 $\mu \mathrm{mol} / \mathrm{L}$ each). Whole cell lysates were extracted, separated on 1-DE and occludin detected using specific antibody as mentioned in the methods section. Four independent experiments were carried out and results represent mean $\pm \mathrm{SEM}$. ${ }^{*}=\mathrm{P}<0.05,{ }^{* *}=\mathrm{P}<0.05$.

\subsubsection{MPA and AcMPAG modulation of Caco-2 F-actin}

The perijunctional ring of F-actin is the fundamental unit of the actin cytoskeleton that supports the tight junction and thus plays an important role in barrier regulation [326]. Structural alterations of the F-actin-based cytoskeleton are used to detect changes in actin and tight junctions [327,328]. 


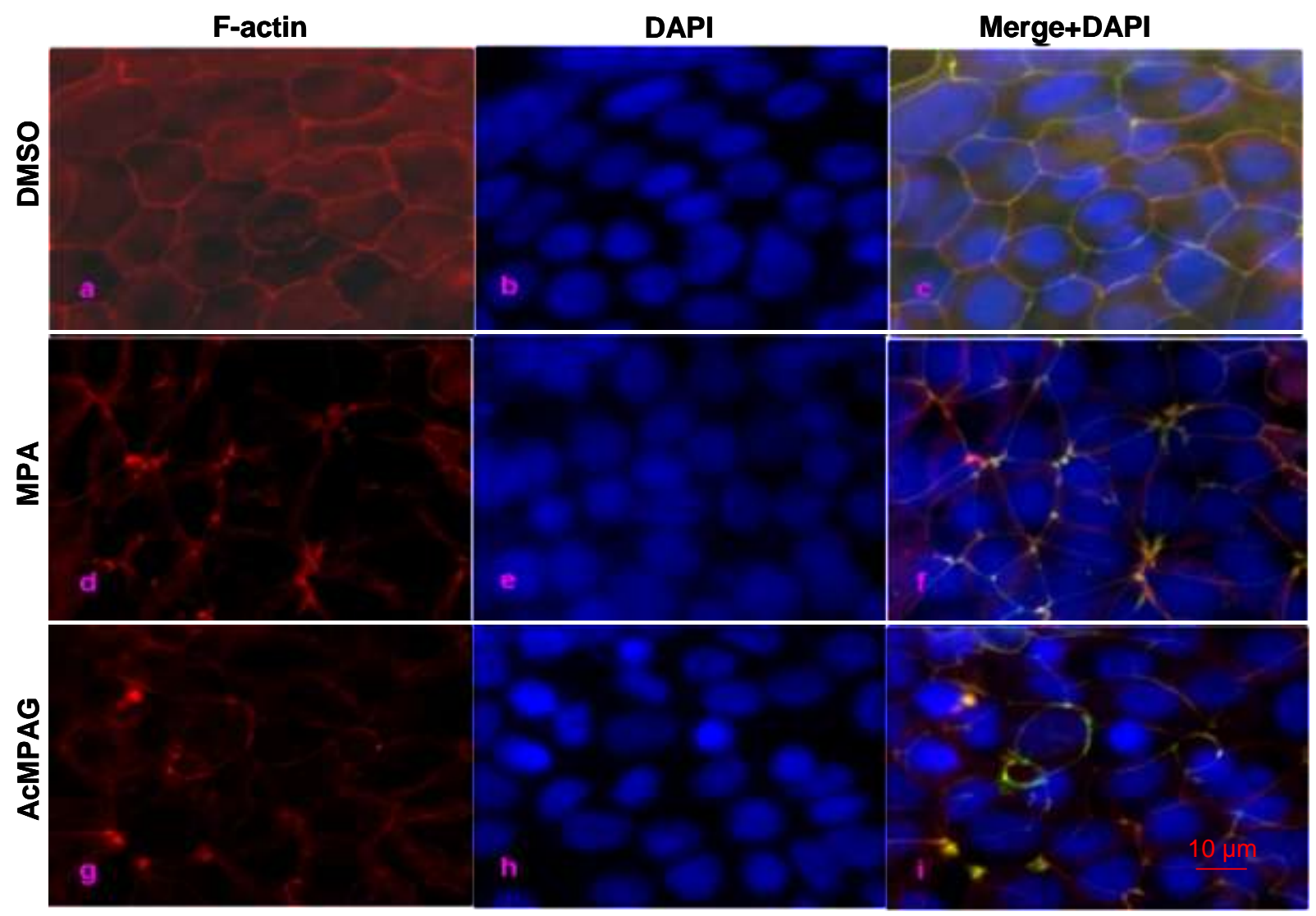

Figure 3.8: MPA and AcMPAG-induced remodelling of the F-actin cytoskeleton.

Caco-2 cells grown to 21 days post-confluence followed by $72 \mathrm{hr}$ treatment with DMSO (a, b), 10 $\mu \mathrm{mol} / \mathrm{L}$ MPA (c, d) and $10 \mu \mathrm{mol} / \mathrm{L} \operatorname{AcMPAG}(\mathrm{e}, \mathrm{f})$. Cells were fixed, permeated, and F-actin was stained with FITC-phalloidin (red) and nuclei were stained with DAPI (blue), as described in methods section. Fluorescence images were obtained using Axiovert 200M confocal microscope. Images are representative of 4 independent experiments.

To investigate whether MPA or AcMPAG mediated colonic epithelial barrier disruption was associated with structural modulation of the F-actin cytoskeleton, we stained Caco-2 cells with FITC-labelled phalloidin, a commonly used fluorescent marker for F- actin [322,328]. In the vehicle control (DMSO) cell monolayers, the Factin cytoskeleton was uniformly organized as shown in figure 3.8 (a-c). Following 72 $\mathrm{hr}$ exposure to $10 \mu \mathrm{mol} / \mathrm{L}$ of either MPA (Figure $3.8 \mathrm{~d}-\mathrm{f}$ ) or AcMPAG (Figure $3.8 \mathrm{~g}-\mathrm{i}$ ), the uniform distribution of actin staining in epithelial cells appeared disrupted and was marked by randomly distributed dense patches of staining, which suggest disruption of the actin cytoskeleton as a possible mechanism for the alterations in the TJs by MPA and AcMPAG. 


\subsubsection{MPA-mediated increase in MLC phosphorylation through MLCK}

To analyze for the possible involvement of MLCK in the MPA mediated TJs disruption, we determined the effect of MPA on total protein expression of MLC2, MLCK, and phospho-expression of MLC2 in the presence of ML-7 (Figure 3.9). ML-7 acts as a selective antagonist of MLCK by competing for its ATP-binding site and reverses the effects of agents involved in TJs disruptions [328]. Previously it was reported that ML-7 had no significant effect on total MLC2 and MLCK expression and that ML-7 mainly affects the phosphorylation of MLC2 by decreasing the activity of MLCK [112]. In the present study, expressional analysis showed that MPA treatment in the presence of ML-7 did not alter total MLC2 and MLCK expression, which was observed after MPA treatment alone. Additionally, we observed that the presence of ML-7 in the medium was able to reverse the effect of MPA on MLC2 phosphorylation (Figure 3.9). To further validate these results, cells were incubated with $C D$ which is an actin-disrupting drug that has previously been reported to increase MLC2 phosphorylation [329]. Our results also showed that CD increased phospho-MLC2 expression; which is consistent with the previous report [329].

In the present study, expressional analysis showed that MPA treatment in the presence of ML-7 did not alter total MLC2 and MLCK expression, which was observed after MPA treatment alone. Additionally, we observed that the presence of ML-7 in the medium was able to reverse the effect of MPA on MLC2 phosphorylation (Figure 3.9). To further validate these results, cells were incubated with $C D$ which is an actin-disrupting drug that has previously been reported to increase MLC2 phosphorylation [329]. Our results also showed that CD increased phospho-MLC2 expression; which is consistent with the previous report [329]. 

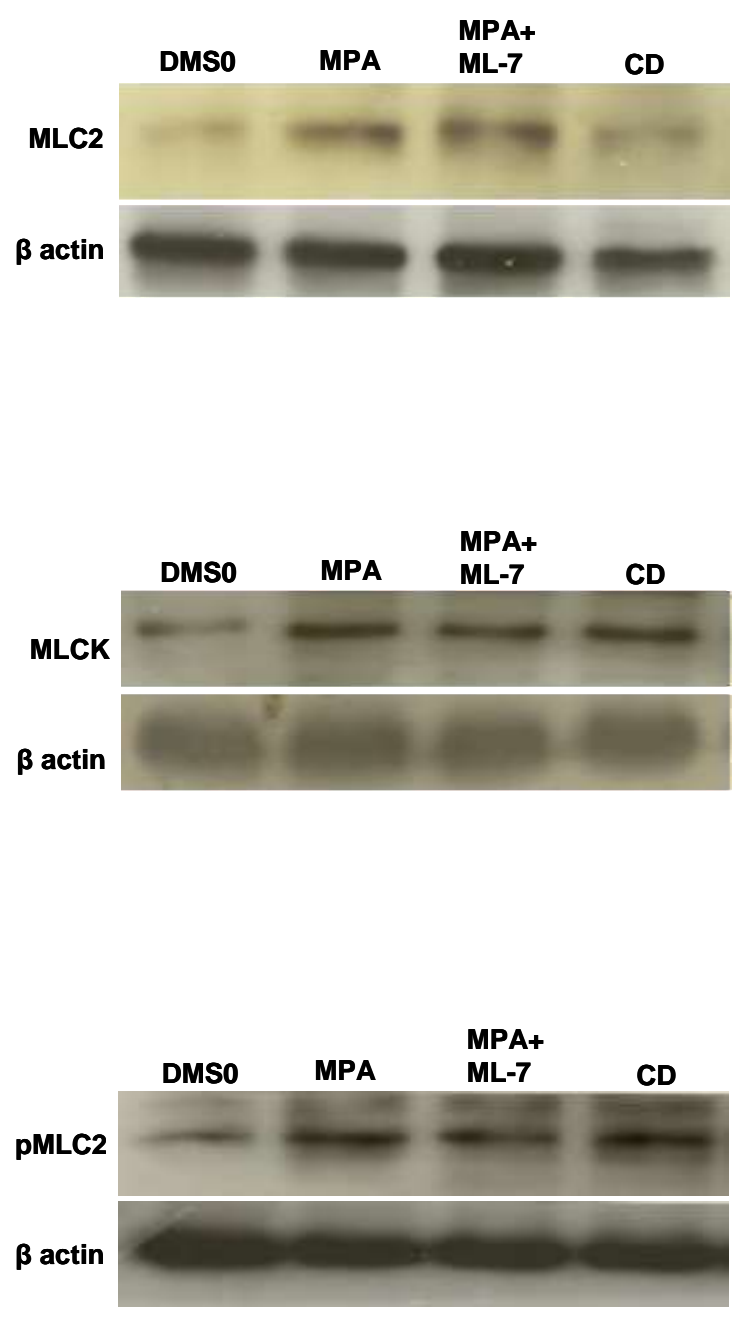
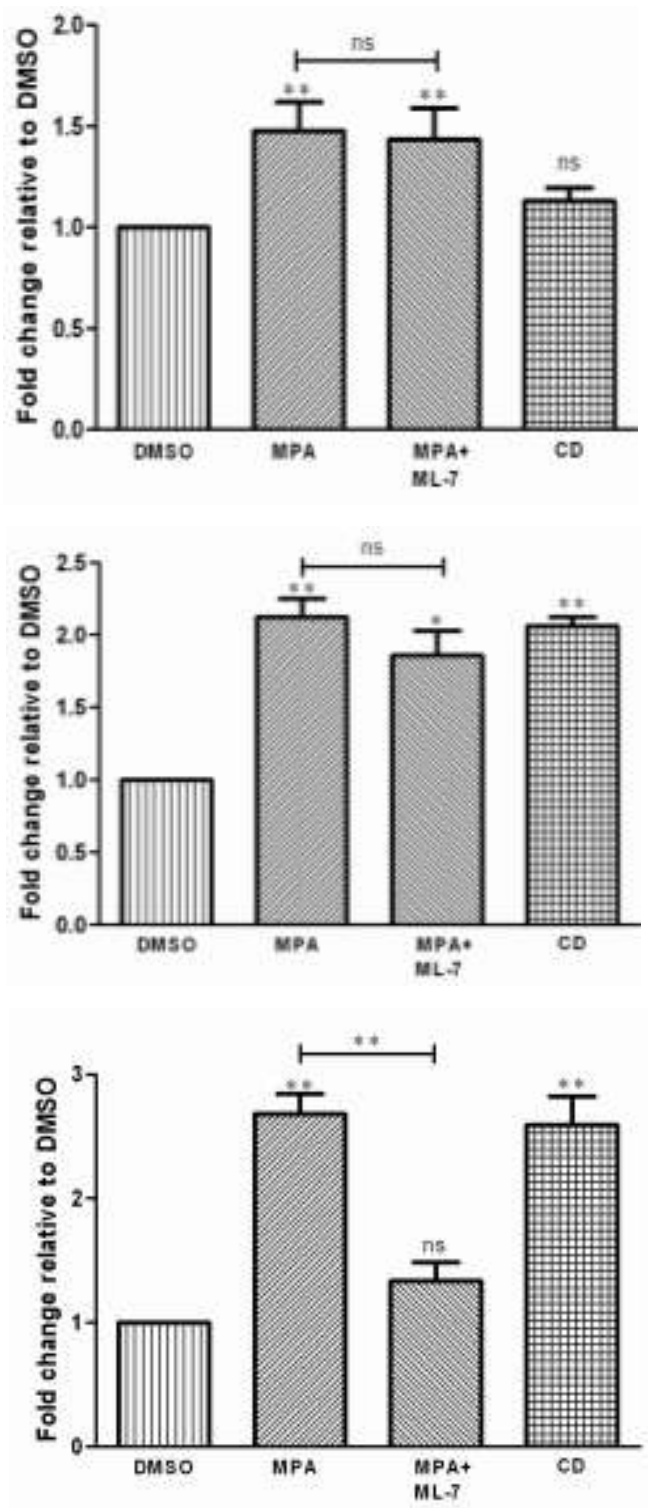

Figure 3.9: Effect of ML-7 on MPA-mediated increases in MLC2, MLCK and MLC phosphorylation.

Caco-2 monolayers (21 days post-confluent) were incubated with either vehicle (DMSO), MPA, MPA+ML-7, or CD for $72 \mathrm{hr}$. Total cell proteins were isolated and equal amount of protein was loaded resolved on 1DE. Expression was analysed by immunoblot analysis using antibodies against MLC2, MLCK and p-MLC2. Beta actin was used as a control for an equal amount of protein load. Bands were quantified using the Lab image software. The data represent the mean of 4 independent experiments \pm SEM. ${ }^{*}=p<0.05,{ }^{* *}=p<0.005$. 


\subsubsection{MLCK inhibition partially prevented MPA effects on TER and permeability}

To investigate whether MPA mediated TJs alteration is through effects on MLCK, we pre-treated Caco-2 monolayers with ML-7 for $1 \mathrm{hr}$ and then co-incubated them with $(10 \mu \mathrm{mol} / \mathrm{L}) \mathrm{MPA}$ for the indicated time periods. It was previously reported that ML-7 prevents TJs disrupting agent mediated decreases in TER and increases the permeability via inhibition of MLCK $[153,328]$. Co-treatment with ML-7 and MPA resulted in a significant higher TER as compared to cells treated with MPA alone. Similarly, apical to basal FD4 influx was also reduced in cells co-treated with MPA and ML-7 (Figure 3.10). CD was previously reported to decrease TER and increase permeability [330]. In the following experiments, similar to MPA, CD treated cells showed significant decreases in TER and increases in FD4 influx (Figure 3.10). These findings suggest that the MPA-induced increases in Caco-2 TJ permeability are at least partly the result of a mechanism closely associated with MLCK expression and activity.

a

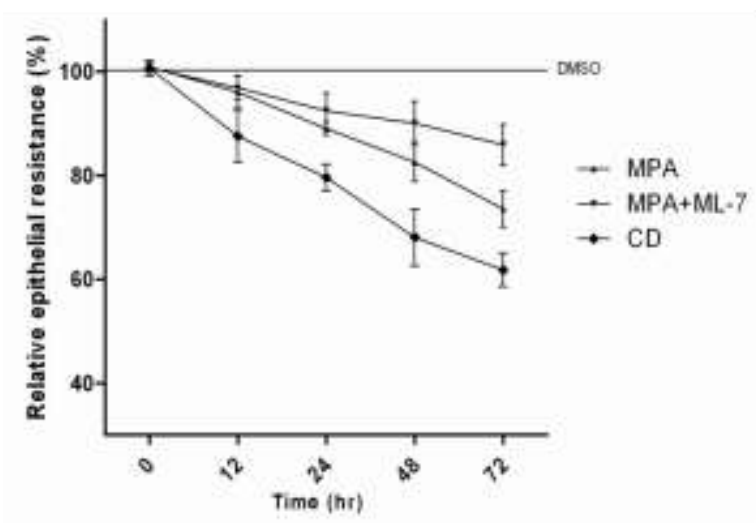

b

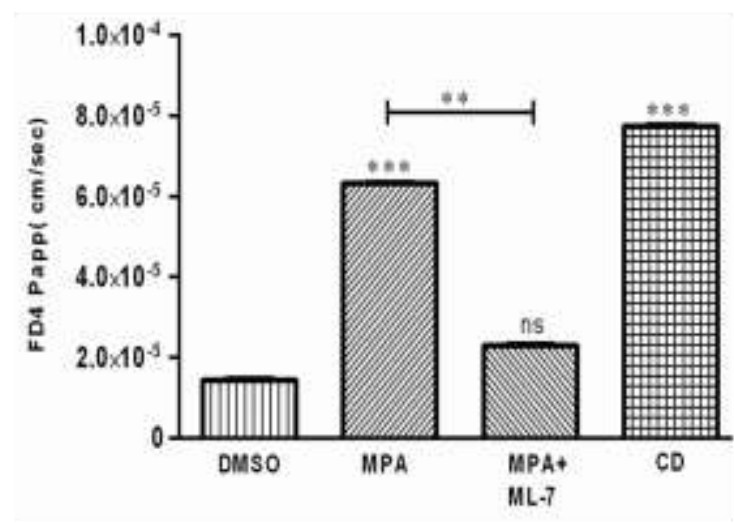

Figure3.10: ML-7 co-treatment reversed the effect of MPA on TER and permeability.

Cells were grown to 21 days post-confluence and incubated with MPA or MPA+ML-7, or CD for $72 \mathrm{hr}$. The effects on (a) TER and (b) FD-4 influx were measured as described in the methods section. ML-7 a specific MLCK inhibitor prevented both the MPA-mediated increase in FD 4 paracellular diffusion and the decreases in TER. Data are the mean \pm SEM of at least four independent experiments. ${ }^{* *}=\mathrm{p}<$ $0.005,{ }^{* * *}=p<0.0005$. 


\subsubsection{Inhibition of MLCK prevented MPA mediated alteration of TJ proteins}

We examined the involvement of MLCK in MPA mediated TJs regulation using immunofluorescence methods. Previously it was reported that the redistribution of TJs proteins by TJs disrupting agents can be reversed by inhibiting MLCK $[215,331,332]$. Immunofluorescence localization of occludin and ZO-1 showed that ML-7 could partly prevent redistribution of ZO-1 and occludin induced by MPA exposure (Figure $3.11 \mathrm{~d}-\mathrm{f}$ ) when compared to cells treated with MPA alone (Figure $3.11 \mathrm{a}-\mathrm{c})$.

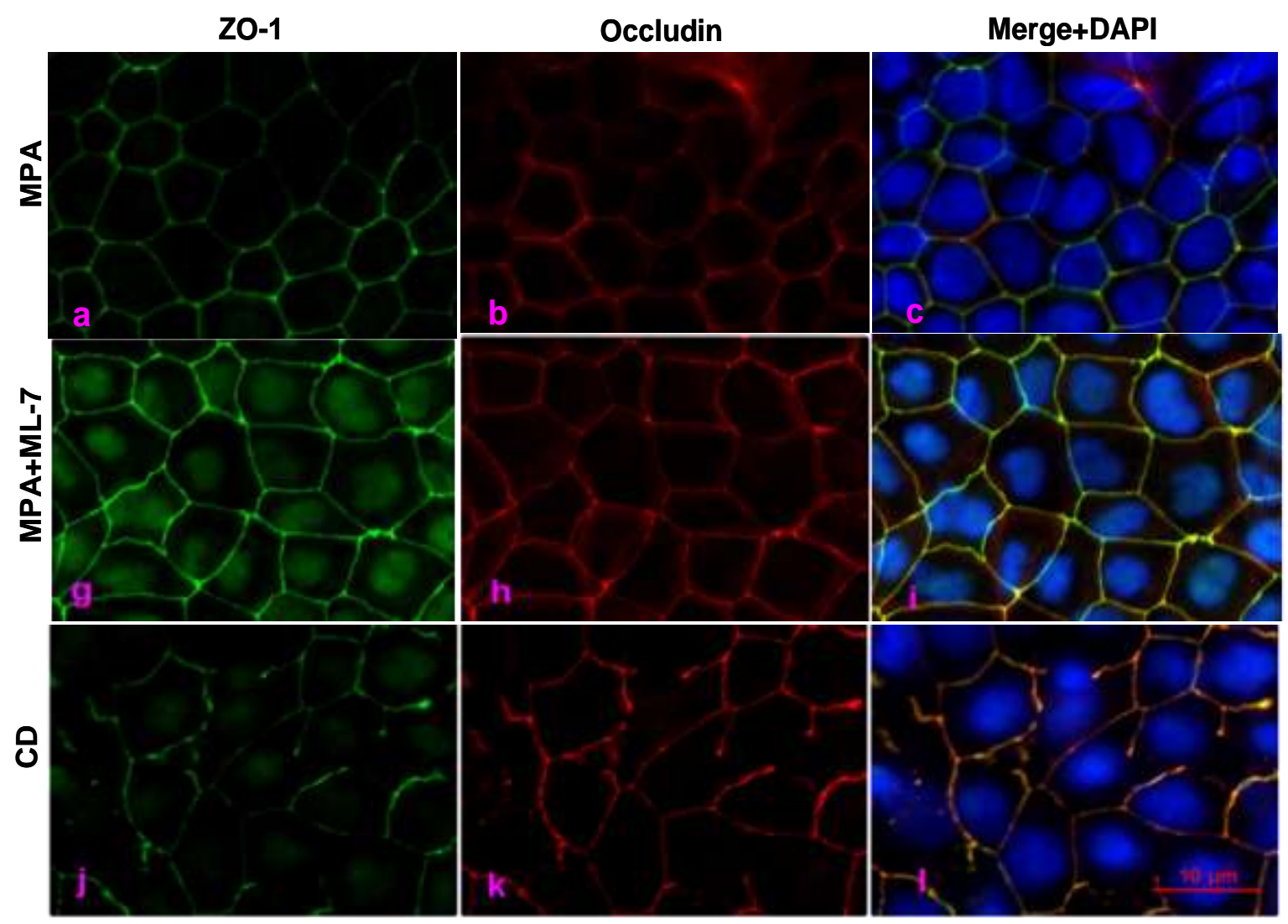

Figure 3.11: ML-7 co-treatment reversed the effect of MPA on distribution of TJs proteins.

Cells following 21 days post-confluency were treated with MPA, and CD or pre-treated with ML-7 followed by MPA treatment. Cells were labelled with florescent antibodies specific for ZO-1 and occludin. Figure shows ZO-1 (a, g, j), occludin (b, h, k) and an overlay of ZO-1 and occludin along with DAPI stained nuclei (c, i, I). Four independent experiments were performed.

ML-7 co-treatment induced reassembly of the ZO-1 and occludin at the cellular borders with reclosure of the paracellular gaps (Figure $3.11 \mathrm{~g}-\mathrm{i}$ ). The MPA induced disruption of TJs proteins distribution was prevented by an MLCK inhibitor (ML-7), indicating that the downstream alteration of TJs proteins is dependent on MLCK 
activation. In contrast, CD, like MPA, disrupts the distribution of ZO-1 and occludin as shown by disappearance of these proteins from the paracellular membrane (Figure $3.11 \mathrm{j}-1)$

We also performed immunoblot analysis for occludin protein expression. Results showed that ML-7 was able to reverse the effect of MPA on occludin expression by increasing its expression by 1.92 fold as compared to cells treated with MPA alone. CD treatment showed a 3.2 fold decrease in occludin protein as compared to DMSO control (Figure 3.12).
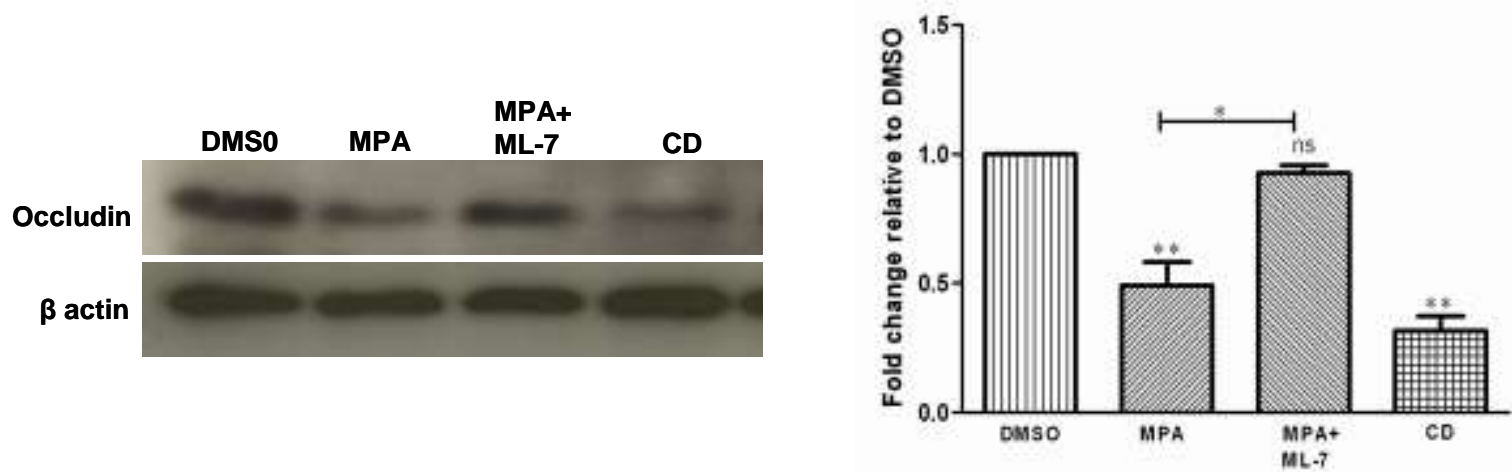

Figure 3.12: Effect of ML-7 co-treatment with MPA on occludin protein expression in Caco-2 cells.

Caco-2 cell monolayers following 21 days post-confluency were incubated with DMSO, MPA (10 $\mu \mathrm{mol} / \mathrm{L})$, MPA $(10 \mu \mathrm{mol} / \mathrm{L})+\mathrm{ML}-7(10 \mu \mathrm{mol} / \mathrm{L})$ or $\mathrm{CD}(10 \mu \mathrm{mol} / \mathrm{L})$ for $72 \mathrm{hr}$. Protein extracts were immunoblotted for occludin and $\beta$-actin. Densitrometric measurement was done with the Lab image software. Values are means $\pm \operatorname{SEM}(n=4)$.

\subsection{Discussion}

Intestinal cells form a crucial physical and functional barrier, which regulates the movement of water, electrolytes, nutrients, and xenobiotics [333]. The gastrointestinal tract is directly involved in the metabolism and transport of various endogenous and exogenous compounds [334]. Several intestinal diseases are characterized by barrier dysfunction including inflammatory bowel disease, graft versus host disease, and infectious enterocolitis (reviewed in [335]). It has been previously reported that epithelial barrier defects lead to increased intestinal 
permeability and the development of diarrhoea in human patients with bowel diseases [336] and in mouse models [337].

MPA associated gastrointestinal adverse effects are a major concern in transplantation medicine and diarrhoea is the most frequent unwanted clinical outcome following treatment with MPA regimes [338]. Previous reports showed that MPA is associated with gastrointestinal mucosal injury [60,65,311,339,340]. The effect of therapeutic concentrations of MPA on the gastrointestinal epithelial barrier is not well described. Diverse physiological and pathophysiological stimuli cause intestinal barrier dysfunction, regulated via several pathways such as those involving protein kinase $\mathrm{C}$, protein kinase $\mathrm{A}, \mathrm{MLCK}$, Rho-kinase, mitogen-activated protein kinases, and phosphoinositide 3-kinase. Disturbances in these pathways can all lead to the alteration in TJs protein expression and distribution $[181,303]$. In a previous study, we observed a significant increase in the MLC2 expression in HEK-293 cells following MPA exposure [323]. MLC2 phosphorylation via MLCK and/or ROCK has been implicated in several barrier disorders [329].

To better understand the possible mechanism of MPA mediated TJs regulation, we used Caco-2 monolayers as a colonic model [341]. The present study demonstrates for the first time in vitro that MPA, at non-toxic and therapeutic concentrations produces a significant modulation of intestinal epithelial barrier function in Caco- 2 cells. The Caco- 2 cell line is widely used as an in vitro intestinal barrier cell model, which exhibits a well differentiated brush border, TJs and intestinal proteins [341,342]. MPA exposure increased TJs permeability and impaired TJ proteins (ZO-1 and occludin) expression and distribution. On the other hand, the MPA concentrations used did not cause significant apoptosis or cell death, suggesting that the effects of MPA on Gl barrier function are the result of a noncytotoxic mechanism.

Previously it was shown that MLCK activity in Caco-2 cells triggers a series of molecular processes such as induction of MLC phosphorylation, myosin- $\mathrm{Mg}^{2+}$ ATPase activation, and perijunctional actin-myosin interaction which are responsible for actin filament disruption leading to Caco-2 epithelial barrier opening [328]. Several agents increase MLCK mediated MLC2 phosphorylation which disrupts tight junction proteins, leading to the increased TJs permeability implicated in barrier associated 
diseases [184]. We investigated the possible disruptive role of MPA on epithelial barrier permeability and attempted to link this effect with MLCK-induced MLC-2 phosphorylation.

To demonstrate the effect of MPA and one of its active metabolites, AcMPAG, on barrier properties of this colonic model, Caco-2 cells were exposed to noncytotoxic concentrations of MPA $(10 \mu \mathrm{mol} / \mathrm{L})$ and AcMPAG $(10 \mu \mathrm{mol} / \mathrm{L})$ followed by measurements of TER and influx of markers. Determination of TER and influx of permeability markers are widely used techniques to assess the integrity and permeability of monolayers [343] because TJs disruption can be reflected by the reduction in TER and the increase in influx of permeability markers [335].

Our data revealed that MPA and AcMPAG increased Caco-2 cell monolayer permeability as shown by decreases in TER and increases in FD4 influx (Fig 1). These findings are in agreement with another report on the effects of MMF (an ester prodrug of MPA) on the barrier function of small bowel and distal colon of Wistar rats [344].

TJs proteins, ZO-1, and occludin are protein markers which are widely used to investigate TJs integrity $[184,345]$. These proteins maintain structure and function of TJs integrity which are vital for normal intestinal architecture [97,148]. The disturbance in the distribution and expression of these proteins has been observed in intestinal barrier disorders $[150,313]$. In the present study, we investigated the effect of MPA and AcMPAG on the distribution and expression of ZO-1 and occludin. We found that exposure of Caco-2 monolayers (21-days post-confluency) to therapeutic, non-cytotoxic concentrations of MPA and AcMPAG for $72 \mathrm{hr}$ led to a decrease in the expression of occludin proteins, as evidenced by Western blot analysis (Figure 3.7). Under normal conditions ZO-1 and occludin are generally present at the pericellular boundary, and distributed homogeneously, presenting a characteristic feature of intact TJs structure. Disruption and redistribution of TJs proteins has been reported previously in several studies that suggested that alteration in these proteins can lead to hyperpermeability [184,346]. MLCK mediated MLC-2 phosphorylation (involved in modulation of ZO-1 and occludin morphologically and biochemically) can induce an increase in TJs permeability $[184,184]$. 
Furthermore, we also demonstrated that MPA and AcMPAG exposure changed the distribution of ZO-1 and occludin proteins, as revealed by a discontinuous pattern of immunofluorescent staining of these TJs proteins (Figure 3.5). To investigate whether MLCK was involved in MPA modulation of TJs, we used a specific MLCK inhibitor, ML-7 which is a selective antagonists of MLCK [347]. Previously it was reported that inhibition of MLCK mediated MLC phosphorylation by ML-7 can prevent or reverse TJs barrier losses induced by several agents such as TNFa, Cytochalasin $B$, and ethanol $[112,153,328,348]$. To investigate the effect of MPA on MLCK activity, we pre-incubated cell monolayers with ML-7 followed by MPA exposure. Results showed that ML-7 could at least partially reverse the MPA mediated decrease in TER as well as the increase in FD4 influx. Additionally, ML-7 was able to prevent the MPA induced redistribution and decrease in expression of ZO-1 and occludin proteins.

Treatment with CD, a known stimulant of MLCK and actin-depolymerising agent [329] which was used as positive control for the effects of MPA treatment, also showed a decrease in TER and increase in paracellular flux (Figure 3.10). Previously, it was reported that CD was able to increase MLCK activity and MLC2 phosphorylation [329], which our results confirmed. In addition, we found that CD was able to alter the expression and distribution of TJs proteins which is consistent with results of a previous study of CD treated epithelial cells [349]. These results showed that both CD and MPA decreased TER and disrupted the actin cytoskeleton. The present study revealed that inhibition of MLCK activity by ML-7 significantly prevented the MPA mediated increase in MLC2 phosphorylation with no significant effect on total MLCK and MLC2 expression.

MLC2 phosphorylation has a key role in maintaining TJs integrity by regulating actomyosin contraction [153]. Several pathways were described previously which regulate the phosphorylation of MLC2; among them Rho-kinase and MLCK signalling are widely studied in the context of barrier defects [191]. MLCK is involved in the regulation of barrier function by phosphorylation of MLC2 in response to diverse stimuli $[153,324]$. ML-7 via MLCK inhibition prevents the disruption of both occludin and actin, which demonstrates the importance of MLCK activity in TJs physiology [350]. Our results suggest that increases in MLCK might be responsible for the MPA induced redistribution of ZO-1 and occludin in Caco-2 monolayers. 


\subsection{Conclusion}

The present study indicates that MPA and its active AcMPAG metabolite at therapeutic concentrations produce functional alterations in TJs of Caco-2 cells resulting in abnormal TJs permeability, and redistribution of TJs proteins including disturbance and displacement of F-actin. These data suggest that MPA mediated increases in permeability required increased MLCK activity which could be reversed by ML-7. While requiring further investigation, MLCK inhibition by ML-7 significantly reduced the effect of MPA exposure on TJs disruption, thus suggesting a pivotal role of MLCK in regulating TJs barrier properties. These findings provide new insights into the mechanism by which therapeutic use of MPA may alter intestinal epithelial barrier functions and suggest mechanisms which may be responsible for some of the GI adverse effects associated with MPA. 


\section{Summary}

Mycophenolic acid (MPA) is a potent inhibitor of inosine monophosphate dehydrogenase (IMPDH), a key regulator of purine biosynthesis. MPA is frequently used as an immunosuppressant drug to prevent acute graft rejection for kidney, liver and lung transplantation. The use of MPA is associated with Gl toxicity which is a problem to the patients, and a challenge for clinicians. The present study was undertaken to identify novel molecular targets of MPA using a proteomics approach (Figure 4.1). Two dimensional gel electrophoresis (2-DE) and mass spectrometry were used to identify proteome alterations in human embryonic cells (HEK-293) following exposure to therapeutic concentrations of MPA. Cells were treated for 72 hours, and total cell lysate was resolved by 2-DE followed by QTOF-MS/MS analysis of all identified differentially regulated proteins. A total of 12 proteins were differentially regulated in HEK-293 cells following exposure to MPA. Among these, 7 proteins were up-regulated (complement component $1 \mathrm{Q}$ subcomponent-binding protein, electron transfer flavoprotein subunit beta, cytochrome b-c1 complex subunit, peroxiredoxin 1 , thioredoxin domain-containing protein 12 , myosin regulatory light chain 2, and profilin 1), while 5 proteins were down-regulated (protein SET, stathmin, $40 \mathrm{~S}$ ribosomal protein $\mathrm{S} 12$, histone $\mathrm{H} 2 \mathrm{~B}$ type $1 \mathrm{~A}$, and histone $\mathrm{H} 2 \mathrm{~B}$ type 1$\mathrm{C} / \mathrm{E} / \mathrm{F} / \mathrm{G} / \mathrm{I})$. Functional annotation tool analysis showed that MPA modulated proteins were mainly involved in the cytoskeleton (26\%), chromatin structure/dynamics $(17 \%)$, and energy production/conversion (17\%). Considering both putative functions and their clinical significance, peroxiredoxin-1 (Prdx-1) and myosin light chain 2 (MLC2) were selected for Western blot and real time PCR analysis. Both proteins showed upregulation at mRNA as well as at protein level following MPA exposure.

MLC2 is known to be involved in several functions including tight junctions (TJ) regulation. Epithelial barrier disruption by phosphorylation of MLC2 has been implicated in several bowel diseases. Since MPA treatment often causes diarrhea when used clinically, we hypothesized that MPA regulated epithelial TJ by modulation of MLC2. To test this hypothesis, we investigated the effect of MPA on the expression of MLC2 in two colonic cell lines, HT-29 and Caco-2. Increased MLC2 expression was observed in both cell lines following MPA exposure. These findings suggest that the increase in MLC2 expression after exposure to MPA is not a cell specific effect. Moreover, we observed similar up-regulation of MLC2 expression in 
whole cell lysates prepared from MMF treated rats, which implies that MPA has similar effects both in vitro and in vivo.

We then used Caco-2 cells grown for 21 days post confluence to develop polarize monolayers to conduct physiological, expressional and microscopic analysis to establish the possible role of MPA in disruption of TJ (Figure 4.1). MPA exposure caused a time and dose dependent decreases in transepithelial resistance (TER), and increases in the FITC-dextran $4 \mathrm{KDa}$ (FD4) paracellular influx in these Caco-2 monolayers. In addition, we found that AcMPAG (a pharmacologically active metabolite of MPA) was also able to cause decreases in TER and increases in FD4 influx. These MPA and AcMPAG mediated increases in permeability were not due to cellular toxicity, as shown by the fact that no significant apoptosis or cell death was observed. In MPA and AcMPAG treated cells, we also found altered expression and distribution of TJ proteins (ZO-1 and occludin).

Since MLC phosphorylation is a key modulator of TJ disruption; we investigated whether MPA also increased MLC2 phosphorylation. Using immunoblot analysis we found that MPA significantly increased MLC2 phosphorylation. We then investigated whether MPA mediated increases in MLC2 phosphorylation was through effects on MLCK. Immunoblot analysis revealed that MPA increased MLCK expression both at mRNA and protein levels. To further confirm that MLCK was the key player in MPA mediated MLC2 phosphorylation and its associated TJ disruption, we pre-incubated cells with ML-7 (a specific MLCK inhibitor), and observed that ML-7 was able to partially prevent the MPA mediated increase in MLC2 phosphorylation. Furthermore, we found that ML-7 partially reversed MPA mediated decreases in TER, and increases in FD4 paracellular influx. ML-7 also prevented the MPA associated disruption of the distribution and expression of TJ proteins (Figure 4.2). These findings suggest that MPA may regulate TJ function via MLCK-driven MLC2 phosphorylation. However, these results do not exclude the possibility that other pathways may also be involved in MPA induced regulation of TJ function.

Taking together findings of the present studies showed that therapeutic concentrations of MPA can modulate the expression of important proteins which are crucial for various cellular functions. MPA may modulate epithelial TJ integrity via MLC2 phosphorylation. These findings will be helpful to understand the molecular mechanisms of MPA-induced proteome alterations, including proteins that are 
involved in disruption of TJ. Further studies are needed to clarify the mechanism(s) and consequences of MPA mediated disruption of TJs, especially in in vivo models, to know whether these TJ barrier changes are responsible for the $\mathrm{Gl}$ adverse events associated with MPA treatment.

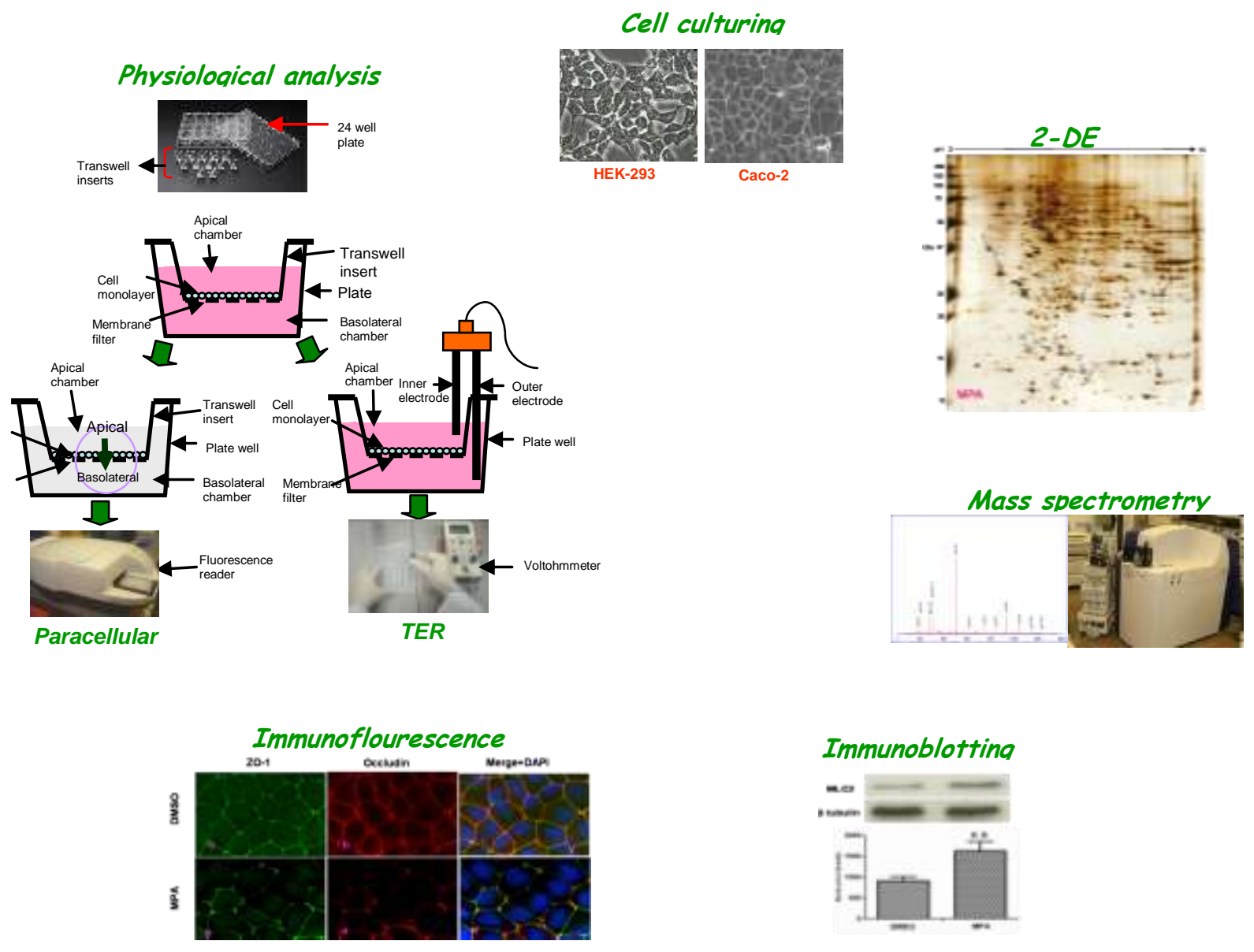

Figure 4.1: A proteomic approach for identification of novel MPA molecular targets.

HEK-293 cells were cultured, treated with MPA, whole cell lysates was resolved using 2-DE, and silver stained. Protein spots were densitometrically analysed and differentially expressed proteins were subjected to in-gel digestion and identified by QTOF-MS/MS. The up-regulation of MLC2 by MPA was further confirmed by immunoblot analysis. The functional involvement of MLC2 in MPA mediated barrier defects was determined by physiological assays such as TER and paracellular influx of FITCdextran using Caco-2 cells monolayers. In addition, the expression and distribution of TJ proteins (ZO1 and occludin) were also investigated using immunoblotting and immunoflurecence microscopy. 


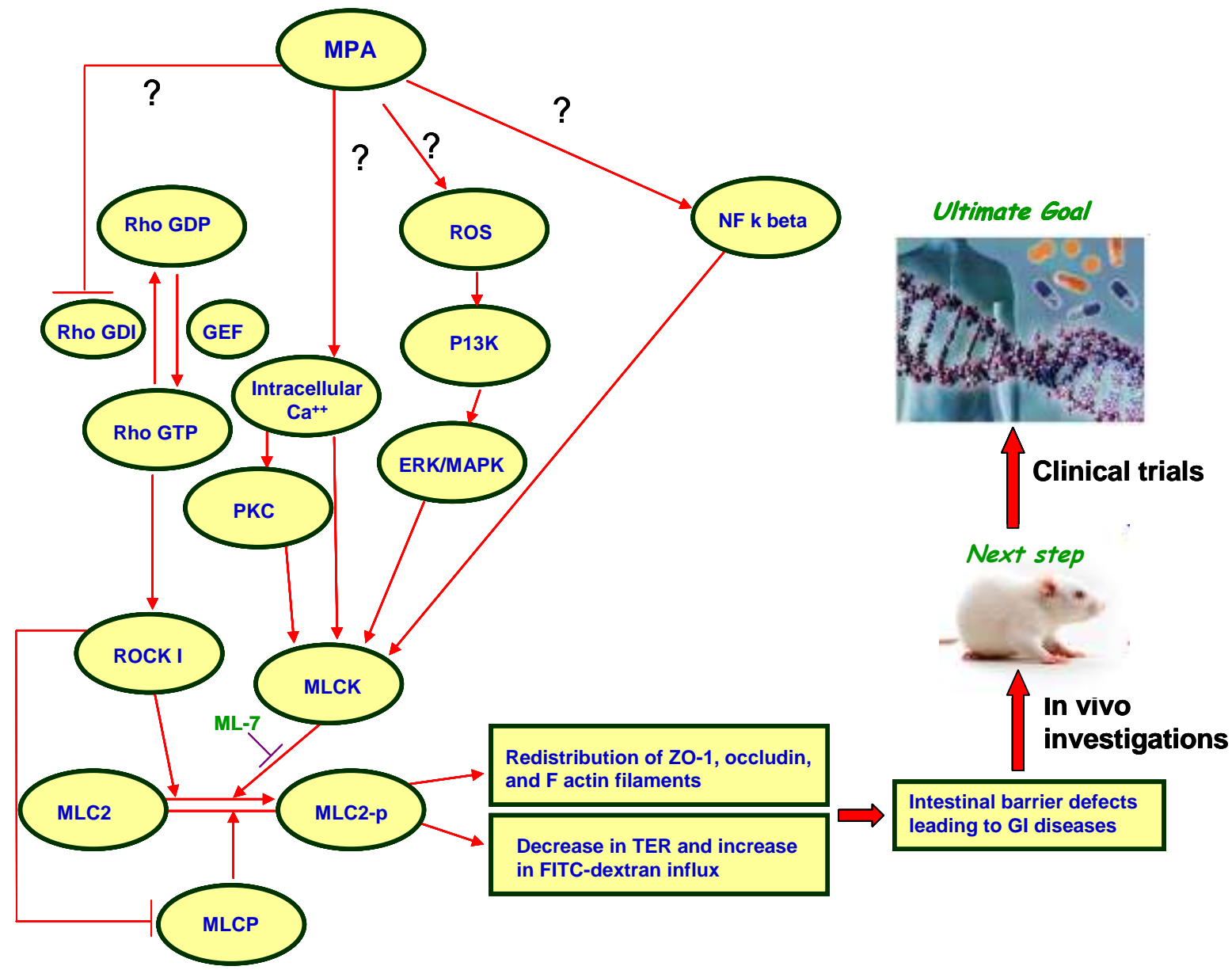

Figure 4.2: Proposed model of MPA mediated TJ distruption.

MPA increased MLCK-mediated MLC2 phosphorylation in Caco-2 cell monolayers. MLC2 phosphorylation altered the expression and distribution of TJ proteins (ZO-1 and occludin) that have been identified as a key factor in the development of barrier defects seen in several intestinal diseases. MLC2 phosphorylation also alters the distribution of F actin filaments and the associated TJ disruption results in decreases in TER and increases in paracellular influx. In the present study we observed that MPA disrupted TJ, was associated with increased MLCK expression, and MLC2 phosphorylation. We therefore propose that MPA associated TJ disturbance is dependant on MLCKdriven MLC phosphorylation that leads to decreased expression and redistribution of TJ proteins. Pretreatment with ML-7 (a specific inhibitor of MLCK) partially prevented the MPA mediated increase in MLC2 phosphorylation, disturbance of TJ proteins, and increase in permeability. We hypothesized that the observed increase in paracellular permeability following MPA treatment is due to TJ disruption caused by MLC2 phosphorylation, which mediates alterations in the expression and distribution of TJ proteins. 


\section{References}

1. Bentley R: Mycophenolic Acid: a one hundred year odyssey from antibiotic to immunosuppressant. Chem Rev 2000, 100: 3801-3826.

2. Kitchin JE, Pomeranz MK, Pak G, Washenik K, Shupack JL: Rediscovering mycophenolic acid: a review of its mechanism, side effects, and potential uses. J Am Acad Dermatol 1997, 37: 445-449.

3. Eugui EM, Almquist SJ, Muller CD, Allison AC: Lymphocyte-selective cytostatic and immunosuppressive effects of mycophenolic acid in vitro: role of deoxyguanosine nucleotide depletion. Scand J Immunol 1991, 33: 161-173.

4. Allison AC, Eugui EM: Mycophenolate mofetil and its mechanisms of action. Immunopharmacology 2000, 47: 85-118.

5. Sintchak MD, Fleming MA, Futer O, Raybuck SA, Chambers SP, Caron PR et al.: Structure and mechanism of inosine monophosphate dehydrogenase in complex with the immunosuppressant mycophenolic acid. Cell 1996, 85: 921-930.

6. Kinsella AR, Smith D, Pickard M: Resistance to chemotherapeutic antimetabolites: a function of salvage pathway involvement and cellular response to DNA damage. $\mathrm{Br} \mathrm{J}$ Cancer 1997, 75: 935-945.

7. Newbold N, Riley B, Hardinger K: A Review of Enteric-coated Mycophenolate Sodium for Renal Transplant Immunosuppression. Clinical Medicine: Therapeutics 2009, 1: 927-933.

8. Srinivas TR, Kaplan B, Meier-Kriesche HU: Mycophenolate mofetil in solid-organ transplantation. Expert Opin Pharmacother 2003, 4: 2325-2345.

9. Abraham EP: The effect of mycophenolic acid on the growth of Staphylococcus aureus in heart broth. Biochem J 1945, 39: 398-408.

10. van Hest RM, van GT, Vulto AG, Mathot RA: Population pharmacokinetics of mycophenolic acid in renal transplant recipients. Clin Pharmacokinet 2005, 44: 10831096.

11. Nowack R, Göbel U, Klooker P, Hergesell O, Andrassy K, van der Woude FJ: Mycophenolate Mofetil for Maintenance Therapy of Wegener's Granulomatosis and Microscopic Polyangiitis: A Pilot Study in 11 Patients with Renallnvolvement. Journal of the American Society of Nephrology 1999, 10: 1965-1971.

12. Schanz S, Ulmer A, Rassner G, Fierlbeck G: Successful treatment of subacute cutaneous lupus erythematosus with mycophenolate mofetil. British Journal of Dermatology 2002, 147: 174-178.

13. Larkin G, Lightman S: Mycophenolate mofetil: A useful immunosuppressive in inflammatory eye disease. Ophthalmology 1999, 106: 370-374. 
14. Enk AH, Knop J: Treatment of pemphigus vulgaris with mycophenolate mofetil. The Lancet 1997, 350: 494.

15. Herrera J, Ferrebuz A, MacGregor EG, Rodriguez-Iturbe B: Mycophenolate mofetil treatment improves hypertension in patients with psoriasis and rheumatoid arthritis. $J$ Am Soc Nephrol 2006, 17: S218-S225.

16. Suzuki C, Takahashi M, Morimoto H, Izawa A, Ise H, Hongo M et al.: Mycophenolate mofetil attenuates pulmonary arterial hypertension in rats. Biochem Biophys Res Commun 2006, 349: 781-788.

17. Chaudhry V, Cornblath DR, Griffin JW, O'Brien R, Drachman DB: Mycophenolate mofetil: A safe and promising immunosuppressant in neuromuscular diseases. Neurology 2001, 56: 94-96.

18. Schneider-Gold C, Hartung HP, Gold R: Mycophenolate mofetil and tacrolimus: New therapeutic options in neuroimmunological diseases. Muscle \& Nerve 2006, 34: 284291.

19. Sebastian L, Madhusudana SN, Ravi V, Desai A: Mycophenolic acid inhibits replication of Japanese encephalitis virus. Chemotherapy 2011, 57: 56-61.

20. Nicoletti R, De SM, De SS, Trincone A, Marziano F: Antagonism against Rhizoctonia solani and fungitoxic metabolite production by some Penicillium isolates.

Mycopathologia 2004, 158: 465-474.

21. Domhan S, Muschal S, Schwager C, Morath C, Wirkner U, Ansorge W et al.: Molecular mechanisms of the antiangiogenic and antitumor effects of mycophenolic acid. Mol Cancer Ther 2008, 7: 1656-1668.

22. Akhyani M, Chams-Davatchi C, Hemami MR, Fateh S: Efficacy and safety of mycophenolate mofetil vs. methotrexate for the treatment of chronic plaque psoriasis. J Eur Acad Dermatol Venereol 2010, 24: 1447-1451.

23. Zwerner J., Fiorentino D.: Mycophenolate mofetil. Dermatologic Therapy 2007, 20: 229-238.

24. Staatz CE, Tett SE: Clinical Pharmacokinetics and Pharmacodynamics of Mycophenolate in Solid Organ Transplant Recipients. Clinical Pharmacokinetics 2007, 46: 13-58.

25. Arns W, Breuer S, Choudhury S, Taccard G, Lee J, Binder V et al.: Enteric-coated mycophenolate sodium delivers bioequivalent MPA exposure compared with mycophenolate mofetil. Clinical Transplantation 2005, 19: 199-206.

26. Pescovitz M, Conti D, Dunn J, Gonwa T, Halloran P, Sollinger H et al.: Intravenous mycophenolate mofetil: safety, tolerability, and pharmacokinetics. Clinical Transplantation 2000, 14: 179-188.

27. Rupprecht K, Schmidt C, Raspé A, Schweda F, Shipkova M, Fischer W et al.: Bioavailability of Mycophenolate Mofetil and Enteric-Coated Mycophenolate Sodium Is Differentially Affected by Pantoprazole in Healthy Volunteers. The Journal of Clinical Pharmacology 2009, 49: 1196-1201. 
28. Bullingham R, Monroe S, Nicholls A, Hale M: Pharmacokinetics and bioavailability of mycophenolate mofetil in healthy subjects after single-dose oral and intravenous administration. The Journal of Clinical Pharmacology 1996, 36: 315-324.

29. Cox VC, Ensom MH: Mycophenolate mofetil for solid organ transplantation: does the evidence support the need for clinical pharmacokinetic monitoring? Ther Drug Monit 2003, 25: 137-157.

30. Bullingham RE, Nicholls AJ, Kamm BR: Clinical pharmacokinetics of mycophenolate mofetil. Clin Pharmacokinet 1998, 34: 425-455.

31. Shipkova M, Strassburg CP, Braun F, Streit F, Grone HJ, Armstrong VW et al.: Glucuronide and glucoside conjugation of mycophenolic acid by human liver, kidney and intestinal microsomes. Br J Pharmacol 2001, 132: 1027-1034.

32. Picard N, Ratanasavanh D, Prémaud A, Le Meur Y, Marquet P: Identification of the udp-glucuronosyltransferase isoforms involved in mycophenolic acid phase ii metabolism. Drug Metabolism and Disposition 2005, 33: 139-146.

33. Shipkova M, Armstrong VW, Wieland E, Niedmann PD, Schutz E, Brenner-Weiss G et al.: Identification of glucoside and carboxyl-linked glucuronide conjugates of mycophenolic acid in plasma of transplant recipients treated with mycophenolate mofetil. Br J Pharmacol 1999, 126: 1075-1082.

34. Picard N, Cresteil T, Prémaud A, Marquet P: Characterization of a Phase 1 Metabolite of Mycophenolic Acid Produced by CYP3A4/5. Therapeutic Drug Monitoring 2004, 26.

35. Nowak I, Shaw LM: Mycophenolic acid binding to human serum albumin: characterization and relation to pharmacodynamics. Clinical Chemistry 1995, 41: 1011-1017.

36. Shipkova M, Armstrong VW, Oellerich M, Wieland E: Acyl glucuronide drug metabolites: toxicological and analytical implications. Ther Drug Monit 2003, 25: 1-16.

37. Maes BD, Dalle I, Geboes K, Oellerich M, Armstrong VW, Evenepoel P et al.: Erosive enterocolitis in mycophenolate mofetil-treated renal-transplant recipients with persistent afebrile diarrhea. Transplantation 2003, 75: 665-672.

38. Takekuma Y, Kakiuchi H, Yamazaki K, Miyauchi S, Kikukawa T, Kamo N et al.: Difference between pharmacokinetics of mycophenolic acid (MPA) in rats and that in humans is caused by different affinities of MRP2 to a glucuronized form. $J$ Pharm Pharm Sci 2007, 10: 71-85.

39. Bullingham R, Monroe S, Nicholls A, Hale M: Pharmacokinetics and bioavailability of mycophenolate mofetil in healthy subjects after single-dose oral and intravenous administration. J Clin Pharmacol 1996, 36: 315-324.

40. Fulton B, Markham A: Mycophenolate Mofetil: A Review of its Pharmacodynamic and Pharmacokinetic Properties and Clinical Efficacy in Renal Transplantation. Drugs 1996, 51.

41. Hesselink DA, Van Hest RM, Mathot RAA, Bonthuis F, Weimar W, De Bruin RWF et al.: Cyclosporine Interacts with Mycophenolic Acid by Inhibiting the Multidrug 
Resistance-Associated Protein 2. American Journal of Transplantation 2005, 5: 987994.

42. Arns W, Breuer S, Choudhury S, Taccard G, Lee J, Binder V et al.: Enteric-coated mycophenolate sodium delivers bioequivalent MPA exposure compared with mycophenolate mofetil. Clin Transplantation 2005, 19: 199-206.

43. Morath C, Reuter H, Simon V, Krautkramer E, Muranyi W, Schwenger V et al.: Effects of mycophenolic acid on human fibroblast proliferation, migration and adhesion in vitro and in vivo. Am J Transplant 2008, 8: 1786-1797.

44. Morath C, Zeier M: Review of the antiproliferative properties of mycophenolate mofetil in non-immune cells. Int J Clin Pharmacol Ther 2003, 41: 465-469.

45. Manitpisitkul W, Lee S, Cooper M: Mycophenolic acid agents: is enteric coating the answer? Transplant Research and Risk Management 2011, 3: 4553.

46. Baer PC, Gauer S, Hauser IA, Scherberich JE, Geiger H: Effects of mycophenolic acid on human renal proximal and distal tubular cells in vitro. Nephrol Dial Transplant 2000, 15: 184-190.

47. Mohacsi PJ, Tuller D, Hulliger B, Wijngaard PL: Different inhibitory effects of immunosuppressive drugs on human and rat aortic smooth muscle and endothelial cell proliferation stimulated by platelet-derived growth factor or endothelial cell growth factor. J Heart Lung Transplant 1997, 16: 484-492.

48. Monguilhott DE, Mendes de Cordova CM, Frode TS: Evidence of an anti-inflammatory effect of mycophenolate mofetil in a murine model of pleurisy. Exp Lung Res 2011.

49. Allison AC, Eugui EM: Purine metabolism and immunosuppressive effects of mycophenolate mofetil (MMF). Clin Transplant 1996, 10: 77-84.

50. Morath C, Schwenger V, Beimler J, Mehrabi A, Schmidt J, Zeier M et al.: Antifibrotic actions of mycophenolic acid. Clin Transplant 2006, 20 Suppl 17: 25-29.

51. Brandhorst G, Brehmer F, Petrova DT, Gross O, Miosge N, Armstrong VW et al.: Mycophenolic acid predose concentrations and renal function in a mouse model for progressive renal fibrosis. Ther Drug Monit 2010, 32: 73-78.

52. Petrova DT, Brandhorst G, Brehmer F, Gross O, Oellerich M, Armstrong VW: Mycophenolic acid displays IMPDH-dependent and IMPDH-independent effects on renal fibroblast proliferation and function. Ther Drug Monit 2010, 32: 405-412.

53. Tressler RJ, Garvin LJ, Slate DL: Anti-tumor activity of mycophenolate mofetil against human and mouse tumors in vivo. Int J Cancer 1994, 57: 568-573.

54. Koehl GE, Wagner F, Stoeltzing O, Lang SA, Steinbauer M, Schlitt HJ et al.: Mycophenolate mofetil inhibits tumor growth and angiogenesis in vitro but has variable antitumor effects in vivo, possibly related to bioavailability. Transplantation 2007, 83: 607-614. 
55. Floryk D, Huberman E: Mycophenolic acid-induced replication arrest, differentiation markers and cell death of androgen-independent prostate cancer cells DU145. Cancer Lett 2006, 231: 20-29.

56. Leckel K, Beecken WD, Jonas D, Oppermann E, Coman MC, Beck KF et al.: The immunosuppressive drug mycophenolate mofetil impairs the adhesion capacity of gastrointestinal tumour cells. Clin Exp Immunol 2003, 134: 238-245.

57. Orvis AK, Wesson SK, Breza TS, Church AA, Mitchell CL, Watkins SW: Mycophenolate mofetil in dermatology. Journal of the American Academy of Dermatology 2009, 60: 183-199.

58. Davies NM, Grinyo J, Heading R, Maes B, Meier-Kriesche HU, Oellerich M: Gastrointestinal side effects of mycophenolic acid in renal transplant patients: a reappraisal. Nephrol Dial Transplant 2007, 22: 2440-2448.

59. Jacqz-Aigrain E, Khan Shaghaghi E, Baudouin V, Popon M, Zhang D, Maisin A et al.: Pharmacokinetics and tolerance of mycophenolate mofetil in renal transplant children. Pediatric Nephrology 2000, 14: 95-99.

60. Nguyen T, Park JY, Scudiere JR, Montgomery E: Mycophenolic acid (cellcept and myofortic) induced injury of the upper Gl tract. Am J Surg Pathol 2009, 33: 1355-1363.

61. McDiarmid SV: Mycophenolate mofetil in liver transplantation. Clin Transplant 1996, 10: $140-145$.

62. Ducloux D, Ottignon Y, Semhoun-Ducloux S, Labbe S, Saint-Hillier Y, Miguet JP et al.: Mycophenolate mofetil-induced villous atrophy. Transplantation 1998, 66: 1115-1116.

63. Kamar N, Faure P, Dupuis E, Cointault O, Joseph-Hein K, Durand D et al.: Villous atrophy induced by mycophenolate mofetil in renal-transplant patients. Transpl Int 2004, 17: 463-467.

64. Dost D, van Leerdam ME, van Dekken $H$, Weimar W, Kuipers EJ, Bijl AH et al.: Crohn's-like enterocolitis associated with mycophenolic acid treatment. Gut 2008, 57: 1330.

65. Phatak UP, Seo-Mayer P, Jain D, Selbst M, Husain S, Pashankar DS: Mycophenolate mofetil-induced colitis in children. J Clin Gastroenterol 2009, 43: 967-969.

66. Mydlarski PR: Mycophenolate mofetil: a dermatologic perspective. Skin Therapy Lett 2005, 10: 1-6.

67. Roche Laboratories Inc.: Important changes in the CellCept® (mycophenolate mofetil) prescribing information: reports of progressive multifocal leukoencephalopathy (PML) in patients treated with CellCept. http://www rocheusa com/products/cellcept/CellceptLetterPML_May2008 pdf 2008, Accessed March 1, 2009.

68. Neff RT, Hurst FP, Falta EM, Bohen EM, Lentine KL, Dharnidharka VR et al.: Progressive Multifocal Leukoencephalopathy and Use of Mycophenolate Mofetil After Kidney Transplantation. Transplantation 2008, 86. 
69. Gross DC, Sasaki TM, Buick MK, Light JA: Acute Respiratory Failure and Pulmonary Fibrosis Secondary To Administration of Mycophenolate Mofetil. Transplantation 1997, 64: 1607-9.

70. Roche Laboratories Inc: Important Changes in the CellCept® (mycophenolate mofetil) Prescribing Information - Reports of Pure Red Cell Aplasia (PRCA) in Patients Treated with CellCept . http://www gene com/gene/products/information/cellcept/pdf/DM009_Dear_Doctor_Letter pdf 2009.

71. Pelletier RP, Akin B, Henry ML, Bumgardner GL, Elkhammas EA, Rajab A et al.: The impact of mycophenolate mofetil dosing patterns on clinical outcome after renal transplantation. Clinical Transplantation 2003, 17: 200-205.

72. Xia Z, Jun C, Hao C, Bing C, Min S, Jie X: The occurrence of diarrhea not related to the pharmacokinetics of MPA and its metabolites in liver transplant patients. European Journal of Clinical Pharmacology 2010, 66: 671-679.

73. Wieland E, Shipkova M, Schellhaas U, Schutz E, Niedmann PD, Armstrong VW et al.: Induction of cytokine release by the acyl glucuronide of mycophenolic acid: a link to side effects? Clin Biochem 2000, 33: 107-113.

74. Dost D, van Leerdam ME, van DH, Weimar W, Kuipers EJ, Bijl AH et al.: Crohn's-like enterocolitis associated with mycophenolic acid treatment. Gut 2008, 57: 1330.

75. Shipkova M, Armstrong VW, Weber L, Niedmann PD, Wieland E, Haley J et al.: Pharmacokinetics and protein adduct formation of the pharmacologically active acyl glucuronide metabolite of mycophenolic acid in pediatric renal transplant recipients. Ther Drug Monit 2002, 24: 390-399.

76. Asif AR, Armstrong VW, Voland A, Wieland E, Oellerich M, Shipkova M: Proteins identified as targets of the acyl glucuronide metabolite of mycophenolic acid in kidney tissue from mycophenolate mofetil treated rats. Biochimie 2007, 89: 393-402.

77. Shipkova M, Beck H, Voland A, Armstrong VW, Grone HJ, Oellerich M et al.: Identification of protein targets for mycophenolic acid acyl glucuronide in rat liver and colon tissue. Proteomics 2004, 4: 2728-2738.

78. Shipkova M, Spielbauer B, Voland A, Grone HJ, Armstrong VW, Oellerich M et al.: cDNA microarray analysis reveals new candidate genes possibly linked to side effects under mycophenolate mofetil therapy. Transplantation 2004, 78: 1145-1152.

79. Blikslager AT, Moeser AJ, Gookin JL, Jones SL, Odle J: Restoration of Barrier Function in Injured Intestinal Mucosa. Physiological Reviews 2007, 87: 545-564.

80. Turner HL, Turner JR: Good fences make good neighbors: Gastrointestinal mucosal structure. Gut Microbes 2010, 1: 22-29.

81. Sherwood L: Human physiology: from cells to system. 7th edition. Publisher: Yolanda Cossio 2010.

82. van der Flier LG, Clevers H: Stem Cells, Self-Renewal, and Differentiation in the Intestinal Epithelium. Annual Review of Physiology 2009, 71: 241-260. 
83. M++ller C, Autenrieth I, Peschel A: Intestinal epithelial barrier and mucosal immunity. Cellular and Molecular Life Sciences 2005, 62: 1297-1307.

84. Farhadi Ashk, Banan Ali, Fields Jere, Keshavarzian Ali: Intestinal barrier: An interface between health and disease. Journal of Gastroenterology and Hepatology 2003, 18: 479-497.

85. Müller C, Autenrieth I, Peschel A: Intestinal epithelial barrier and mucosal immunity. Cellular and Molecular Life Sciences 2005, 62: 1297-1307.

86. Blikslager AT, Moeser AJ, Gookin JL, Jones SL, Odle J: Restoration of barrier function in injured intestinal mucosa. Physiol Rev 2007, 87: 545-564.

87. Groschwitz KR, Hogan SP: Intestinal barrier function: molecular regulation and disease pathogenesis. J Allergy Clin Immunol 2009, 124: 3-20.

88. Smithson KW, Millar DB, Jacobs LR, Gray GM: Intestinal diffusion barrier: unstirred water layer or membrane surface mucous coat? Science 1981, 214: 1241-1244.

89. Qin X, Caputo FJ, Xu DZ, Deitch EA: Hydrophobicity of Mucosal Surface and Its Relationship To Gut Barrier Function. Shock 2008, 29.

90. Kunzelmann K, Mall M: Electrolyte transport in the mammalian colon: mechanisms and implications for disease. Physiol Rev 2002, 82: 245-289.

91. Barrett KE, Keely SJ: Chloride Secretion by the Intestinal Epithelium: Molecular Basis and Regulatory Aspects. Annual Review of Physiology 2000, 62: 535-572.

92. Dong-yan L, Weiguo J, Pei L: Reduction of the amount of intestinal secretory $\lg A$ in fulminant hepatic failure. Brazilian Journal of Medical and Biological Research 2011, 44: 477-482.

93. Greger R: Role of CFTR in the colon. Annu Rev Physiol 2000, 62: 467-491.

94. Spitz JC, Ghandi S, Taveras M, Aoys E, Alverdy JC: Characteristics of the intestinal epithelial barrier during dietary manipulation and glucocorticoid stress. Critical Care Medicine 1996, 24: 635-641.

95. Powell DW: Barrier function of epithelia. Am J Physiol 1981, G275-88.

96. Van Itallie CM, Anderson JM: Claudins and epithelial paracellular transport. Annu Rev Physiol 2006, 68: 403-429.

97. Schneeberger EE, Lynch RD: The tight junction: a multifunctional complex. $A m \mathrm{~J}$ Physiol Cell Physiol 2004, 286: C1213-C1228.

98. Schneeberger EE, Lynch RD: Tight junctions. Their structure, composition, and function. Circ Res 1984, 55: 723-733.

99. Gonzalez-Mariscal L, Betanzos A, Nava P, Jaramillo BE: Tight junction proteins. Prog Biophys Mol Biol 2003, 81: 1-44. 
100. Farquhar MG, Palade GE: Junctional complexes in various epithelila. JCB 1963, 17: 375-412.

101. Matter K, Balda MS: Signalling to and from tight junctions. Nat Rev Mol Cell Biol 2003, 4: $225-236$.

102. Shin K FVMB: Tight junctions and cell polarity. Annu Rev Cell Dev Biol 2006, 207-235.

103. Clayburgh DR, Shen L, Turner JR: A porous defense: the leaky epithelial barrier in intestinal disease. Lab Invest 2004, 84: 282-291.

104. Shen L, Weber CR, Raleigh DR, Yu D, Turner JR: Tight Junction Pore and Leak Pathways: A Dynamic Duo. Annual Review of Physiology 2011, 73: 283-309.

105. Stevenson BR, Siliciano JD, Mooseker MS, Goodenough DA: Identification of ZO-1: a high molecular weight polypeptide associated with the tight junction (zonula occludens) in a variety of epithelia. J Cell Biol 1986, 103: 755-766.

106. Gonzalez-Mariscal L, Betanzos A, Avila-Flores A: MAGUK proteins: structure and role in the tight junction. Semin Cell Dev Biol 2000, 11: 315-324.

107. Itoh M, Furuse M, Morita K, Kubota K, Saitou M, Tsukita S: Direct binding of three tight junction-associated MAGUKs, ZO-1, ZO-2, and ZO-3, with the $\mathrm{COOH}$ termini of claudins. J Cell Biol 1999, 147: 1351-1363.

108. Fanning AS, Jameson BJ, Jesaitis LA, Anderson JM: The tight junction protein ZO-1 establishes a link between the transmembrane protein occludin and the actin cytoskeleton. J Biol Chem 1998, 273: 29745-29753.

109. Schulzke JD, Fromm M: Tight junctions: molecular structure meets function. Ann N Y Acad Sci 2009, 1165: 1-6.

110. Walsh SV, Hopkins AM, Nusrat A: Modulation of tight junction structure and function by cytokines. Adv Drug Deliv Rev 2000, 41: 303-313.

111. Youakim A, Ahdieh M: Interferon-gamma decreases barrier function in T84 cells by reducing ZO-1 levels and disrupting apical actin. Am J Physiol 1999, 276: G1279G1288.

112. Ma TY, Nguyen D, Bui $\mathrm{V}$, Nguyen $\mathrm{H}, \mathrm{Hoa} \mathrm{N}$ : Ethanol modulation of intestinal epithelial tight junction barrier. Am J Physiol 1999, 276: G965-G974.

113. Musch MW, Walsh-Reitz MM, Chang EB: Roles of ZO-1, occludin, and actin in oxidant-induced barrier disruption. Am J Physiol Gastrointest Liver Physiol 2006, 290: G222-G231.

114. Furuse M, Itoh M, Hirase T, Nagafuchi A, Yonemura S, Tsukita S et al.: Direct association of occludin with ZO-1 and its possible involvement in the localization of occludin at tight junctions. J Cell Biol 1994, 127: 1617-1626.

115. Furuse M, Hirase T, Itoh M, Nagafuchi A, Yonemura S, Tsukita S et al.: Occludin: a novel integral membrane protein localizing at tight junctions. J Cell Biol 1993, 123: 1777-1788. 
116. Sanchez-Pulido L, Martin-Belmonte F, Valencia A, Alonso MA: MARVEL: a conserved domain involved in membrane apposition events. Trends Biochem Sci 2002, 27: 599601.

117. Tavelin S, Hashimoto K, Malkinson J, Lazorova L, Toth I, Artursson P: A new principle for tight junction modulation based on occludin peptides. Mol Pharmacol 2003, 64: 1530-1540.

118. Furuse $M$, Itoh $M$, Hirase $T$, Nagafuchi A, Yonemura S, Tsukita S et al.: Direct association of occludin with ZO-1 and its possible involvement in the localization of occludin at tight junctions. J Cell Biol 1994, 127: 1617-1626.

119. Al-Sadi R, Khatib K, Guo S, Ye D, Youssef M, Ma T: Occludin regulates macromolecule flux across the intestinal epithelial tight junction barrier. Am J Physiol Gastrointest Liver Physiol 2011, 300: G1054-G1064.

120. Ciccocioppo R, Finamore A, Ara C, Di SA, Mengheri E, Corazza GR: Altered expression, localization, and phosphorylation of epithelial junctional proteins in celiac disease. Am J Clin Pathol 2006, 125: 502-511.

121. Gassler N, Rohr C, Schneider A, Kartenbeck J, Bach A, Obermuller N et al.: Inflammatory bowel disease is associated with changes of enterocytic junctions. $\mathrm{Am} \mathrm{J}$ Physiol Gastrointest Liver Physiol 2001, 281: G216-G228.

122. Coeffier M, Gloro R, Boukhettala N, Aziz M, Lecleire S, Vandaele N et al.: Increased proteasome-mediated degradation of occludin in irritable bowel syndrome. $A m \mathrm{~J}$ Gastroenterol 2010, 105: 1181-1188.

123. Fries W, Mazzon E, Squarzoni S, Martin A, Martines D, Micali A et al.: Experimental colitis increases small intestine permeability in the rat. Lab Invest 1999, 79: 49-57.

124. Gassler N, Rohr C, Schneider A, Kartenbeck J, Bach A, Obermuller N et al:: Inflammatory bowel disease is associated with changes of enterocytic junctions. $\mathrm{Am} \mathrm{J}$ Physiol Gastrointest Liver Physiol 2001, 281: G216-G228.

125. Sakakibara A, Furuse M, Saitou M, Ando-Akatsuka Y, Tsukita S: Possible involvement of phosphorylation of occludin in tight junction formation. J Cell Biol 1997, 137: 13931401.

126. Rao R: Occludin phosphorylation in regulation of epithelial tight junctions. Ann $N Y$ Acad Sci 2009, 1165: 62-8.

127. Wong V: Phosphorylation of occludin correlates with occludin localization and function at the tight junction. Am J Physiol 1997, 273: 1859-1867.

128. Rao RK, Basuroy S, Rao VU, Karnaky Jr KJ, Gupta A: Tyrosine phosphorylation and dissociation of occludin-ZO-1 and E-cadherin-beta-catenin complexes from the cytoskeleton by oxidative stress. Biochem J 2002, 368: 471-481.

129. Atkinson KJ, Rao RK: Role of protein tyrosine phosphorylation in acetaldehydeinduced disruption of epithelial tight junctions. Am J Physiol Gastrointest Liver Physiol 2001, 280: G1280-G1288. 
130. Tsukita S, Furuse M, Itoh M: Multifunctional strands in tight junctions. Nat Rev Mol Cell Biol 2001, 2: 285-293.

131. Anderson JM, Van Itallie CM: Physiology and function of the tight junction. Cold Spring Harb Perspect Biol 2009, 1: a002584.

132. Yamazaki Y, Tokumasu R, Kimura H, Tsukita S: Role of claudin species-specific dynamics in reconstitution and remodeling of the zonula occludens. Mol Biol Cell 2011, 22: 1495-1504.

133. McCarthy KM, Francis SA, McCormack JM, Lai J, Rogers RA, Skare IB et al.: Inducible expression of claudin-1-myc but not occludin-VSV-G results in aberrant tight junction strand formation in MDCK cells. J Cell Sci 2000, 113 Pt 19: 3387-3398.

134. Fujita $\mathrm{H}$, Chiba $\mathrm{H}$, Yokozaki $\mathrm{H}$, Sakai $\mathrm{N}$, Sugimoto $\mathrm{K}$, Wada $\mathrm{T}$ et al.: Differential expression and subcellular localization of claudin-7, $-8,-12,-13$, and -15 along the mouse intestine. J Histochem Cytochem 2006, 54: 933-944.

135. Tamagawa H, Takahashi I, Furuse M, Yoshitake-Kitano Y, Tsukita S, Ito T et al.: Characteristics of claudin expression in follicle-associated epithelium of Peyer's patches: preferential localization of claudin-4 at the apex of the dome region. Lab Invest 2003, 83: 1045-1053.

136. Kucharzik T, Walsh SV, Chen J, Parkos CA, Nusrat A: Neutrophil transmigration in inflammatory bowel disease is associated with differential expression of epithelial intercellular junction proteins. Am J Pathol 2001, 159: 2001-2009.

137. Burgel N, Bojarski C, Mankertz J, Zeitz M, Fromm M, Schulzke JD: Mechanisms of diarrhea in collagenous colitis. Gastroenterology 2002, 123: 433-443.

138. Aktories K, Barbieri JT: Bacterial cytotoxins: targeting eukaryotic switches. Nat Rev Microbiol 2005, 3: 397-410.

139. Wang X, Li B, Zhao WD, Liu YJ, Shang DS, Fang WG et al.: Perfluorooctane sulfonate triggers tight junction "opening" in brain endothelial cells via phosphatidylinositol 3-kinase. Biochem Biophys Res Commun 2011, 410: 258-263.

140. Wolburg H, Wolburg-Buchholz K, Kraus J, Rascher-Eggstein G, Liebner S, Hamm S et al.: Localization of claudin-3 in tight junctions of the blood-brain barrier is selectively lost during experimental autoimmune encephalomyelitis and human glioblastoma multiforme. Acta Neuropathol 2003, 105: 586-592.

141. Takano K, Kojima T, Go M, Murata M, Ichimiya S, Himi T et al.: HLA-DR- and CD11Cpositive dendritic cells penetrate beyond well-developed epithelial tight junctions in human nasal mucosa of allergic rhinitis. J Histochem Cytochem 2005, 53: 611-619.

142. Assimakopoulos SF, Tsamandas AC, Louvros E, Vagianos CE, Nikolopoulou VN, Thomopoulos KC et al.: Intestinal epithelial cell proliferation, apoptosis and expression of tight junction proteins in patients with obstructive jaundice. Eur J Clin Invest 2011, 41: 117-125. 
143. Kwon O, Nelson WJ, Sibley R, Huie P, Scandling JD, Dafoe D et al.: Backleak, tight junctions, and cell- cell adhesion in postischemic injury to the renal allograft. $J$ Clin Invest 1998, 101: 2054-2064.

144. Sabath E, Denker BM: Cell-cell interactions in the kidney: inducible expression of mutant G protein alpha-subunits in Madin-Darby canine kidney cells for studies of epithelial cell junction structure and function. Methods Mol Biol 2006, 341: 61-72.

145. Felinski EA, Antonetti DA: Glucocorticoid regulation of endothelial cell tight junction gene expression: novel treatments for diabetic retinopathy. Curr Eye Res 2005, 30: 949-957.

146. Turksen K, Troy TC: Junctions gone bad: claudins and loss of the barrier in cancer. Biochim Biophys Acta 2011, 1816: 73-79.

147. Sawada N, Murata M, Kikuchi K, Osanai M, Tobioka H, Kojima T et al.: Tight junctions and human diseases. Med Electron Microsc 2003, 36: 147-156.

148. Salim SY, Soderholm JD: Importance of disrupted intestinal barrier in inflammatory bowel diseases. Inflamm Bowel Dis 2011, 17: 362-381.

149. Henderson P, van Limbergen JE, Schwarze J, Wilson DC: Function of the intestinal epithelium and its dysregulation in inflammatory bowel disease. Inflamm Bowel Dis 2011, 17: 382-395.

150. Clayburgh DR, Barrett TA, Tang Y, Meddings JB, Van Eldik LJ, Watterson DM et al.: Epithelial myosin light chain kinase-dependent barrier dysfunction mediates $\mathrm{T}$ cell activation-induced diarrhea in vivo. J Clin Invest 2005, 115: 2702-2715.

151. Hering NA, Schulzke JD: Therapeutic options to modulate barrier defects in inflammatory bowel disease. Dig Dis 2009, 27: 450-454.

152. Brown GR, Lindberg G, Meddings J, Silva M, Beutler B, Thiele D: Tumor necrosis factor inhibitor ameliorates murine intestinal graft-versus-host disease. Gastroenterology 1999, 116: 593-601.

153. Turner JR, Rill BK, Carlson SL, Carnes D, Kerner R, Mrsny RJ et al.: Physiological regulation of epithelial tight junctions is associated with myosin light-chain phosphorylation. Am J Physiol 1997, 273: C1378-C1385.

154. Lowe PJ, Miyai K, Steinbach JH, Hardison WG: Hormonal regulation of hepatocyte tight junctional permeability. Am J Physiol 1988, 255: G454-G461.

155. Kinoshita N, Takahashi T, Tada S, Shinozuka K, Mizuno N, Takahashi K: Activation of P2Y receptor enhances high-molecular compound absorption from rat ileum. J Pharm Pharmacol 2006, 58: 195-200.

156. Nusrat A, Parkos CA, Bacarra AE, Godowski PJ, Delp-Archer C, Rosen EM et al.: Hepatocyte growth factor/scatter factor effects on epithelia. Regulation of intercellular junctions in transformed and nontransformed cell lines, basolateral polarization of cmet receptor in transformed and natural intestinal epithelia, and induction of rapid wound repair in a transformed model epithelium. J Clin Invest 1994, 93: 2056-2065. 
157. Harhaj NS, Barber AJ, Antonetti DA: Platelet-derived growth factor mediates tight junction redistribution and increases permeability in MDCK cells. J Cell Physiol 2002, 193: 349-364.

158. Soler AP, Laughlin KV, Mullin JM: Effects of epidermal growth factor versus phorbol ester on kidney epithelial (LLC-PK1) tight junction permeability and cell division. Exp Cell Res 1993, 207: 398-406.

159. Söderholm JD, Perdue MH: II. Stress and intestinal barrier function. American Journal of Physiology - Gastrointestinal and Liver Physiology 2001, 280: G7-G13.

160. Ulluwishewa D, Anderson RC, McNabb WC, Moughan PJ, Wells JM, Roy NC: Regulation of Tight Junction Permeability by Intestinal Bacteria and Dietary Components. J Nutr 2011, 141: 769-776.

161. Drago S, El Asmar R, Di Pierro M, Grazia Clemente M, Sapone ATA, Thakar M et al.: Gliadin, zonulin and gut permeability: Effects on celiac and non-celiac intestinal mucosa and intestinal cell lines. Scandinavian Journal of Gastroenterology 2006, 41: 408-419.

162. Amasheh S, Barmeyer C, Koch CS, Tavalali S, Mankertz J, Epple HJ et al.: Cytokinedependent transcriptional down-regulation of epithelial sodium channel in ulcerative colitis. Gastroenterology 2004, 126: 1711-1720.

163. Barmeyer C, Amasheh S, Tavalali S, Mankertz J, Zeitz M, Fromm M et al.: IL-1beta and TNF alpha regulate sodium absorption in rat distal colon. Biochem Biophys Res Commun 2004, 317: 500-507.

164. Schmitz H, Barmeyer C, Gitter AH, Wullstein F, Bentzel CJ, Fromm M et al.: Epithelial barrier and transport function of the colon in ulcerative colitis. Ann N Y Acad Sci 2000, 915: 312-326.

165. Grotjohann I, Schmitz H, Fromm M, Schulzke JD: Effect of TNF alpha and IFN gamma on epithelial barrier function in rat rectum in vitro. Ann N Y Acad Sci 2000, 915: 282286.

166. Stefanelli T, Malesci A, Repici A, Vetrano S, Danese S: New insights into inflammatory bowel disease pathophysiology: paving the way for novel therapeutic targets. Curr Drug Targets 2008, 9: 413-418.

167. Suenaert P, Bulteel V, Lemmens L, Noman M, Geypens B, Van AG et al.: Anti-tumor necrosis factor treatment restores the gut barrier in Crohn's disease. $A m \mathrm{~J}$ Gastroenterol 2002, 97: 2000-2004.

168. Zolotarevsky Y, Hecht G, Koutsouris A, Gonzalez DE, Quan C, Tom J et al.: A membrane-permeant peptide that inhibits MLC kinase restores barrier function in in vitro models of intestinal disease. Gastroenterology 2002, 123: 163-172.

169. Clayburgh DR, Musch MW, Leitges M, Fu YX, Turner JR: Coordinated epithelial NHE3 inhibition and barrier dysfunction are required for TNF-mediated diarrhea in vivo. $J$ Clin Invest 2006, 116: 2682-2694. 
170. Marchiando AM, Graham WV, Turner JR: Epithelial barriers in homeostasis and disease. Annu Rev Pathol 2010, 5: 119-144.

171. Santos J, Yang PC, Söderholm JD, Benjamin M, Perdue MH: Role of mast cells in chronic stress induced colonic epithelial barrier dysfunction in the rat. Gut 2001, 48: 630-636.

172. O'Sullivan M, Clayton, Breslin, Harman, Bountra, Mclaren et al.: Increased mast cells in the irritable bowel syndrome. Neurogastroenterology \& Motility 2000, 12: 449-457.

173. Alican I, Kubes P: A critical role for nitric oxide in intestinal barrier function and dysfunction. American Journal of Physiology - Gastrointestinal and Liver Physiology 1996, 270: G225-G237.

174. Berkes J, Viswanathan VK, Savkovic SD, Hecht G: Intestinal epithelial responses to enteric pathogens: effects on the tight junction barrier, ion transport, and inflammation. Gut 2003, 52: 439-451.

175. García-Lafuente A, Antolín M, Guarner F, Crespo E, Malagelada JR: Modulation of colonic barrier function by the composition of the commensal flora in the rat. Gut 2001, 48: 503-507.

176. Davidson G, Kritas S, Butler R: Stressed mucosa. Nestle Nutr Workshop Ser Pediatr Program 2007, 59: 133-142.

177. Rao R: Oxidative stress-induced disruption of epithelial and endothelial tight junctions. Front Biosci 2008, 1: 7210-26.

178. Anderson JM, Balda MS, Fanning AS: The structure and regulation of tight junctions. Curr Opin Cell Biol 1993, 5: 772-778.

179. Balda MS, Gonzalez-Mariscal L, Contreras RG, Macias-Silva M, Torres-Marquez ME, Garcia-Sainz JA et al.: Assembly and sealing of tight junctions: possible participation of G-proteins, phospholipase C, protein kinase C and calmodulin. J Membr Biol 1991, 122: 193-202.

180. Madara JL, Parkos C, Colgan S, Nusrat A, Atisook K, Kaoutzani P: The movement of solutes and cells across tight junctions. Ann N Y Acad Sci 1992, 664: 47-60.

181. Gonzalez-Mariscal L, Tapia R, Chamorro D: Crosstalk of tight junction components with signaling pathways. Biochim Biophys Acta 2008, 1778: 729-756.

182. Anderson JM, Van Itallie CM: Tight junctions and the molecular basis for regulation of paracellular permeability. Am J Physiol 1995, 269: G467-G475.

183. Hartsock A, Nelson WJ: Adherens and tight junctions: structure, function and connections to the actin cytoskeleton. Biochim Biophys Acta 2008, 1778: 660-669.

184. Shen L, Black ED, Witkowski ED, Lencer WI, Guerriero V, Schneeberger EE et al.: Myosin light chain phosphorylation regulates barrier function by remodeling tight junction structure. J Cell Sci 2006, 119: 2095-2106. 
185. Madara JL: Intestinal absorptive cell tight junctions are linked to cytoskeleton. Am J Physiol 1987, 253: C171-5.

186. Shen L, Su L, Turner JR: Mechanisms and functional implications of intestinal barrier defects. Dig Dis 2009, 27: 443-449.

187. Staddon JM, Herrenknecht K, Smales C, Rubin LL: Evidence that tyrosine phosphorylation may increase tight junction permeability. J Cell Sci 1995, 108: 609619.

188. Tsukamoto T, Nigam SK: Role of tyrosine phosphorylation in the reassembly of occludin and other tight junction proteins. Am J Physiol 1999, 276: F737-F750.

189. Gopalakrishnan S, Raman N, Atkinson SJ, Marrs JA: Rho GTPase signaling regulates tight junction assembly and protects tight junctions during ATP depletion. Am J Physiol 1998, 275: C798-C809.

190. Bruewer M, Hopkins AM, Hobert ME, Nusrat A, Madara JL: RhoA, Rac1, and Cdc42 exert distinct effects on epithelial barrier via selective structural and biochemical modulation of junctional proteins and F-actin. Am J Physiol Cell Physiol 2004, 287: C327-C335.

191. Terry S, Nie M, Matter K, Balda MS: Rho signaling and tight junction functions. Physiology (Bethesda) 2010, 25: 16-26.

192. Raleigh DR, Boe DM, Yu D, Weber CR, Marchiando AM, Bradford EM et al.: Occludin S408 phosphorylation regulates tight junction protein interactions and barrier function. J Cell Biol 2011, 193: 565-582.

193. Fujibe M, Chiba H, Kojima T, Soma T, Wada T, Yamashita T et al.: Thr203 of claudin1, a putative phosphorylation site for MAP kinase, is required to promote the barrier function of tight junctions. Exp Cell Res 2004, 295: 36-47.

194. Nusrat A, Giry M, Turner JR, Colgan SP, Parkos CA, Carnes D et al.: Rho protein regulates tight junctions and perijunctional actin organization in polarized epithelia. Proceedings of the National Academy of Sciences 1995, 92: 10629-10633.

195. Al-Sadi R, Ye D, Said HM, Ma TY: Cellular and molecular mechanism of interleukin1 beta modulation of Caco-2 intestinal epithelial tight junction barrier. J Cell Mol Med 2011, 15: 970-982.

196. Al-Sadi RM, Ma TY: IL-1beta causes an increase in intestinal epithelial tight junction permeability. J Immunol 2007, 178: 4641-4649.

197. Moriez R, Salvador-Cartier C, Theodorou V, Fioramonti J, Eutamene H, Bueno L: Myosin light chain kinase is involved in lipopolysaccharide-induced disruption of colonic epithelial barrier and bacterial translocation in rats. Am J Pathol 2005, 167: 1071-1079.

198. Rao RK.: Acetaldehyde-induced barrier disruption and paracellular permeability in Caco-2 cell monolayer. Methods Mol Biol 2008, 447: 171-183. 
199. Yuhan R, Koutsouris A, Savkovic SD, Hecht G: Enteropathogenic Escherichia coliinduced myosin light chain phosphorylation alters intestinal epithelial permeability. Gastroenterology 1997, 113: 1873-1882.

200. Manjarrez-Hernandez HA, Baldwin TJ, Williams PH, Haigh R, Knutton S, Aitken A: Phosphorylation of myosin light chain at distinct sites and its association with the cytoskeleton during enteropathogenic Escherichia coli infection. Infect Immun 1996, 64: 2368-2370.

201. Fedwick JP, Lapointe TK, Meddings JB, Sherman PM, Buret AG: Helicobacter pylori activates myosin light-chain kinase to disrupt claudin-4 and claudin-5 and increase epithelial permeability. Infect Immun 2005, 73: 7844-7852.

202. Wroblewski LE, Shen L, Ogden S, Romero-Gallo J, Lapierre LA, Israel DA et al.: Helicobacter pylori dysregulation of gastric epithelial tight junctions by ureasemediated myosin II activation. Gastroenterology 2009, 136: 236-246.

203. Scott KG, Meddings JB, Kirk DR, Lees-Miller SP, Buret AG: Intestinal infection with Giardia spp. reduces epithelial barrier function in a myosin light chain kinasedependent fashion. Gastroenterology 2002, 123: 1179-1190.

204. Walsh SV, Hopkins AM, Chen J, Narumiya S, Parkos CA, Nusrat A: Rho kinase regulates tight junction function and is necessary for tight junction assembly in polarized intestinal epithelia. Gastroenterology 2001, 121: 566-579.

205. Koizumi Ji, Kojima T, Ogasawara N, Kamekura R, Kurose M, Go M et al.: Protein Kinase $\mathrm{C}$ enhances tight junction barrier function of human nasal epithelial cells in primary culture by transcriptional regulation. Molecular Pharmacology 2008, 74: 432442.

206. Banan A, Zhang LJ, Shaikh M, Fields JZ, Choudhary S, Forsyth CB et al.: Theta isoform of protein kinase $C$ Alters barrier function in intestinal epithelium through modulation of distinct claudin isotypes: A novel mechanism for regulation of permeability. Journal of Pharmacology and Experimental Therapeutics 2005, 313: 962-982.

207. Turner JR, Angle JM, Black ED, Joyal JL, Sacks DB, Madara JL: PKC-dependent regulation of transepithelial resistance: roles of MLC and MLC kinase. American Journal of Physiology - Cell Physiology 1999, 277: C554-C562.

208. Basuroy S, Seth A, Elias B, Naren AP, Rao R: MAPK interacts with occludin and mediates EGF-induced prevention of tight junction disruption by hydrogen peroxide. Biochem J 2006, 393: 69-77.

209. Samak G, Aggarwal S, Rao RK: ERK is involved in EGF-mediated protection of tight junctions, but not adherens junctions, in acetaldehyde-treated Caco-2 cell monolayers. American Journal of Physiology - Gastrointestinal and Liver Physiology 2011, 301: G50-G59.

210. Cereijido M, Robbins ES, Dolan WJ, Rotunno CA, Sabatini DD: Polarized monolayers formed by epithelial cells on a permeable and translucent support. J Cell Biol 1978, 77: 853-880. 
211. Balimane PV, Chong S: Cell culture-based models for intestinal permeability: a critique. Drug Discov Today 2005, 10: 335-343.

212. Balimane PV, Chong S, Morrison RA: Current methodologies used for evaluation of intestinal permeability and absorption. J Pharmacol Toxicol Methods 2000, 44: 301312.

213. Madara JL: Regulation of the movement of solutes across tight junctions. Annu Rev Physiol 1998, 60: 143-159.

214. Weber CR, Raleigh DR, Su L, Shen L, Sullivan EA, Wang Y et al.: Epithelial myosin light chain kinase activation induces mucosal interleukin-13 expression to alter tight junction ion selectivity. J Biol Chem 2010, 285: 12037-12046.

215. Yu D, Marchiando AM, Weber CR, Raleigh DR, Wang $Y$, Shen $L$ et al.: MLCKdependent exchange and actin binding region-dependent anchoring of ZO-1 regulate tight junction barrier function. Proc Natl Acad Sci U S A 2010, 107: 8237-8241.

216. Hidalgo IJ, Raub TJ, Borchardt RT: Characterization of the human colon carcinoma cell line (Caco-2) as a model system for intestinal epithelial permeability. Gastroenterology 1989, 96: 736-749.

217. Wilson G, Hassan IF, Dix CJ, Williamson I, Shah R, Mackay M et al.: Transport and permeability properties of human Caco-2 cells: An in vitro model of the intestinal epithelial cell barrier. Journal of Controlled Release 1990, 11: 25-40.

218. Sambruy Y, Ferruzza S, Ranaldi G, de A, I: Intestinal cell culture models: applications in toxicology and pharmacology. Cell Biol Toxicol 2001, 17: 301-317.

219. Fogh J, Fogh JM, Orfeo T: One hundred and twenty-seven cultured human tumor cell lines producing tumors in nude mice. J Natl Cancer Inst 1977, 59: 221-226.

220. Braun A, Hammerle S, Suda K, Rothen-Rutishauser B, Gunthert M, Kramer SD et al.: Cell cultures as tools in biopharmacy. Eur J Pharm Sci 2000, 11 Suppl 2: S51-S60.

221. Pinto M., Robine LS., Appay D., Kedinger M., Triadou N., Dussaulx E. et al.: Enterocyte-like differentiation and polarization of the human colon carcinoma cell line Caco-2 in culture . Biol Cell 1983, 47: 323-330.

222. Delie F, Rubas W: A human colonic cell line sharing similarities with enterocytes as a model to examine oral absorption: advantages and limitations of the Caco-2 model. Crit Rev Ther Drug Carrier Syst 1997, 14: 221-286.

223. Ward PD, Tippin TK, Thakker DR: Enhancing paracellular permeability by modulating epithelial tight junctions. Pharm Sci Technolo Today 2000, 3: 346-358.

224. Borlak J, Zwadlo C: Expression of drug-metabolizing enzymes, nuclear transcription factors and ABC transporters in Caco-2 cells. Xenobiotica 2003, 33: 927-943.

225. Artursson $\mathrm{P}$, Karlsson J: Correlation between oral drug absorption in humans and apparent drug permeability coefficients in human intestinal epithelial (Caco-2) cells. Biochemical and Biophysical Research Communications 1991, 175: 880-885. 
226. Artursson P: Cell cultures as models for drug absorption across the intestinal mucosa. Rev Ther Drug Carrier Syst 1991, 8: 305-330.

227. Quaroni A, Hochman J: Development of intestinal cell culture models for drug transport and metabolism studies. Advanced Drug Delivery Reviews 1996, 22: 3-52.

228. Hartmann F, Owen R, Bissell DM: Characterization of isolated epithelial cells from rat small intestine. Am J Physiol 1982, 242: G147-G155.

229. Gumbiner B, Simons K: A functional assay for proteins involved in establishing an epithelial occluding barrier: identification of a uvomorulin-like polypeptide. J Cell Biol 1986, 102: 457-468.

230. Staddon JM, Herrenknecht K, Smales C, Rubin LL: Evidence that tyrosine phosphorylation may increase tight junction permeability. J Cell Sci 1995, 108: 609619.

231. Lo CM, Keese CR, Giaever I: Cell-substrate contact: another factor may influence transepithelial electrical resistance of cell layers cultured on permeable filters. Exp Cell Res 1999, 250: 576-580.

232. Balimane PV, Chong S, Morrison RA: Current methodologies used for evaluation of intestinal permeability and absorption. Journal of Pharmacological and Toxicological Methods 2007, 44: 301-312.

233. Harhaj NS, Antonetti DA: Regulation of tight junctions and loss of barrier function in pathophysiology. The International Journal of Biochemistry \& Cell Biology 2004, 36: 1206-1237.

234. Claude P: Morphological factors influencing transepithelial permeability: A model for the resistance of the Zonula Occludens. Journal of Membrane Biology 1978, 39: 219232.

235. Obert G, Peiffer I, Servin AL: Rotavirus-induced structural and functional alterations in tight junctions of polarized intestinal Caco-2 cell monolayers. J Virol 2000, 74: 46454651 .

236. Al-Sadi R, Ye D, Said HM, Ma TY: Cellular and molecular mechanism of interleukin1beta modulation of Caco-2 intestinal epithelial tight junction barrier. $J$ Cell Mol Med 2011, 15: 970-982.

237. Ma TY, Iwamoto GK, Hoa NT, Akotia V, Pedram A, Boivin MA et al.: TNF-alphainduced increase in intestinal epithelial tight junction permeability requires NF-kappa B activation. Am J Physiol Gastrointest Liver Physiol 2004, 286: G367-G376.

238. Kawedia JD, Jiang M, Kulkarni A, Waechter HE, Matlin KS, Pauletti GM et al.: The protein kinase A pathway contributes to $\mathrm{Hg} 2+$-induced alterations in phosphorylation and subcellular distribution of occludin associated with increased tight junction permeability of salivary epithelial cell monolayers. J Pharmacol Exp Ther 2008, 326: 829-837.

239. Schipper NGM, Vsrum KM, Stenberg P, Ocklind Gr, LennernSs H, Artursson P: Chitosans as absorption enhancers of poorly absorbable drugs: 3: Influence of mucus 
on absorption enhancement. European Journal of Pharmaceutical Sciences 1999, 8: 335-343.

240. Cui W, Li LX, Sun CM, Wen Y, Zhou Y, Dong YL et al.: Tumor necrosis factor alpha increases epithelial barrier permeability by disrupting tight junctions in Caco-2 cells. Braz J Med Biol Res 2010, 43: 330-337.

241. Dvorak HF, Nagy JA, Feng D, Brown LF, Dvorak AM: Vascular permeability factor/vascular endothelial growth factor and the significance of microvascular hyperpermeability in angiogenesis. Curr Top Microbiol Immunol 1999, 237: 97-132.

242. Messina E, Gazzaniga P, Micheli V, Guaglianone MR, Barbato S, Morrone S et al.: Guanine nucleotide depletion triggers cell cycle arrest and apoptosis in human neuroblastoma cell lines. Int J Cancer 2004, 108: 812-817.

243. Nagai M, Natsumeda $Y$, Konno $Y$, Hoffman R, Irino S, Weber G: Selective upregulation of type II inosine 5'-monophosphate dehydrogenase messenger RNA expression in human leukemias. Cancer Res 1991, 51: 3886-3890.

244. Park YJ, Ahn HJ, Chang HK, Kim JY, Huh KH, Kim MS et al.: The RhoGDI-alpha/JNK signaling pathway plays a significant role in mycophenolic acid-induced apoptosis in an insulin-secreting cell line. Cell Signal 2009, 21: 356-364.

245. von VS, Ouyang H, Ley K: Mycophenolic acid suppresses granulopoiesis by inhibition of interleukin-17 production. Kidney Int 2010, 79-88.

246. Ha H, Kim MS, Park J, Huh JY, Huh KH, Ahn HJ et al.: Mycophenolic acid inhibits mesangial cell activation through p38 MAPK inhibition. Life Sci 2006, 79: 1561-1567.

247. Heller T, Asif AR, Petrova DT, Doncheva Y, Wieland E, Oellerich M et al.: Differential proteomic analysis of lymphocytes treated with mycophenolic acid reveals caspase 3induced cleavage of rho GDP dissociation inhibitor 2. Ther Drug Monit 2009, 31:211217.

248. Villarroel MC, Hidalgo M, Jimeno A: Mycophenolate mofetil: An update. Drugs Today (Barc) 2009, 45: 521-532.

249. Van den Branden C, Ceyssens B, Pauwels M, Van WG, Heirman I, Jie N et al.: Effect of mycophenolate mofetil on glomerulosclerosis and renal oxidative stress in rats. Nephron Exp Nephrol 2003, 95: e93-e99.

250. Stassen PM, Kallenberg CG, Stegeman CA: Use of mycophenolic acid in nontransplant renal diseases. Nephrol Dial Transplant 2007, 22: 1013-1019.

251. Shipkova M, Armstrong VW, Oellerich M, Wieland E: Mycophenolate mofetil in organ transplantation: focus on metabolism, safety and tolerability. Expert Opin Drug Metab Toxicol 2005, 1: 505-526.

252. Bradford MM: A rapid and sensitive method for the quantitation of microgram quantities of protein utilizing the principle of protein-dye binding. Anal Biochem 1976, 72: $248-254$. 
253. Asif AR, Armstrong VW, Voland A, Wieland E, Oellerich M, Shipkova M: Proteins identified as targets of the acyl glucuronide metabolite of mycophenolic acid in kidney tissue from mycophenolate mofetil treated rats. Biochimie 2007, 89: 393-402.

254. Gorg A, Obermaier C, Boguth G, Harder A, Scheibe B, Wildgruber R et al.: The current state of two-dimensional electrophoresis with immobilized $\mathrm{pH}$ gradients. Electrophoresis 2000, 21: 1037-1053.

255. blum $\mathrm{H}$, Beier $\mathrm{H}$, Gross $\mathrm{HJ}$ : Improved silver staining of plant proteins, RNA and DNA in polyacrylamide gels. Electrophoresis 1987, 8: 93-99.

256. Luhn S, Berth M, Hecker M, Bernhardt J: Using standard positions and image fusion to create proteome maps from collections of two-dimensional gel electrophoresis images. Proteomics 2003, 3: 1117-1127.

257. Shevchenko A, Wilm M, Vorm O, Mann M: Mass spectrometric sequencing of proteins silver-stained polyacrylamide gels. Anal Chem 1996, 68: 850-858.

258. Tatusov RL, Fedorova ND, Jackson JD, Jacobs AR, Kiryutin B, Koonin EV et al.: The COG database: an updated version includes eukaryotes. BMC Bioinformatics 2003, 4: 41.

259. Rozen S, Skaletsky H: Primer3 on the WWW for general users and for biologist programmers. Methods Mol Biol 2000, 132: 365-386.

260. Schmittgen TD, Livak KJ: Analyzing real-time PCR data by the comparative $C(T)$ method. Nat Protoc 2008, 3: 1101-1108.

261. Hubner GI, Eismann R, Sziegoleit W: Relationship between mycophenolate mofetil side effects and mycophenolic acid plasma trough levels in renal transplant patients. Arzneimittelforschung 2000, 50: 936-940.

262. Prat O, Berenguer F, Malard V, Tavan E, Sage N, Steinmetz G et al.: Transcriptomic and proteomic responses of human renal HEK293 cells to uranium toxicity.

Proteomics 2005, 5: 297-306.

263. MacDonald ML, Lamerdin J, Owens S, Keon BH, Bilter GK, Shang Z et al.: Identifying off-target effects and hidden phenotypes of drugs in human cells. Nat Chem Biol 2006, 2: 329-337.

264. Sohn SH, Ko E, Jo Y, Kim SH, Kim Y, Shin M et al.: The genome-wide expression profile of Paeonia suffruticosa-treated cisplatin-stimulated HEK 293 cells. Environ Toxicol Pharmacol 2009, 28: 453-458.

265. Suizu F, Ueda K, Iwasaki T, Murata-Hori M, Hosoya H: Activation of Action-Activated MgATPase Activity of Myosin II by Phyosphorylation with MAPK-Activated Protein Kinase-1b (RSK-2). Journal of Biochemistry 2000, 128: 435-440.

266. Mondin M, Moreau V, Genot E, Combe C, Ripoche J, Dubus I: Alterations in cytoskeletal protein expression by mycophenolic acid in human mesangial cells requires Rac inactivation. Biochem Pharmacol 2007, 73: 1491-1498. 
267. Dubus I, L'Azou B, Gordien M, Delmas Y, Labouyrie JP, Bonnet J et al.: Cytoskeletal reorganization by mycophenolic acid alters mesangial cell migration and contractility. Hypertension 2003, 42: 956-961.

268. Yuan SY, Wu MH, Ustinova EE, Guo M, Tinsley JH, De LP et al.: Myosin light chain phosphorylation in neutrophil-stimulated coronary microvascular leakage. Circ Res 2002, 90: 1214-1221.

269. Zhao Y, Rhoades RA, Packer CS: Hypoxia-induced pulmonary arterial contraction appears to be dependent on myosin light chain phosphorylation. Am J Physiol 1996, 271: L768-L774.

270. Ishii T, Yanagawa T: Stress-induced peroxiredoxins. Subcell Biochem 2007, 44: 375384.

271. Neumann CA, Krause DS, Carman CV, Das S, Dubey DP, Abraham JL et al.: Essential role for the peroxiredoxin Prdx1 in erythrocyte antioxidant defence and tumour suppression. Nature 2003, 424: 561-565.

272. Mowbray AL, Kang DH, Rhee SG, Kang SW, Jo H: Laminar shear stress up-regulates peroxiredoxins (PRX) in endothelial cells: PRX 1 as a mechanosensitive antioxidant. J Biol Chem 2008, 283: 1622-1627.

273. Schreibelt G, van HJ, Haseloff RF, Reijerkerk A, van der Pol SM, Nieuwenhuizen O et al.: Protective effects of peroxiredoxin-1 at the injured blood-brain barrier. Free Radic Biol Med 2008, 45: 256-264.

274. Jung JY, Kang GC, Jeong YJ, Kim SH, Kwak YG, Kim WJ: Proteomic analysis in cyclosporin A-induced overgrowth of human gingival fibroblasts. Biol Pharm Bull 2009, 32: 1480-1485.

275. de CM, Silva S, Cruz D, Basso F, Corradi V, Lentini P et al.: Oxidative stress and 'monocyte reprogramming' after kidney transplant: a longitudinal study. Blood Purif 2008, 26: 105-110.

276. Land W, Vincenti F: Toxicity-sparing protocols using mycophenolate mofetil in renal transplantation. Transplantation 2005, 80: S221-S234.

277. Cao J, Schulte J, Knight A, Leslie NR, Zagozdzon A, Bronson R et al.: Prdx1 inhibits tumorigenesis via regulating PTEN/AKT activity. EMBO J 2009, 28: 1505-1517.

278. Yanagawa T, Iwasa S, Ishii T, Tabuchi K, Yusa H, Onizawa K et al.: Peroxiredoxin I expression in oral cancer: a potential new tumor marker. Cancer Lett 2000, 156: 2735.

279. Hoshino I, Matsubara H, Hanari N, Mori M, Nishimori T, Yoneyama Y et al.: Histone deacetylase Inhibitor FK228 activates tumor suppressor Prdx1 with apoptosis induction in esophageal cancer cells. Clin Cancer Res 2011, 11: 7945-7952.

280. Rawe VY, Payne C, Schatten G: Profilin and actin-related proteins regulate microfilament dynamics during early mammalian embryogenesis. Hum Reprod 2006, 21: 1143-1153. 
281. Das T, Bae YH, Wells A, Roy P: Profilin-1 overexpression upregulates PTEN and suppresses AKT activation in breast cancer cells. J Cell Physiol 2009, 218: 436-443.

282. Zou L, Ding Z, Roy P: Profilin-1 overexpression inhibits proliferation of MDA-MB-231 breast cancer cells partly through p27kip1 upregulation. J Cell Physiol 2010, 223: 623629.

283. Rubin $\mathrm{Cl}$, Atweh GF: The role of stathmin in the regulation of the cell cycle. J Cell Biochem 2004, 93: 242-250.

284. Feichtiger H, Wieland E, Armstrong VW, Shipkova M: The acyl glucuronide metabolite of mycophenolic acid induces tubulin polymerization in vitro. Clin Biochem 2010, 43: 208-213.

285. Miyashita H, Kanemura M, Yamazaki T, Abe M, Sato Y: Vascular endothelial zinc finger 1 is involved in the regulation of angiogenesis: possible contribution of stathmin/OP18 as a downstream target gene. Arterioscler Thromb Vasc Biol 2004, 24: 878-884.

286. Alli E, Yang JM, Hait WN: Silencing of stathmin induces tumor-suppressor function in breast cancer cell lines harboring mutant p53. Oncogene 2007, 26: 1003-1012.

287. Liu F, Rong YP, Zeng LC, Zhang X, Han ZG: Isolation and characterization of a novel human thioredoxin-like gene hTLP19 encoding a secretory protein. Gene 2003, 315: 71-78.

288. Trotta R, Ciarlariello D, Dal CJ, Allard J, Neviani P, Santhanam R et al.: The PP2A inhibitor SET regulates natural killer cell IFN-gamma production. J Exp Med 2007, 204: 2397-2405.

289. Seo SB, McNamara P, Heo S, Turner A, Lane WS, Chakravarti D: Regulation of histone acetylation and transcription by INHAT, a human cellular complex containing the set oncoprotein. Cell 2001, 104: 119-130.

290. Sontag E: Protein phosphatase 2A: the Trojan Horse of cellular signaling. Cell Signal 2001, 13: 7-16.

291. Neviani P, Santhanam R, Trotta R, Notari M, Blaser BW, Liu S et al.: The tumor suppressor PP2A is functionally inactivated in blast crisis CML through the inhibitory activity of the BCR/ABL-regulated SET protein. Cancer Cell 2005, 8: 355-368.

292. Sun XX, Dai MS, Lu H: Mycophenolic acid activation of p53 requires ribosomal proteins L5 and L11. J Biol Chem 2008, 283: 12387-12392.

293. Wu D, Ingram A, Lahti JH, Mazza B, Grenet J, Kapoor A et al.: Apoptotic release of histones from nucleosomes. J Biol Chem 2002, 277: 12001-12008.

294. Spencer VA, Davie JR: Role of covalent modifications of histones in regulating gene expression. Gene 1999, 240: 1-12.

295. Petrova DT, Heller T, Hitt R, Wieland E, Oellerich M, Armstrong VW et al.: Regulation of IL2 and NUCB1 in mononuclear cells treated with acyl glucuronide of mycophenolic 
acid reveals effects independent of inosine monophosphate dehydrogenase inhibition. Ther Drug Monit 2009, 31: 31-41.

296. Huang M, Ji Y, Itahana K, Zhang Y, Mitchell B: Guanine nucleotide depletion inhibits pre-ribosomal RNA synthesis and causes nucleolar disruption. Leuk Res 2008, 32: 131-141.

297. Yoshioka N, Wang L, Kishimoto K, Tsuji T, Hu GF: A therapeutic target for prostate cancer based on angiogenin-stimulated angiogenesis and cancer cell proliferation. Proc Natl Acad Sci U S A 2006, 103: 14519-14524.

298. Sanchez-Alcazar JA, Khodjakov A, Schneider E: Anticancer drugs induce increased mitochondrial cytochrome c expression that precedes cell death. Cancer Res 2001, 61: 1038-1044.

299. Taylor PR, Carugati A, Fadok VA, Cook HT, Andrews M, Carroll MC et al.: A hierarchical role for classical pathway complement proteins in the clearance of apoptotic cells in vivo. J Exp Med 2000, 192: 359-366.

300. Botto M, Dell'Agnola C, Bygrave AE, Thompson EM, Cook HT, Petry F et al.: Homozygous $\mathrm{C} 1 \mathrm{q}$ deficiency causes glomerulonephritis associated with multiple apoptotic bodies. Nat Genet 1998, 19: 56-59.

301. Matter K, Balda MS: Signalling to and from tight junctions. Nat Rev Mol Cell Biol 2003, 4: 225-236.

302. Steed E, Balda MS, Matter K: Dynamics and functions of tight junctions. Trends Cell Biol 2010, 20: 142-149.

303. Catalioto RM, Maggi CA, Giuliani S: Intestinal epithelial barrier dysfunction in disease and possible therapeutical interventions. Curr Med Chem 2011, 18: 398-426.

304. Shin K, Fogg VC, Margolis B: Tight junctions and cell polarity. Annu Rev Cell Dev Biol 2006, 22: 207-235.

305. Helderman $\mathrm{JH}$ : Prophylaxis and treatment of gastrointestinal complications following transplantation. Clin Transplant 2001, 15 Suppl 4: 29-35.

306. Arslan H, Inci EK, Azap OK, Karakayali H, Torgay A, Haberal M: Etiologic agents of diarrhea in solid organ recipients. Transpl Infect Dis 2007, 9: 270-275.

307. Helderman JH, Goral S: Gastrointestinal complications of transplant immunosuppression. J Am Soc Nephrol 2002, 13: 277-287.

308. Ponticelli C, Passerini P: Gastrointestinal complications in renal transplant recipients. Transpl Int 2005, 18: 643-650.

309. Dalle IJ, Maes BD, Geboes KP, Lemahieu W, Geboes K: Crohn's-like changes in the colon due to mycophenolate? Colorectal Dis 2005, 7: 27-34.

310. Maes BD, Dalle I, Geboes K, Oellerich M, Armstrong VW, Evenepoel P et al.: Erosive enterocolitis in mycophenolate mofetil-treated renal-transplant recipients with persistent afebrile diarrhea. Transplantation 2003, 75: 665-672. 
311. Papadimitriou JC, Cangro CB, Lustberg A, Khaled A, Nogueira J, Wiland A et al.: Histologic features of mycophenolate mofetil-related colitis: a graft-versus-host disease-like pattern. Int J Surg Pathol 2003, 11: 295-302.

312. Kim HC, Park SB: Mycophenolate mofetil-induced ischemic colitis. Transplant Proc 2000, 32: 1896-1897.

313. Clayburgh DR, Shen L, Turner JR: A porous defense: the leaky epithelial barrier in intestinal disease. Lab Invest 2004, 84: 282-291.

314. Alvarez-Hernandez X, Nichols GM, Glass J: Caco-2 cell line: a system for studying intestinal iron transport across epithelial cell monolayers. Biochimica et Biophysica Acta (BBA) - Biomembranes 1991, 1070: 205-208.

315. Peterson MD, Mooseker MS: Characterization of the enterocyte-like brush border cytoskeleton of the C2BBe clones of the human intestinal cell line, Caco-2. Journal of Cell Science 1992, 102: 581-600.

316. Levy P, Robin H, Bertrand F, Kornprobst M, Capeau J: Butyrate-treated colonic Caco2 cells exhibit defective integrin-mediated signaling together with increased apoptosis and differentiation. J Cell Physiol 2003, 197: 336-347.

317. Koeneman BA, Zhang Y, Westerhoff P, Chen Y, Crittenden JC, Capco DG: Toxicity and cellular responses of intestinal cells exposed to titanium dioxide. Cell Biol Toxicol 2010, 26: 225-238.

318. Schlegel N, Burger S, Golenhofen N, Walter U, Drenckhahn D, Waschke J: The role of VASP in regulation of CAMP- and Rac 1-mediated endothelial barrier stabilization. Am J Physiol Cell Physiol 2008, 294: C178-C188.

319. Schlegel N, Meir M, Spindler V, Germer CT, Waschke J: Differential role of Rho GTPases in intestinal epithelial barrier regulation in vitro. J Cell Physiol 2011, 226: 1196-1203.

320. Rozen S SH: Primer3 on the WWW for general users and for biologist programmers. Methods Mol Bio 2000, 132: 365-386.

321. Dodane V, Amin KM, Merwin JR: Effect of chitosan on epithelial permeability and structure. Int J Pharm 1999, 182: 21-32.

322. Ranaldi G, Marigliano I, Vespignani I, Perozzi G, Sambuy Y: The effect of chitosan and other polycations on tight junction permeability in the human intestinal Caco-2 cell line(1). J Nutr Biochem 2002, 13: 157-167.

323. Qasim $\mathrm{M}$, Rahman $\mathrm{H}$, Oellerich $\mathrm{M}$, Asif $\mathrm{A}$ : Differential proteome analysis of human embryonic kidney cell line (HEK-293) following mycophenolic acid treatment.

Proteome Science 2011, 9: 57.

324. Turner JR, Black ED, Ward J, Tse CM, Uchwat FA, Alli HA et al.: Transepithelial resistance can be regulated by the intestinal brush-border $\mathrm{Na}+/ \mathrm{H}+$ exchanger $\mathrm{NHE}$. American Journal of Physiology - Cell Physiology 2000, 279: C1918-C1924. 
325. Jain S, Suzuki T, Seth A, Samak G, Rao R: Protein kinase C phosphorylates occludin and promotes assembly of epithelial tight junctions. Biochemical Journal 2011, 437: 289-299.

326. Madara JL, Pappenheimer JR: Structural basis for physiological regulation of paracellular pathways in intestinal epithelia. J Membr Biol 1987, 100: 149-164.

327. Xu Lf, Xu C, Mao ZQ, Teng X, Ma L, Sun M: Disruption of the F-actin cytoskeleton and monolayer barrier integrity induced by PAF and the protective effect of ITF on intestinal epithelium. Archives of Pharmacal Research 2011, 34: 245-251.

328. Ma TY, Hoa NT, Tran DD, Bui V, Pedram A, Mills S et al.: Cytochalasin B modulation of Caco-2 tight junction barrier: role of myosin light chain kinase. Am J Physiol Gastrointest Liver Physiol 2000, 279: G875-G885.

329. Feighery LM, Cochrane SW, Quinn T, Baird AW, O'Toole D, Owens SE et al.: Myosin light chain kinase inhibition: correction of increased intestinal epithelial permeability in vitro. Pharm Res 2008, 25: 1377-1386.

330. Schliwa M: Action of cytochalasin D on cytoskeletal networks. J Cell Biol 1982, 92: 7991.

331. Scott KGE, Meddings JB, Kirk DR, Lees-Miller SP, Buret AG: Intestinal infection with Giardia spp. reduces epithelial barrier function in a myosin light chain kinasedependent fashion. Gastroenterology 2002, 123: 1179-1190.

332. Subramanian VS, Marchant JS, Ye D, Ma TY, Said HM: Tight junction targeting and intracellular trafficking of occludin in polarized epithelial cells. American Journal of Physiology - Cell Physiology 2007, 293: C1717-C1726.

333. Shimizu M.: Interaction between food substances and the intestinal epithelium. Biosci Biotechnol Biochem 2010, 74: 232-241.

334. Duggan C, Gannon J, Walker WA: Protective nutrients and functional foods for the gastrointestinal tract. Am J Clin Nutr 2002, 75: 789-808.

335. Clayburgh DR, Barrett TA, Tang Y, Meddings JB, Van Eldik LJ, Watterson DM et al.: Epithelial myosin light chain kinase-dependent barrier dysfunction mediates $\mathrm{T}$ cell activation-induced diarrhea in vivo. J Clin Invest 2005, 115: 2702-2715.

336. Dunlop SP, Hebden J, Campbell E, Naesdal J, Olbe L, Perkins AC et al.: Abnormal intestinal permeability in subgroups of diarrhea-predominant irritable bowel syndromes. Am J Gastroenterol 2006, 101: 1288-1294.

337. Clayburgh DR, Barrett TA, Tang Y, Meddings JB, Van Eldik LJ, Watterson DM et al.: Epithelial myosin light chain kinase-dependent barrier dysfunction mediates $\mathrm{T}$ cell activation-induced diarrhea in vivo. J Clin Invest 2005, 115: 2702-2715.

338. Davies NM, Grinyo J, Heading R, Maes B, Meier-Kriesche HU, Oellerich M: Gastrointestinal side effects of mycophenolic acid in renal transplant patients: a reappraisal. Nephrol Dial Transplant 2007, 22: 2440-2448. 
339. Parfitt JR, Jayakumar S, Driman DK: Mycophenolate mofetil-related gastrointestinal mucosal injury: variable injury patterns, including graft-versus-host disease-like changes. Am J Surg Pathol 2008, 32: 1367-1372.

340. Dalle IJ, Maes BD, Geboes KP, Lemahieu W, Geboes K: Crohn's-like changes in the colon due to mycophenolate? Colorectal Dis 2005, 7: 27-34.

341. Sambuy Y, de A, I, Ranaldi G, Scarino ML, Stammati A, Zucco F: The Caco-2 cell line as a model of the intestinal barrier: influence of cell and culture-related factors on Caco-2 cell functional characteristics. Cell Biol Toxicol 2005, 21: 1-26.

342. van Breemen RB, Li Y: Caco-2 cell permeability assays to measure drug absorption. Expert Opin Drug Metab Toxicol 2005, 1: 175-185.

343. von Bonsdorff $\mathrm{CH}$, Fuller SD, Simons K: Apical and basolateral endocytosis in MadinDarby canine kidney (MDCK) cells grown on nitrocellulose filters. EMBO J 1985, 4: 2781-2792.

344. Malinowski M, Martus P, Lock JF, Neuhaus P, Stockmann M: Systemic influence of immunosuppressive drugs on small and large bowel transport and barrier function. Transpl Int 2011, 24: 184-193.

345. Furuse M, Itoh M, Hirase T, Nagafuchi A, Yonemura S, Tsukita S et al.: Direct association of occludin with ZO-1 and its possible involvement in the localization of occludin at tight junctions. J Cell Biol 1994, 127: 1617-1626.

346. Wang F, Graham WV, Wang Y, Witkowski ED, Schwarz BT, Turner JR: Interferongamma and tumor necrosis factor-alpha synergize to induce intestinal epithelial barrier dysfunction by up-regulating myosin light chain kinase expression. Am J Pathol 2005, 166: 409-419.

347. Saitoh M, Ishikawa T, Matsushima S, Naka M, Hidaka H: Selective inhibition of catalytic activity of smooth muscle myosin light chain kinase. J Biol Chem 1987, 262: 7796-7801.

348. Guntaka SR, Samak G, Seth A, Larusso NF, Rao R: Epidermal growth factor protects the apical junctional complexes from hydrogen peroxide in bile duct epithelium. Lab Invest 2011.

349. Stevenson BR, Begg DA: Concentration-dependent effects of cytochalasin D on tight junctions and actin filaments in MDCK epithelial cells. Journal of Cell Science 1994, 107: 367-375.

350. Subramanian VS, Marchant JS, Ye D, Ma TY, Said HM: Tight junction targeting and intracellular trafficking of occludin in polarized epithelial cells. Am J Physiol Cell Physiol 2007, 293: C1717-C1726. 


\section{Appendix}

Figure 5.1: A graphical representation of relative abundance (\% volume) of all differentially regulated proteins.

Relative abundance of the proteins differentially expressed in DMSO and MPA treated HEK-293 cells. Results shown as mean of four independent experiments $\left({ }^{*} p<0.05\right.$ or $\left.{ }^{* *} p<0.005\right)$.

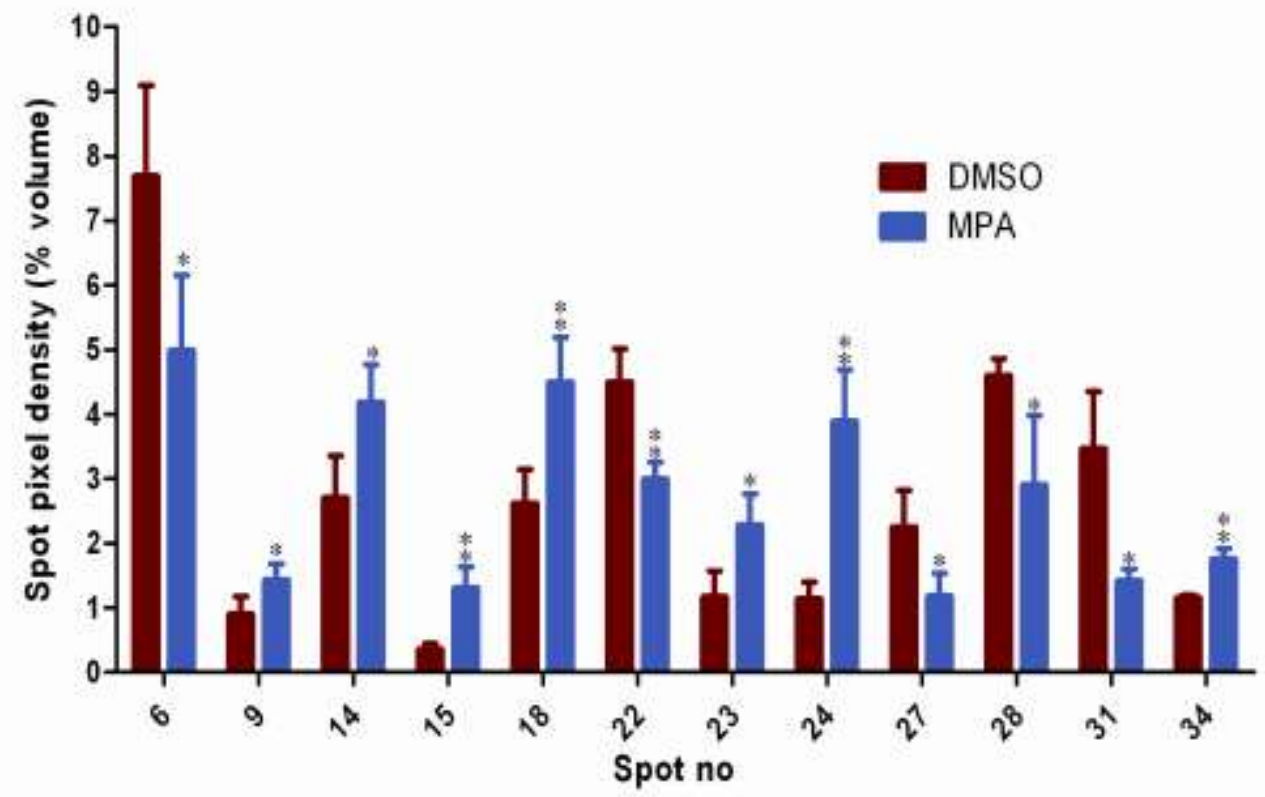


Table 5.1: MS/MS analysis table of all differentially regulated proteins.

Spot no: the spot identification number on 2-DE; Accession no: Swiss-prot protein identification number; Sequence coverage: the percentage of the protein's sequence represented by the peptides identified by MS/MS; MS/MS analysis: peptides sequences (bold \& red) identified for a particular protein, including MS/MS queries, and the MS/MS sepectra of an exemplary peptide.

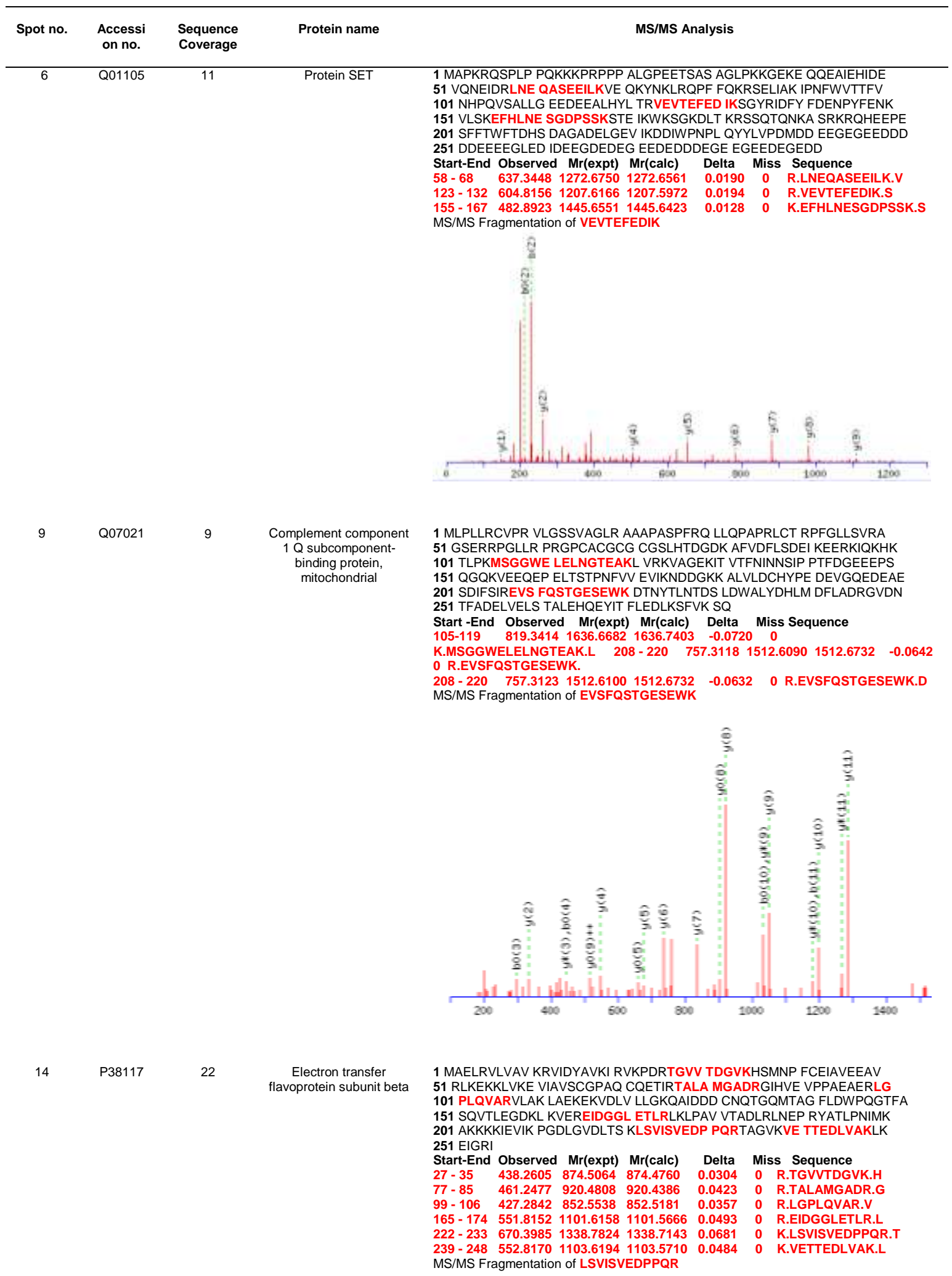




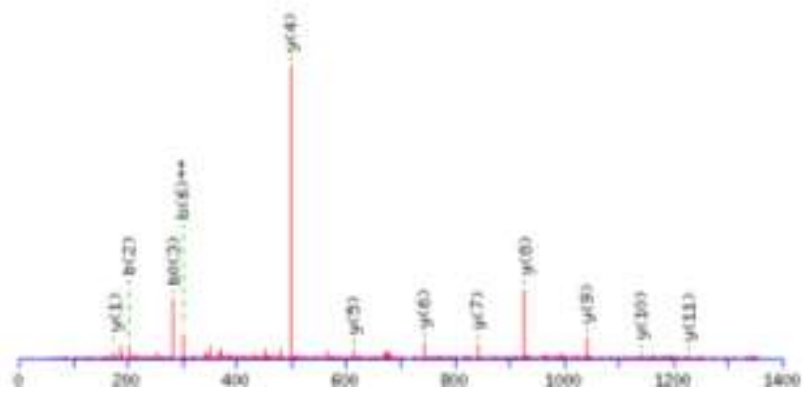

1 MLSVASRSGP FAPVLSATSR GVAGALRPLV QATVPATPEQ PVLDLKRPFL 51 SRESLSGQAV RRPLVASVGL NVPASVCYSH TDIKVPDFSE YRRLEVLDST 101 KSSRESSEAR KGFSYLVTGV TTVGVAYAAK NAVTQFVSSM SASADVLALA 151 KIEIKLSDIP EGKNMAFKWR GKPLFVRHRT QKEIEQEAAV ELSQLRDPQH 201 DLDRVKKPEW VILIGVCTHL GCVPIANAGD FGGYYCPCHG SHYDASGRIR 251 LGPAPLNLEV PTYEFTSDDM VIVG

Start-End Observed Mr(expt) Mr(calc) Delta Miss Sequence

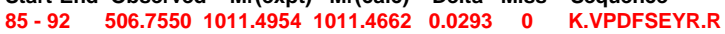

$\begin{array}{lllllll}93-101 & 530.8184 & 1059.6222 & 1059.5924 & 0.0298 & 1 & \text { R.RLEVLDSTK.S }\end{array}$

$\begin{array}{lllllll}94-101 & 452.7524 & 903.4902 & 903.4913 & -0.0011 & 0 & \text { R.LEVLDSTK.S }\end{array}$

$\begin{array}{lllllll}171-177 & 408.7669 & 815.5192 & 815.5018 & 0.0175 & 0 & \text { R.GKPLFVR.H }\end{array}$

183 - $196 \quad 807.9452 \quad 1613.87581613 .8260 \quad 0.0498 \quad 0 \quad$ K.EIEQEAAVELSQLR.D

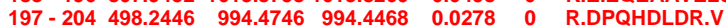

MS/MS Fragmentation of DPQHDLDR

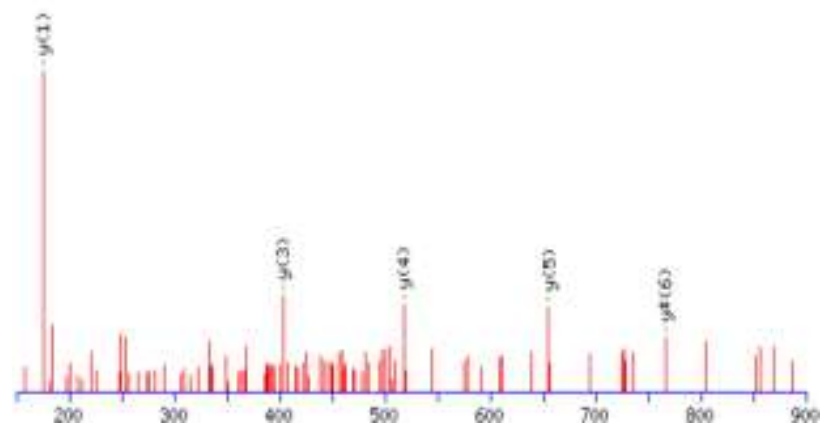

1 MSSGNAKIGH PAPNFKATAV MPDGQFKDIS LSDYKGKYVV FFFYPLDFTF 51 VCPTEIIAFS DRAEEFKKLN CQVIGASVDS HFCHLAWVNT PKKQGGLGPM 101 NIPLVSDPKR TIAQDYGVLK ADEGISFRGL FIIDDKGILR QITVNDLPVG 151 RSVDETLRLV QAFQFTDKHG EVCPAGWKPG SDTIKPDVQK SKEYFSKQK Start-End Observed Mr(expt) Mr(calc) Delta Miss Sequence $\begin{array}{lllllll}111-120 & 554.2855 & 1106.5564 & 1106.5972 & -0.0407 & 0 & \text { R.TIAQDYGVLK.A }\end{array}$

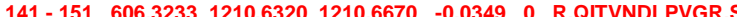
MS/MS Fragmentation of TIAQDYGVLK.

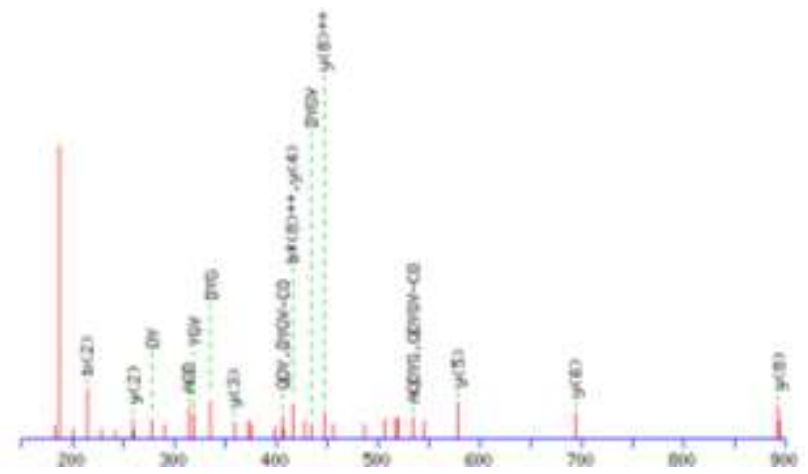




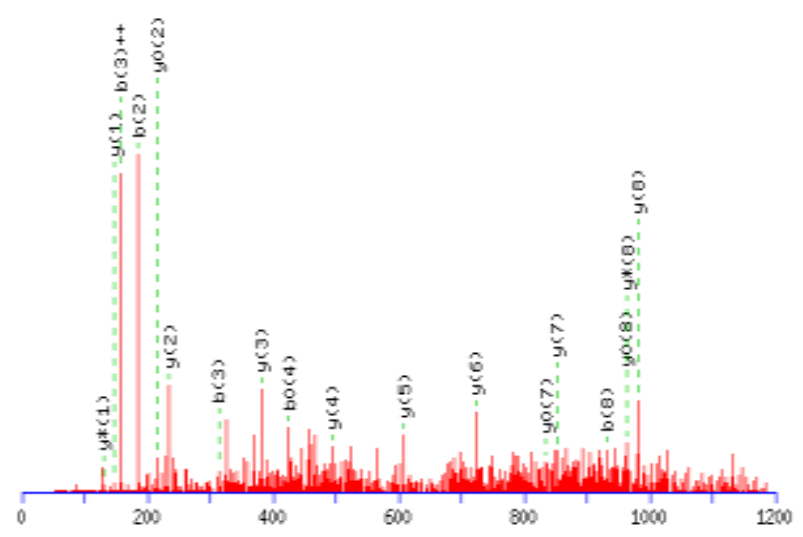

1 METRPRLGAT CLLGFSFLLL VISSDGHNGL GKGFGDHIHW RTLEDGKKEA 51 AASGLPLMVI IHKSWCGACK ALKPKFAEST EISELSHNFV MVNLEDEEEP 101 KDEDFSPDGG YIPRILFLDP SGKVHPEIIN ENGNPSYKYF YVSAEQVVQG 151 MKEAQERLTG DAFRKKHLED EL

Start-End Observed Mr(expt) Mr(calc) Delta Miss Sequence

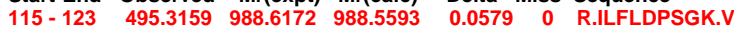

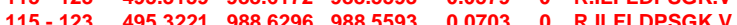

$\begin{array}{lllllllll}139-152 & 832.9714 & 1663.9282 & 1663.7916 & 0.1367 & 0 & \text { K.YFYVSAEQVVQGMK.E }\end{array}$

$\begin{array}{lllllll}139-152 & 832.9714 & 1663.9282 & 1663.7916 & 0.1367 & 0 & \text { K.YFYVSAEQVVQGMK.E } \\ 139-152 & 832.9721 & 1663.9296 & 1663.7916 & 0.1381 & 0 & \text { K.YFYVSAEQVVQGMK.E }\end{array}$ $139-152832.9721$
MS/MS Fragmentation of YFYVSAEQVVQGMK

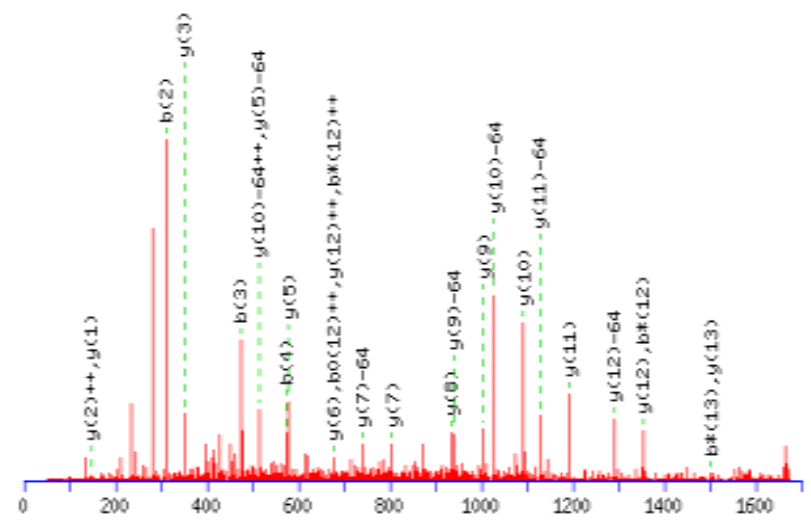

1 MSSKKAKTKT TKKRPQRATS NVFAMFDQSQ IQEFKEAFNM IDQNRDGFID 51 KEDLHDMLAS LGKNPTDAYL DAMMNEAPGP INFTMFLTMF GEKLNGTDPE 101 DVIRNAFACF DEEATGTIQE DYLRELLTTM GDRFTDEEVD ELYREAPIDK 151 KGNFNYIEFT RILKHGAKDK DD

Start - End Observed Mr(expt) Mr(calc) Delta Miss Sequence

$\begin{array}{lllllll}94-104 & 614.8414 & 1227.6682 & 1227.6095 & 0.0587 & 0 & \text { K.LNGTDPEDVIR.N }\end{array}$

$\begin{array}{lllllll}125-133 & 526.2847 & 1050.5548 & 1050.5016 & 0.0533 & 0 & \text { R.ELLTTMGDR.F }\end{array}$

$\begin{array}{lllllll}134-144 & 708.3533 & 1414.6920 & 1414.6252 & 0.0668 & 0 & \text { R.FTDEEVDELYR.E }\end{array}$

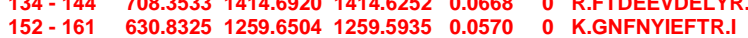

MS/MS Fragmentation of LNGTDPEDVIR

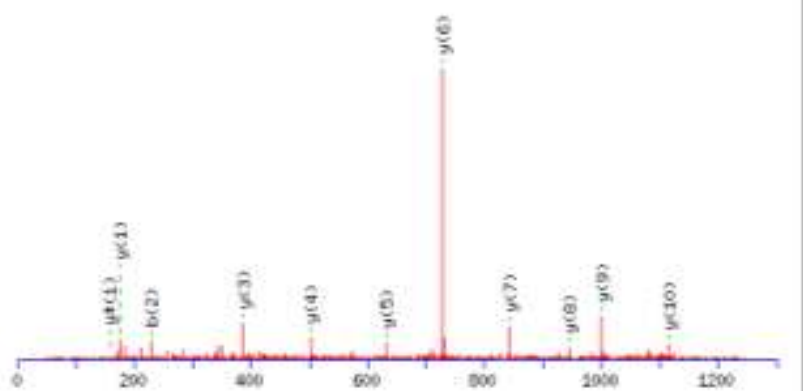


1 MPEVSSKGAT ISKKGFKKAV VKTQKKEGKK RKRTRKESYS IYIYKVLKQV 51 HPDTGISSKA MSIMNSFVTD IFERIASEAS RLAHYSKRST ISSREIQTAV 101 RLLLPGELAK HAVSEGTKAV TKYTSSK

Start - End Observed $\operatorname{Mr}($ expt) $\operatorname{Mr}($ calc) Delta Miss Sequence

$\begin{array}{llllllll}95-101 & 408.7352 & 815.4558 & 815.4501 & 0.0057 & 0 & \text { R.EIQTAVR.L }\end{array}$ $\begin{array}{lllllll}102-110 & 477.3018 & 952.5890 & 952.5957 & -0.0066 & 0 & \text { R.LLLPGELAK. }\end{array}$ MS/MS Fragmentation of LLLPGELAK

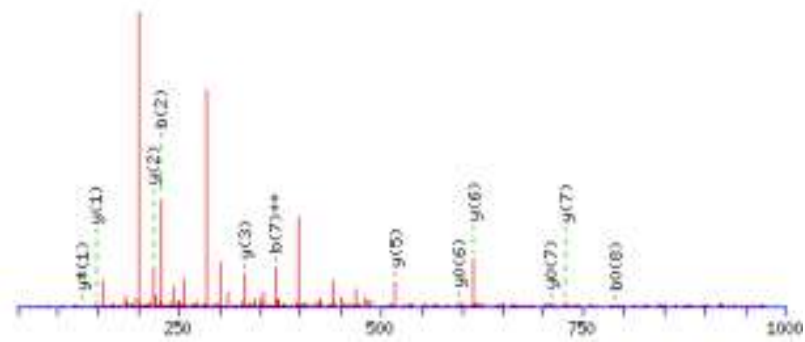

1 MPEPAKSAPA PKKGSKKAVT KAQKKDGKKR KRSRKESYSV YVYKVLKQVH 51 PDTGISSKAM GIMNSFVNDI FERIAGEASR LAHYNKRSTI TSREIQTAVR 101 LLLPGELAKH AVSEGTKAVT KYTSK

Start - End Observed Mr(expt) Mr(calc) Delta Miss Sequence

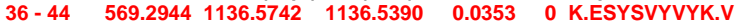

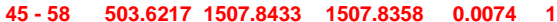

K.VLKQVHPDTGISSK.A

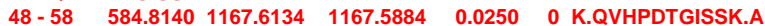

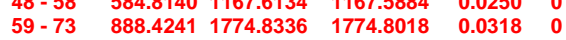

K.AMGIMNSFVNDIFER

$\begin{array}{llllll}88-100 & 487.9460 & 1460.8162 & 1460.7947 & 0.0215 & 1\end{array}$

$\begin{array}{llllll}94-100 & 408.7277 & 815.4408 & 815.4501 & -0.0093 & 0 \\ 0 & \text { R.EIQTAVR.L }\end{array}$

$\begin{array}{llllll}101-109 & 477.2920 & 952.5694 & 952.5957 & -0.0262 & 0 \\ 0 & \text { R.LLLPGELAK.H }\end{array}$

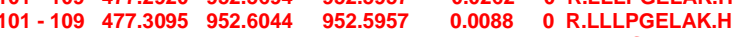

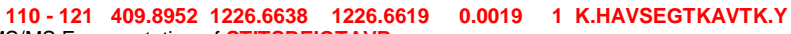
MS/MS Fragmentation of STITSREIQTAVR

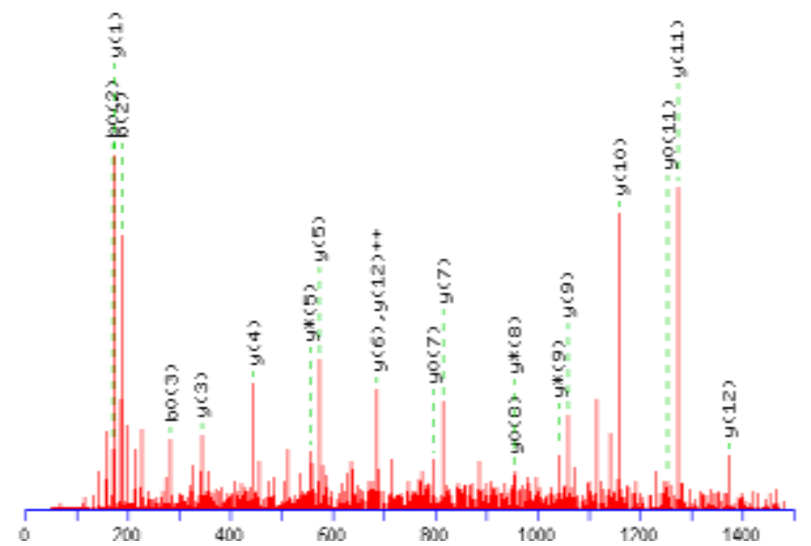

1 MAEEGIAAGG VMDVNTALQE VLKTALIHDG LARGIREAAK ALDKRQAHLC 51 VLASNCDEPM YVKLVEALCA EHQINLIKVD DNKKLGEWVG LCKIDREGKP 101 RKVVGCSCVV VKDYGKESQA KDVIEEYFKC KK

Start - End Observed Mr(expt) Mr(calc) Delta Miss Sequence

$\begin{array}{lllllll}24-33 & 533.7745 & 1065.5344 & 1065.5931 & -0.0586 & 0 & \text { K.TALIHDGLAR.G ) }\end{array}$

$\begin{array}{lllllll}24-33 & 533.7747 & 1065.5348 & 1065.5931 & -0.0582 & 0 & \text { K.TALIHDGLAR.G }\end{array}$

$\begin{array}{lllllll}85-93 & 531.2432 & 1060.4718 & 1060.5376 & 0.0657 & 0 & \text { K.LGEWVGLCK.I }\end{array}$ MS/MS Fragmentation of LGEWVGLCK

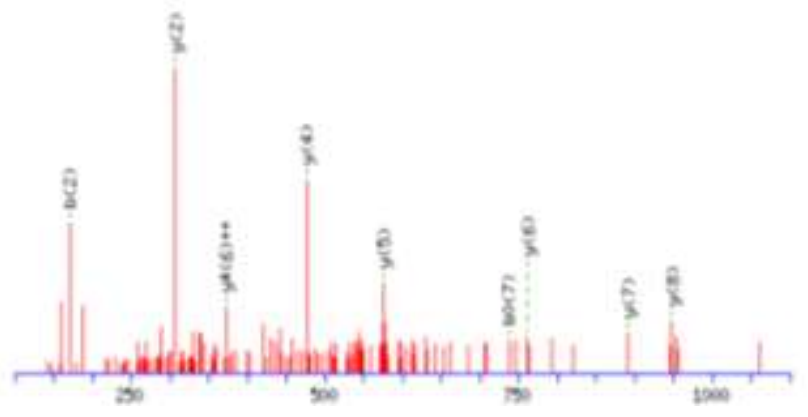


1 MAGWNAYIDN LMADGTCQDA AIVGYKDSPS VWAAVPGKTF VNITPAEVGV 51 LVGKDRSSFY VNGLTLGGOK CSVIRDSLLQDGEFSMDLRT KSTGGAPTFN 101 VTVTKTDKTL VLLMGKEGVH GGLINKKCYE MASHLRRSQY

Start - End Observed Mr(expt) Mr(calc) Delta Miss Sequence

$\begin{array}{lllll}39-54 & 822.4751 & 1642.9356 & 1642.9294 & 0.0062\end{array}$

K.TFVNITPAEVGVLVGK.D

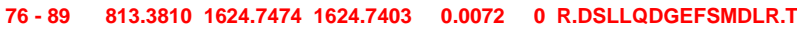

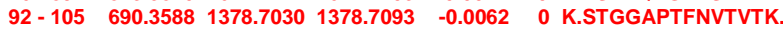

$\begin{array}{llllll}106-116 & 609.8624 & 1217.7102 & 1217.7053 & 0.0049 & 1 \text { K.TDKTLVLLMGK.E }\end{array}$

$\begin{array}{cccccc}106-116 & 609.8624 & 1217.7102 & 1217.7053 & 0.0049 & 1 \text { K.TDKTLVLLMGK.E } \\ 117-127 & 576.3310 & 1150.6474 & 1150.6458 & 0.0016 & 1 \text { K.EGVHGGLINKK.C }\end{array}$

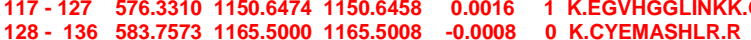

MS/MS Fragmentation of TFVNITPAEVGVLVGK

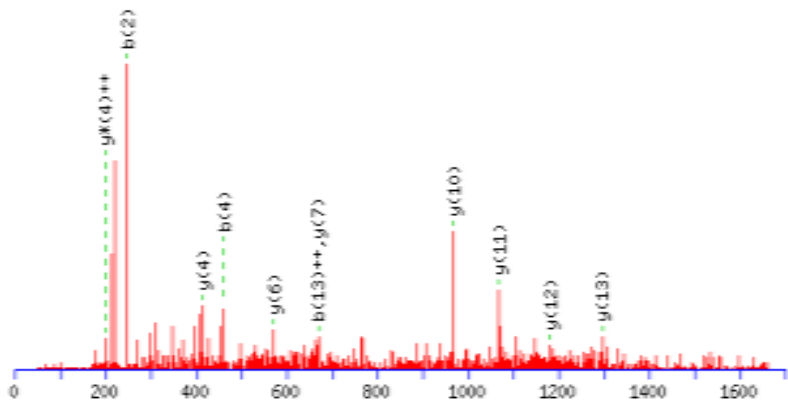




\section{Acknowledgements}

My sincere gratitude to Prof. Dr. Michael Oellerich and PD. Dr. Abdul Rahman Asif for their constant encouraging guidance, support, and invaluable suggestions. They provide me inspiring energy and have always been ready for both scientific and social discussions during this period. Their creativity and expertise in research, patience, and motivational skills are exceptional.

I would like to express my gratitude to Prof. Dr. Uwe Groß and Prof. Dr. Stefenne Pöggeler for serving on my thesis committee, and for their constructive criticisms and endless help throughout this study. I also have the deepest gratitude for my subject examination committee members, Dr. Michael Hoppert, Dr. Rolf Daniel, Prof. Dr. Petr Karlovsky, and Dr. Marko Rohlfs for their thoughtful comments and suggestions.

Special thanks to Hazir Rahman and Misbah Tauseef for giving me critical advice during our discussions and helped me to turn results into science. They were with me through the thick and thin of this long and arduous $\mathrm{PhD}$ journey.

I was fortunate to work with great colleagues Dr. Darinka Petrova, Dr. Christoph Eberle, Dr. Gunner Brandhorst, Prof. Dr. Nico Von Ahsen, Dr. Lutz Binder, Dr. Raees Ahmed for their invaluable support and perceptive comments. I am deeply indebted to my former colleagues Saima Zafar, Saadia Zahid, Bharat Singh and Dr. Saagarika Biswas for their always being there and helping me in more ways than one probably know. I would like to express my appreciation to our proteomics laboratory technicians, especially Christina Wiese, Christa Schultz, Susanne Goldmann for their technical support and expertise. I also wish to thank Ulrike Bonitz, Rainer Andaq and Sandra Hartung, for creating a supportive and pleasant work atmosphere.

I wish to express my gratitude to Prof. Dr. Philips Walson for their constructive criticism and for giving me valuable suggestions for improvement of my dissertation. I also offer special thanks to Vicky Maixner for editiding support for my thesis and manuscripts. I am grateful to Prof. Dr. Gabor Kottra for providing me TER instrument and special thanks to Prof. Dr. Giuliano Ramadori for the providing access to the immunofluorescence microscope facility.

I would like to pay special thanks to Kohat University of Science and Technology and Higher Education Commission of Pakistan for giving me the opportunity, and financial support to complete $\mathrm{PhD}$ work in such a world class University. 
I express gratitude to my friends Abdul Malik, Waheed Murad, Hayat Khan Sherani, Muhammad Naveed, Muhammad Adnan, Sajjad Ahmed, Tayyab Tahir, Ihtzaz Ahmed, Naeem Misdaq, Naila Naz, Sadaf Sultan, Aneela Javed, Saadia Qammar, Nazim Khan, Abdullah Jalal, Noor Muhammad, Kalimullah Khan, Jamil-urRehman, Adeel, Altaf Husain, Muhammad Haroon, Nouman, and many others, for supporting me in difficult moments and understanding my needs. Wholehearted thanks to the peoples of Göttingen especially Pakistani community for all the good care and great help throughout the way. In addition, I share my success to all of the wonderful people who have supported, assisted, and loved me in Germany and also those back in Pakistan.

I would especially like to acknowledge my past teachers Prof. Dr. Mansoor-ulHassan Alvi, Prof. Dr. Shahida Hasnain, and Prof. Dr. Abdul Rauf Shakoori, for guiding me during the earlier days in my scientific career. They have been a continuous source of inspiration and motivation to me in this tough journey.

Last but not the least; words are insufficient to express my thanks to my parents, sisters and brother for all their undying love, constant support, encouragement and blessings through out my PhD course. My warmest thanks belong to my wife and children for their understanding, never-ending support, love and sharing my affection. 


\section{Curriculum Vitae}

Name: Muhammad Qasim

Date and Place of birth: $25^{\text {th }}$ December 1978, Mardan, Pakistan

Nationality: Pakistani

\section{Educational background}

2008 - continue PhD (Biology) from Georg-August University, Goettingen, Germany.

$2004-2006$ M.Sc (Microbiology and Molecular Genetics) from University of the Punjab, Lahore, Pakistan.

$2000-2003$ B.Sc (Medical Laboratory Technology) from University of the Punjab, Lahore Pakistan

\section{Professional experience}

2003 - 2005 Lecturer Microbiology, Institute of Health Management, Lahore, Pakistan.

2004 - 2005 Research Scholar, Department of Microbiology, Children Hospital, Lahore, Pakistan.

2006 - 2008 Medical Technologist (Clinical scientist), Department of Microbiology, Federal Post Graduate Medical Institute, Shaikh Zayed Hospital Lahore, Pakistan.

2008 - to date Lecturer Microbiology, Department of Microbiology, Kohat University of Science and Technology, Kohat, Pakistan (study leave).

\section{Publications}

1. Qasim M, Rahman H, Oellerich M, Asif AR. Differential proteome analysis of human embryonic kidney cell line following mycophenolic acid treatment. Proteome Sci. 2011 Sep 20;9:57.

2. Rahman H, Qasim M, Schultze FC, Oellerich M, Asif AR. Influence of fetal calf serum heat inactivation and lipopolysaccharides contamination on human $\mathrm{T}$ lymphoblasts proteome and phosphoproteome. Proteome Sci. 2011 Nov 15;9(1):71.

3. Qasim M, Rahman H, Ahmed R, Oellerich M, Asif AR. Mycophenolic acid mediated disruption of the intestinal epithelial tight junctions. Submitted.

4. Rahman H, Qasim M, Ahmed R, Oellerich M, Asif AR. mTORC1 interactomics; mtorc1 interplay in the mRNA decapping through Edc4. Submitted. 


\section{Abstarcts published}

1. Qasim M, Rahman H, Oellerich M, Asif AR. Protein alterations in human cell line in response to mycophenolic acid. Clin Chem. 2010; 57(S10): A78.

2. Qasim M, Rahman H, Ahmed R, Oellerich M, Asif AR. Mycophenolic acid modulation of epithelial tight junctions-a mechanism of gastrointestinal toxicity? Clin Chem Lab Med. 2011; 49(9): A112.

\section{Research presentations}

1. Qasim M, Hasnain S, Zafar A. Bacteria isolated from indwelling medical devices and their antibiotic susceptibility pattern in children. International Symposium on Genomics, Proteomics and Metabolomics at University of the Punjab, Lahore, Pakistan (22 $2^{\text {nd }}$ to $23^{\text {rd }}$ Oct 2007) (Poster).

2. Qasim M, Rahman $H$, Oellerich $M$, Asif AR. Protein alterations in human cell line in response to mycophenolic acid. DGKL Congress Mannheim, Germany (29 ${ }^{\text {th }}$ Sept to $2^{\text {nd }}$ Oct 2010) (Poster).

3. Rahman H, Qasim M, Schultze FC, Oellerich M, Asif AR. Dynamin 2: is a new interacting partner of mechanistic target of rapamycin complex 1 in human $\mathrm{T}$ lymphocytes. Berlin Proteomic Forum, Germany ( $3^{\text {rd }}$ to $7^{\text {th }}$ April 2011) (Poster).

4. Rahman H, Qasim M, Schultze FC, Oellerich M, Asif AR. Fetal calf serum heat inactivation and lipopolysaccharide contamination influence the human $\mathrm{T}$ lymphoblasts proteome and phosphoproteome. Berlin Proteomic Forum, Germany ( $3^{\text {rd }}$ to $7^{\text {th }}$ April 2011) (Poster).

5. Tauseef M, Qasim M, Asif AR, Oellerich M, Ahsen NC. Differential protein profiling of thiopurines in T lypmhocytes. Berlin Proteomic Forum, Germany ( $3^{\text {rd }}$ to $7^{\text {th }}$ April 2011) (Poster).

6. Sing B, Qasim M, Rahman H, Sharma GL, Oellerich M, Kumar R, Asif AR. Proteomics based identification of diagnostically relevant and vaccine candidate molecules of Aspergillus fumigatus at the meeting of Goettingen International Health Network, Goettingen, Germany (23 $3^{\text {rd }}$ to $24^{\text {th }}$ May 2011) (Poster).

7. Qasim M, Rahman H, Ahmed R, Oellerich M, Asif AR. Mycophenolic acid modulation of epithelial tight junctions-a mechanism of gastrointestinal toxicity?. AACC annual meeting 2011, Atlanta, Georgia, USA (24 $4^{\text {th }}$ to $28^{\text {th }}$ July 2011) (Poster).

8. Qasim M. Epithelial tight junction regulation by Mycophenolic acid. Symposium of Transporttage 2011 at the Department of Physiology and Patho physiology, University Medical Center, Goettingen, Germany (22 $2^{\text {nd }}$ to $23^{\text {rd }}$ Oct 2011) (Oral).

\section{Distinction and award}

1. Second position in the institute in BSc Medical Lab Technology (2003), University of the Punjab, Lahore, Pakistan.

2. PhD scholarship for Germany under the faculty development scholarship program from the Kohat University Science and Technology, Pakistan (2008-2011). 